\title{
INFLUENCE OF SUPPORT MEDIA ON MEMBRANE FOULING REDUCTION OF WATER WITH DIFFERENT ORGANIC AND INORGANIC MATTER CONTENT
}

\author{
A thesis submitted to \\ the Faculty of Graduate and Postdoctoral Affairs \\ in Partial Fulfillment of the requirements for the degree
}

Master of Applied Science in Environmental Engineering

by

Mohammad Alresheedi

(B. Eng.)

Department of Civil and Environmental Engineering

Carleton University

Ottawa-Carleton Institute of Civil and Environmental Engineering May 2013 
Library and Archives

Canada

Published Heritage

Branch

395 Wellington Street

Ottawa ON K1A ON4

Canada
Bibliothèque et

Archives Canada

Direction du

Patrimoine de l'édition

395 , rue Wellington

Ottawa ON K1A ON4

Canada
Your file Votre référence

ISBN: 978-0-494-94660-2

Our file Notre référence

ISBN: $978-0-494-94660-2$
NOTICE:

The author has granted a nonexclusive license allowing Library and Archives Canada to reproduce, publish, archive, preserve, conserve, communicate to the public by telecommunication or on the Internet, loan, distrbute and sell theses worldwide, for commercial or noncommercial purposes, in microform, paper, electronic and/or any other formats.

The author retains copyright ownership and moral rights in this thesis. Neither the thesis nor substantial extracts from it may be printed or otherwise reproduced without the author's permission.
AVIS:

L'auteur a accordé une licence non exclusive permettant à la Bibliothèque et Archives Canada de reproduire, publier, archiver, sauvegarder, conserver, transmettre au public par télécommunication ou par l'Internet, prêter, distribuer et vendre des thèses partout dans le monde, à des fins commerciales ou autres, sur support microforme, papier, électronique et/ou autres formats.

L'auteur conserve la propriété du droit d'auteur et des droits moraux qui protege cette thèse. $\mathrm{Ni}$ la thèse ni des extraits substantiels de celle-ci ne doivent être imprimés ou autrement reproduits sans son autorisation.
In compliance with the Canadian Privacy Act some supporting forms may have been removed from this thesis.

While these forms may be included in the document page count, their removal does not represent any loss of content from the thesis.
Conformément à la loi canadienne sur la protection de la vie privée, quelques formulaires secondaires ont été enlevés de cette thèse.

Bien que ces formulaires aient inclus dans la pagination, il n'y aura aucun contenu manquant. 


\begin{abstract}
A number of factorial design experiments were performed to investigate the influence of support media on fouling reduction in a submerged hollow fiber membrane ultrafiltration system filtering synthetic water with different organic and inorganic matter content. Support media was added into a membrane reactor and fouling and water quality parameters were assessed. Linear regression modelling for a factorial design experiment was used to identify important main and interaction effects of parameters that contributed to membrane fouling reduction. The addition of support media into the membrane reactor resulted in $35 \%-50 \%$ reduction in membrane fouling with different humic acid and Kaolin clay concentrations whereas there was no apparent impact of support media on cellulose. The support media in the membrane reactor did not generally affect any of the water quality measured; however, there was an observable difference in the permeate volume and flux recovery in the presence or absence of support media.
\end{abstract}




\section{ACKNOWLEDGMENTS}

I would like to thank the Saudi Arabian Ministry of higher education (MOHE) for funding this research project.

I would like to thank my supervisor Dr. Onita Basu. Your unconditional support from start to finish, your encouragement and your exceptional guidance throughout this research project has been a constant source of motivation.

I also would like to thank Dr. Marie Tudoret Chow for her constant availability to provide help and advice in the laboratory.

I give special thanks to Nigel De Suza for teaching me the basics that I needed to start my research experiments. Also, for helping me with the data filtering macro code $I$ used in this research. Thank you

Finally, I would like to address sincere thanks to my family members for their absolute support and encouragement during this research project. 


\section{Table of Contents}

ABSTRACT

ACKNOWLEDGMENTS...................................................................................................... iii

TABLE OF CONTENTS ..................................................................................................... iv

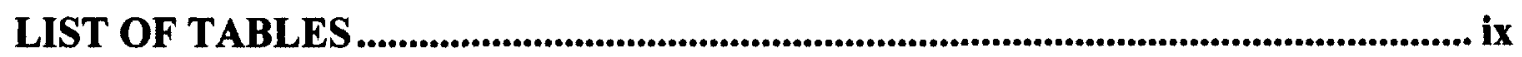

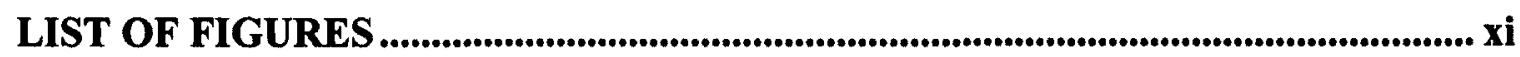

LIST OF ACRONYMES............................................................................................................... xiii

CHAPTER 1- Introduction ............................................................................................................. 1

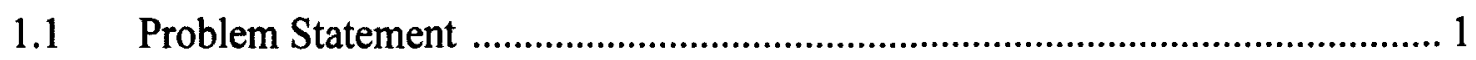

1.2 Research Objectives.................................................................................. 4

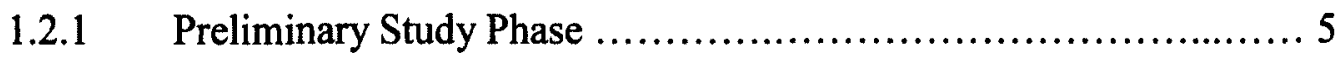

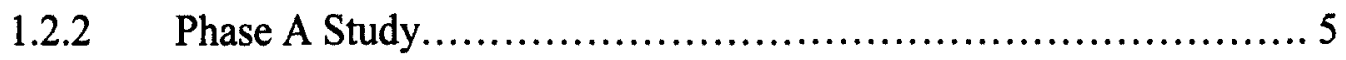

1.2.3 Phase B Study ..................................................

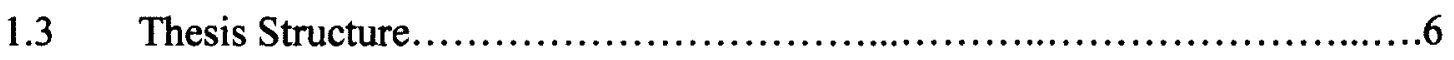

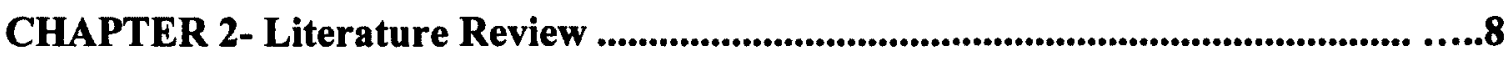

2.1 Membrane Filtration Processes For Drinking Water ......................................... 8

2.1.1 Type of Membranes............................................

2.1.2 Membrane Filtration Configurations.............................. 9

2.1.3 Membrane Operational Parameters...............................11 
2.2 Ultrafiltration Application in Water Treatment............................12

2.3 Membrane Fouling..................................................... 14

2.3.1 Organic Fouling................................................... 14

2.3.2 Inorganic Fouling ..............................................

2.3.3 Colloidal Fouling.................................................

2.3.4 Biofouling Fouling .............................................

2.4 Fouling Control in UF Membranes............................................16

2.4.1 Fouling Control Through Feed Water Pretreatment............... 17

2.4.2 Fouling Control Through Membrane Physical Cleaning ...............18

2.4.3 Fouling Control Through Membrane Chemical Cleaning.............19

2.5 The impact of Raw Water Characteristics and Support Media on UF

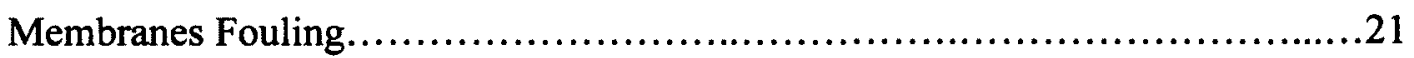

2.5.1 Effect of Organics...........................................21

2.5.2 Effect of Inorganics.........................................25

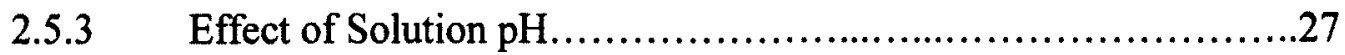

2.5.4 Impact of Support Media on Membrane Fouling....................29

CHAPTER 3- Materials and Methods..............................................................................31

3.1 Experimental Setup ...............................................31

3.1.1 Membrane Module...............................................31

3.1.2 Process Configuration..........................................31

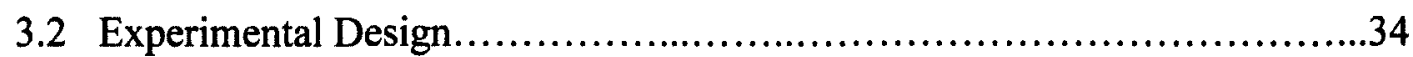

3.2.1 Preliminary Study Phase.........................................34

3.2.1.1 Feedwater Characteristics..............................34

3.2.1.2 Operational Conditions................................36 
3.2.1.3 Support Media.......................................37

3.2.1.4 Water Quality Monitoring and Data Recording..........38

3.2.1.5 Preliminary Phase Experiments Analysis...............39

3.2.1.5.1 T-Test.................................39

3.2.2 Phase A Study: The Influence of Different Organic and Inorganic

Concentrations on Membrane Fouling in the Presence or Absence of

Support Media...........................................................

3.2.2.1 Feedwater Characteristics............................42

3.2.2.2 Water Quality Monitoring and Data Recording ........43

3.2.3 Phase B Study: The Relationship between Natural Source Water

Organic Types and Membrane Fouling in the Presence or Absence of

Support Media...........................................................

3.2.3.1 Feedwater Characteristics...........................45

3.2.3.2 Water Quality Monitoring and Data Recording ........47

3.2.4 Phase A / Phase B Experiments Analysis........................47

3.2.4.1 Fouling measurement during Phase A / Phase B

Experiments...............................................47

3.2.4.2 Phase A / Phase B Results Analysis: Regression Analysis....................................................48

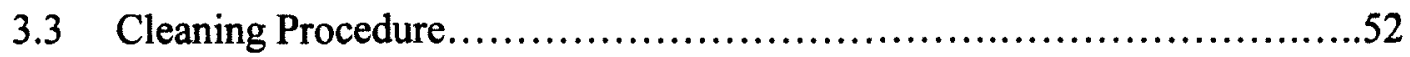

CHAPTER 4 - Preliminary Study Phase Results.....................................53

4.1 TMP Graphs and TMP Values.......................................53

4.1.1 General Observation......................................55

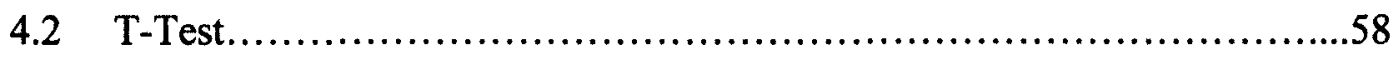

4.2.1 T-Test Results Discussion...................................60 
$4.3 \quad$ Water Quality Assessment...........................................60

4.4 Preliminary Study Phase Conclusion.................................62

CHAPTER 5 - Membrane Fouling with Different Organic and Inorganic Matter

Content in the Presence or Absence of Support Media..................................63

5.1 Phase A Study Results: The Influence of Different Organic and Inorganic Concentrations on Membrane Fouling in the Presence or Absence of Support Media .64

5.1.1 TMP Graphs and TMP Values...................................64

5.1.2 General Observation........................................67

5.1.3 Fouling Analysis: Main and Interaction effects Identification........69

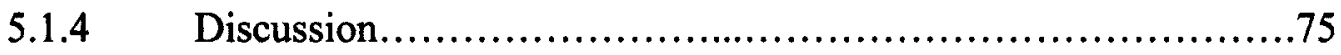

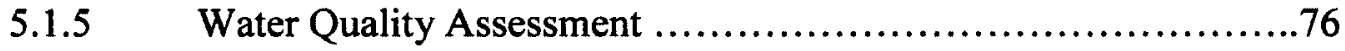

5.1.6 Phase A Conclusion...........................................79

5.2 Phase B Study Results: The Relationship between Humic Acid and Cellulose with Membrane Fouling in the Presence or Absence of Support Media.............81

5.2.1 TMP Graphs and TMP Values................................81

5.2.2 General Observation........................................... 84

5.2.3 Fouling Analysis: Main and Interaction effects Identification.........85

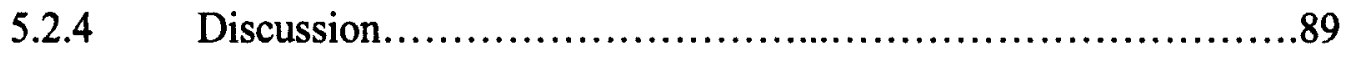

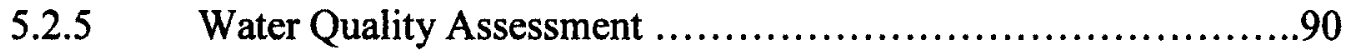

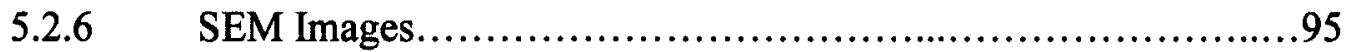

5.2.7 Phase B Conclusion............................................97 


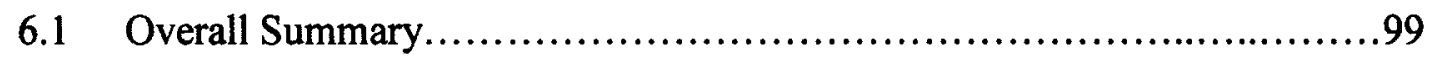

6.2 Preliminary Phase Conclusion........................................ 100

6.3 Phase A Conclusion.........................................................100

6.4 Phase B Conclusion............................................... 102

6.5 Significance of Results for Full Scale Issues.............................104

$6.6 \quad$ Future Studies....................................................... 104

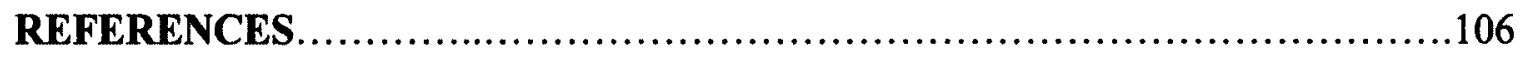

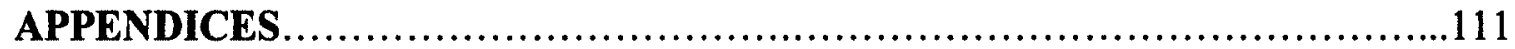

APPENDIX (A) - Membrane specifications.................................112

APPENDIX (B) - Feed line, Permeate lines, and Air flow line materials...........113

APPENDIX (C) - Humic acid and Cellulose calibration curves....................114

APPENDIX (D) - Support media characteristics................................115

APPENDIX (E) - Macro filter code used in data analysis.........................116

APPENDIX (F) - Water quality assessment for preliminary study phase

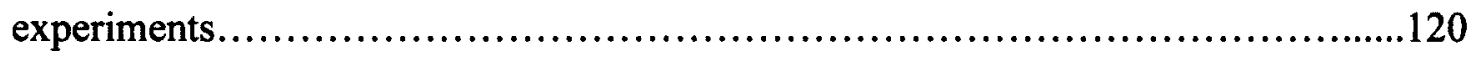

APPENDIX (G) - Phase A study: replicates experiments........................132

APPENDIX (H) - Stepwise regression output estimated by SPSS 20.0 based on

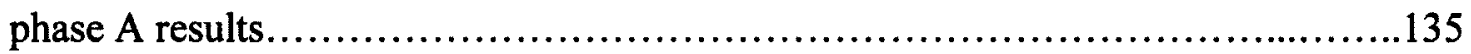

APPENDIX (I) - Water quality assessment for Phase A experiments...............139

APPENDIX (J) - Cellulose vs. Humic acid fouling during first hour of filtration....148 APPENDIX (K) - Stepwise regression output estimated by SPSS 20.0 based on

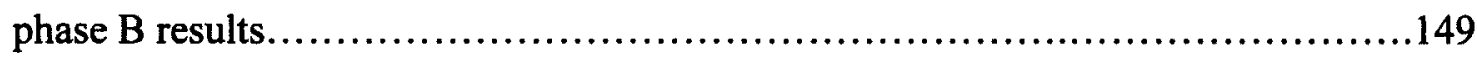

APPENDIX (L) - Water quality assessment for Phase B experiments..............152

APPENDIX (M)- SEM images of the membrane units...........................161 


\section{LIST OF TABLES}

Table 2.1 - Effect of organics on membrane fouling and performance.................24

Table 2.2 - Effect of inorganics on membrane fouling and performance...............26

Table 2.3 - Effect of $\mathrm{pH}$ on membrane fouling and performance...................28

Table 2.4 - Effect of support media on membrane fouling and performance...........30

Table 3.1 - Characteristics of feed water used in the Preliminary Study Phase .........36

Table 3.2 - Operational parameters used in the Preliminary Experiments .............37

Table 3.3 - Volume of Support Media at different fill fraction ......................38

Table 3.4 - Phase A Study Experiments Factorial Design..........................41

Table 3.5 - Characteristics of feed water used in the Phase A experiments ............43

Table 3.6 - Phase B Study Experiments Factorial Design .........................45

Table 3.7 - Characteristics of feed water used in the Phase B experiments ............46

Table 4.1 - A summary of \% reduction in TMP at different fill fractions of support

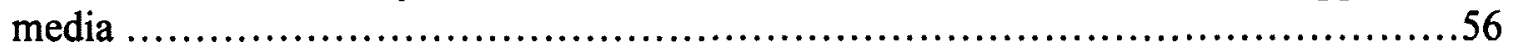

Table 4.2 - $\triangle$ TMP values resulted from the Preliminary Study Phase Experiments at different fill fractions of Support Media..........................................57

Table 4.3 - Parameters used for T-test..........................................59

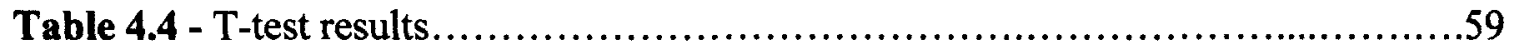

Table 5.1 - TMP values resulted from phase A experiments at different organics and inorganics components in the presence or absence of support media.

Table 5.2 - Main and interaction effects of parameters estimated by linear regression analysis. 
Table 5.3 - Comparison of the fouling predicted by full and simplified regression models for each experiment and the corresponding Sum of Squares of Residuals. .73

Table 5.4 - Identification of Important Main / Interaction effects of Parameters........74

Table 5.5 - Volume of permeate produced during 5 days of filtration (L).............77

Table 5.6 - Membrane fouling by cellulose vs. membrane fouling by humic acid ......83

Table 5.7 - Comparison of chemical properties of cellulose vs. humic acid ............85

Table 5.8 - Main and interaction effects of parameters estimated by linear regression analysis

Table 5.9 - Comparison of the fouling predicted by full and simplified regression models for each experiment and the corresponding Sum of Squares of Residuals.................88

Table 5.10 - Identification of Important Main / Interaction effects of Parameters ......89

Table 5.11 - Measured TOC for feed solutions and permeates for each experiment......92

Table 5.12 - Measured $\mathrm{UV}_{254 \mathrm{~nm}}$ absorbance for feed solutions and permeates for each

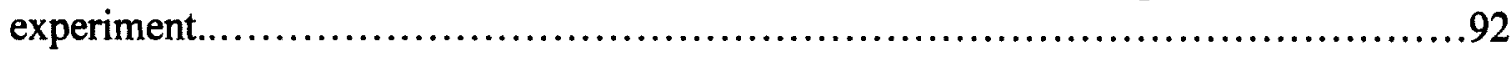

Table 5.13 - SUVA values for feed solutions and permeates for each experiment.......93 


\section{LIST OF FIGURES}

Figure 1.1 The sequence of research study phases..............................

Figure 3.1 A schematic representation of the two bench scale membrane filtration setups.

Figure 4.1 TMP graphs for membrane system with different fill fractions of support media compared to membrane system without support media (Trial \#1).

Figure 4.2 TMP graphs for membrane system with different fill fractions of support media compared to membrane system without support media (Trial $\$ 2$ )...................54

Figure 4.3 TMP graphs for membrane system with different fill fractions of support media compared to membrane system without support media (Trial \#3) ................54

Figure 4.4 A representation of average $\triangle \mathrm{TMP}$ at $0 \%, 10 \%, 20 \%$, and $30 \%$ fill

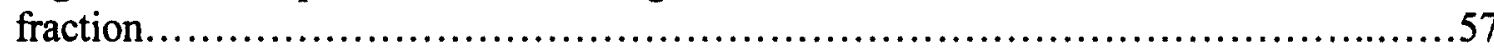

Figure 5.1 Comparison of low organic and inorganic fouling conditions with and

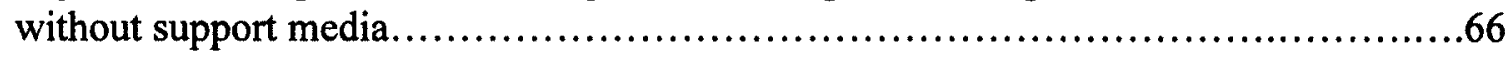

Figure 5.2 Comparison of high organic, low inorganic fouling conditions with and without support media.

Figure 5.3 Comparison of low organic, high inorganic fouling conditions with and without support media.

Figure 5.4 Comparison of high organic and inorganic fouling conditions with and without support media.

Figure 5.5 Photo images of membrane fouling from: a) experiment 1, b) experiment 2,

c) experiment 7 , and d) experiment 8

Figure 5.6 Flux recovery comparisons of two membranes systems......................78

Figure 5.7 Comparison of membrane fouling by cellulose vs. membrane fouling by humic acid without support media at low turbidity

Figure 5.8 Comparison of membrane fouling by cellulose vs. membrane fouling by humic acid with support media at low turbidity. 
Figure 5.9 Comparison of membrane fouling by cellulose vs. membrane fouling by humic acid without support media at high turbidity

Figure 5.10 Comparison of membrane fouling by cellulose vs. membrane fouling by humic acid with support media at high turbidity

Figure 5.11 SUVA values for feed solutions and permeates of cellulose

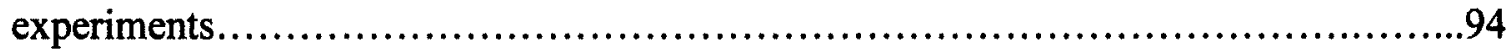

Figure 5.12 SUVA values for feed solutions and permeates of humic acid

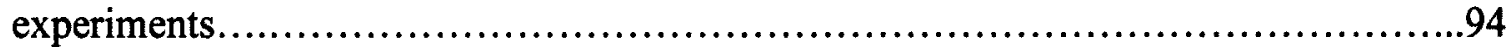

Figure 5.13 SEM images of membranes units, (60x magnification $20 \mathrm{kV}) \ldots \ldots \ldots \ldots \ldots . .95$

Figure 5.14 SEM images of membranes units, $(2.00 \mathrm{kx}$ magnification $20 \mathrm{kV}) \ldots \ldots \ldots \ldots . . .96$

Figure 5.15 SEM images of membranes units, $(25.00 \mathrm{kx}$ magnification $20 \mathrm{kV}) \ldots \ldots \ldots . .96$ 


\section{LIST OF ACRONYMES}

\begin{tabular}{|c|c|}
\hline CEB & Chemically enhanced backwash \\
\hline CIP & Clean in place \\
\hline COD & Chemical oxygen demand \\
\hline DBPs & Disinfection by-products \\
\hline DOC & Dissolved organic carbon \\
\hline DOM & Dissolved organic matter \\
\hline EPS & Extracellular polymeric substance \\
\hline $\mathbf{F A}$ & Fulvic acid \\
\hline GAC & Granular activated carbon \\
\hline HA & Humic acid \\
\hline HAA & Haloacetic acids \\
\hline HPMs & High pressure membranes \\
\hline HS & Humic substance \\
\hline $\mathbf{J}$ & Filtration flux \\
\hline LMH & Litres $/$ meter $^{2} /$ hour \\
\hline LPM & Liters per minute \\
\hline $\begin{array}{l}\text { LPMs } \\
\end{array}$ & Low pressure membranes \\
\hline MF & Microfiltration \\
\hline$\overline{\mathbf{N F}}$ & Nanofiltration \\
\hline NOM & Natural organic matter \\
\hline NTU & Nephelometric Turbidity Unit \\
\hline $\mathbf{R}$ & Membrane recovery \\
\hline RO & Reverse Osmosis \\
\hline$\overline{\text { SEM }}$ & Scanning electron microscopy \\
\hline SMBR & Submerged membrane bioreactor \\
\hline SUVA & Specific ultraviolet absorbance \\
\hline TC & Total Carbon \\
\hline THMs & Trihalomethanes \\
\hline
\end{tabular}




\begin{tabular}{|c|c|}
\hline TMP/ $\mathbf{A M P}$ & Transmembrane pressure / Change in TMP \\
\hline TOC & Total Organic Carbon \\
\hline UF & Ultrafiltration \\
\hline $\mathbf{U V}_{254 \mathrm{~nm}}$ & Absorbance of ultraviolet (UV) light at a wavelength of 254 nm \\
\hline
\end{tabular}




\section{CHAPTER 1- INTRODUCTION}

\subsection{Problem Statement}

The main goal of drinking water treatment is to produce drinking water that doesn't interfere with human health. Most source water (surface, groundwater, etc.) are not without contamination and can contain many dissolved and suspended contaminants that are harmful to human health. Water contaminants can be classified into two categories: chemical and microbiological. Chemical contaminants include heavy metals, organic compounds, total suspended solids, and turbidity while microbiological contaminants include Coliform bacteria, E. coli, pathogens, viruses and protozoa. Over the past decades, the use of membrane filtration for the production of drinking water has grown significantly. Membranes have become an attractive and economical alternatives to conventional methods because of their good removal efficiency towards microorganisms, natural organic matter (NOM), dissolved organic matter (DOM), disinfection by products precursors (DBPs), and other components (Huang et al., 2009; Bellona et al., 2004). Moreover, beyond the high quality water produced from membrane systems, they also require a smaller footprint requirements compared to conventional treatment options (Gao et al., 2011). Membrane processes can be categorized according to the driving force used for operations. This can include pressure, electrical voltage, temperature, concentration gradient, or a combination of more than one driving force. Pressure driven membrane processes include RO, NF, UF and MF, are the most commonly used membrane processes for drinking water treatment (Freeman et al., 2006). 
However, while membranes provide a high degree of treatment efficiency, all types of membranes are subjected to a major limitation: membrane fouling (Jerman et al., 2007). During membrane operation period, dissolved and suspended constituents in the source water build up as a cake layer on the membrane surface and/or contribute to the clogging of the membrane pores. Fouled membranes suffer from a loss of performance and decrease in membrane productivity as a result of increase in the transmembrane pressure (TMP). Furthermore, a well-known consequence of membrane fouling is an increase in the frequency of hydraulic backwashing and chemical cleaning (Hilal et al., 2005). This in turn has a negative impact on the operating costs. Fouling is inevitable but can be controlled to a certain extent. Different approaches are usually applied to control membrane fouling during operation including various feedwater pretreatment methods, and different operating conditions.

Pretreatment methods can alter the physical, chemical, and biological properties of feedwater with a goal of decreasing the membrane fouling and improving the performance of the process (Howe et al., 2002). However, the high capital cost is the main concern associated with pretreatment methods (Huang et al., 2009).

On the other hand, different operating conditions which include backwash and air scouring can reduce membrane fouling to some extent. When backwash is applied the pores of a membrane are flushed inside out. The pressure on the permeate side of the membrane is higher than the pressure within the membranes, causing the pores to be cleaned. On the other hand, air scouring helps to remove and minimize fouling from the membrane surface during operation period (Johir et al. 2011). 
Identification of foulants and understanding the interactions between foulants and fouling mechanism are also very important to membrane fouling control. In surface water treatment, major membrane foulants include natural organic matter (NOM), inorganic particles (clay minerals, calcium carbonate, calcium sulphate), particulate and colloidal, and microorganisms (bacteria, protozoa, algae) (Howe et al., 2002).

NOM and inorganic particles are thought to play a critical role in membrane fouling because they interact with and/or adsorb onto many surfaces in an aqueous environment. Also, they can adsorb onto a membrane material and block or constrict the membrane pores (Zularisam et al.2006).

As noted previously, fouling control approaches have been found to be effective in reducing membrane fouling to a manageable degree. However, since these fouling control options are considered as an integral parts of the membrane operation, it is very important to optimize these methods in order to reduce the operational cost and energy requirements of the membrane process.

The use of various types of support media in many studies such as Granular Activated Carbon (GAC), high density polyethylene media, and other supporting materials in water treatment as in submerged membrane bioreactor (SMBR) have shown a great potential in terms of water impurities reduction and removal (Aryal et al., 2010; Basu and Huck, 2005). Also, other researchers (Krause et al., 2008, Siembida et al., 2010, Johir et al., 2011) have used mechanical cleaning of membranes by introducing granular material into the submerged membrane reactor which resulted in the enhancement of scouring of the membrane surface. 
Although, these studies indicate that introducing support materials has a significant role in controlling fouling, there have been no published articles that investigated the relative effect of support media with different surface water organics and inorganics components on the degree of fouling in submerged membranes systems for drinking water treatment.

\subsection{Research Objectives}

The main objectives of this research were:

1- To investigate the influence of support media at different fill fractions on the reduction of fouling of a bench scale submerged hollow fiber ultrafiltration membrane.

2- To investigate the effect of different organic and inorganic concentrations on fouling of a bench scale submerged hollow fiber ultrafiltration membrane system in the presence or absence of support media.

3- To study the relationship between organic types and fouling of a bench scaled submerged hollow fiber ultrafiltration membrane in the presence or absence of support media.

The research study was carried out in three phases; Preliminary Study Phase, Phase A Study and Phase B Study. 


\subsubsection{Preliminary Study Phase Objectives}

A number of experiments were conducted prior to the main study phase of this research. The main objectives for the preliminary phase were to investigate the influence of support media at different fill fractions on membrane fouling reduction. Also, to identify the best fill fraction in terms of fouling reduction to be used in the main study phase experiments. The preliminary study phase was carried out by performing 5 day long experiments using three different fill fractions of support media $(10 \%, 20 \%$, and $30 \%$ ). The support media were added to the membrane reactor and were compared to the same membrane system with no support media $(0 \%)$.

\subsubsection{Phase A Study: The influence of different organic and inorganic concentrations on membrane fouling in the presence or absence of support media.}

A $2^{3}$ factorial designed experiment was performed to investigate the influence of different organic and inorganic concentrations on membrane fouling in the presence or absence of support media. The results from the preliminary study were taken into account and used to determine the fill fraction of support media for these experiments. A fill fraction of $10 \%$ was incorporated into the experimental trials. Phase A study was carried out by performing 5 day long experiments. Humic acid and kaolin clay were selected to represent organic and inorganic components respectively. The organic compound (humic acid) in the feed solution was varied from $1.5 \mathrm{mgC} / \mathrm{L}$ and $3 \mathrm{mgC} / \mathrm{L}$ whereas kaolin clay (measured as turbidity) was varied from 5 NTU and 20 NTU. 


\subsubsection{Phase B Study: The relationship between natural source water organic types and membrane fouling in the presence or absence of support media}

Similar to Phase A, a $2^{3}$ factorial designed experiment was conducted to study the relationship between natural source water organic types and membrane fouling in the presence or absence of support media. A fill fraction of $10 \%$ of support media was also used in phase B experiments. Phase B study was also carried out by performing 5 day long experiments. Two organic compounds were studied, $3 \mathrm{mg} / \mathrm{L} \mathrm{TOC}$ of humic acid and $3 \mathrm{mg} / \mathrm{L}$ TOC of cellulose. Each of these organic compounds was examined separately to help understand their fouling behaviour and their influence on membrane performance. The level of turbidity in the feed solution was varied from 5 NTU and 20 NTU.

A summary of the research phases and the objectives of each phase can be seen in Figure 1.1 .

\subsection{Thesis Structure}

The literature review presented in chapter 2 includes an overview of published information related to this research study. The materials and methods employed during the research phases are described in chapter 3. The results from the preliminary study phase experiments and the selected fill fraction of support media are presented in chapter 4 . Chapter 5 presents the results of the phase A / phase B experiments. The influence of support media on membrane fouling with different organic and inorganic matter content are presented in this chapter. 
Chapter 6 presents the overall conclusions and recommendations for future

research.

\section{Preliminary Study Phase}

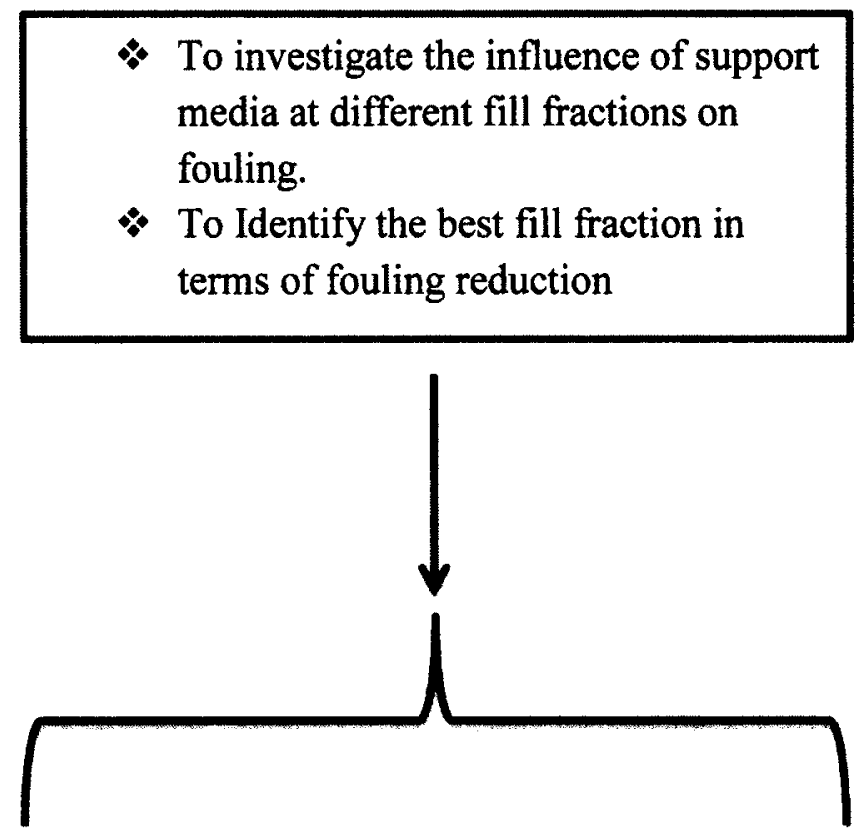

Phase A Study

\section{$2^{3}$ factorial design experiments}

To investigate the influence of different organic and inorganic concentrations on membrane fouling in the presence or absence of support media
Phase B Study

\section{$2^{3}$ factorial design experiments}

To study the relationship between natural source water organic types and membrane fouling in the presence or absence of support media

Figure 1.1 The sequence of research study phases 


\section{CHAPTER 2 - LITERATURE REVIEW}

The literature review is divided into five sections. First, general concepts of membranes

filtration for drinking water applications are discussed, followed by a review of ultrafiltration (UF) application in water treatment. Also, a review of fouling phenomena especially in UF membranes and fouling control are discussed. In addition, the impacts of raw water characteristics and support media on UF membranes fouling are presented.

\subsection{Membrane filtration processes for drinking water}

Due to the increase in water regulations and the need for safe source of drinking water that doesn't interfere with human health, the use of membrane filtration for the production of drinking water has significantly grown over the past decade. The advantages of membrane techniques include continuous separation of turbidity and organic matters, high water quality effluent, and easy combination with other existing techniques (Gao et al., 2011).

Membrane processes in water treatment are increasingly used for desalination, water softening, and removal of bacteria, microorganisms, particulates, and organic impurities, which could cause problems of color and odor in drinking water and can lead to further complications of the process (Tian et al., 2008). In membrane filtration process, water is pushed through a semi-permeable membrane by applying a driving force such as gradients in temperature, energy, concentration or pressure across the membrane. The water that passes through the membrane is called permeate or filtered water while the 
water portion that remains on the feed side is called retenate or concentrate. The accumulation of feed constituents on the surface of the membrane or within membrane pores over time increases the transmembrane pressure and causes a sever flux decline, affect the quality of water produced as well as the membrane lifetime. The loss in membrane performance is due to membrane fouling which is caused by cake formation, pore constriction, and pore blocking. Membrane fouling phenomena is discussed in section 2.3 .

\subsubsection{Type of membrane}

Membrane filtration is divided into four types based on pore size and the removal efficiency. Microfiltration (MF) membranes, which have a pore size of approximately $(0.1-10) \mu \mathrm{m}$, are used to separate suspended particles from dissolved substances (i.e. bacteria and protozoa). Ultrafiltration (UF) membranes, which have a pore size of approximately $(0.001-0.1) \mu \mathrm{m}$, will remove all microbiological species removed by MF, as well as viruses. Nanofiltration (NF) membranes, which have a pore size of $(0.0001-0.001) \mu \mathrm{m}$, and Reverse osmosis (RO) (pore size $<0.0001 \mu \mathrm{m}$ ) membranes are used in applications that require the removal of dissolved contaminants, as in the case of softening or desalination.

\subsubsection{Membrane filtration configurations}

Membranes can be classified as low and high pressure membranes. Low pressure membranes (LPMs) include MF and UF while high pressure membranes (HPMs) include $\mathrm{NF}$ and RO. Low-pressure membranes are considered as a good alternative to 
conventional methods because of their ability to remove particles and microorganisms, produce high quality treated water, the relatively low cost, and the small plant footprint (Freeman et al., 2006). However, LPMs are not efficient for removing of low micro molecular organics such as humic substances (Tian et al., 2008). Thus, pretreatment processes are required prior LPMs process (Tian et al., 2008). In addition, the presence of natural organic matter (NOM) in water causes a serious fouling of the membrane unit. As a result, frequent replacement or cleaning of the membrane unit is required (Lee et al., 2004). High pressure membranes, on the other hand, are designed to retain very small particles and have been used for desalination and softening.

Membranes can also be classified into two operation filtrations, dead-end filtration and cross-flow filtration. In dead-end filtration, the feed water flows perpendicular to the membrane. The suspended solids accumulate on the surface of the membrane which can be removed from the surface of the membrane during backwash. However, the retained suspended solids build up with time as a cake layer resulting in an increased resistance to filtration. This requires frequent cleaning or replacement of the membrane unit. In cross-flow filtration, on the other hand, the feed water flows parallel to the membrane surface. This causes some of the particles to pass through the membrane. Remaining particles continue to flow across the membrane. In contrast to the dead -end filtration, the use of cross flow prevents suspended particles from building which assists in reducing the fouling (Wang et al., 2008). However, in cross- flow filtration, one feed generates two product streams, retentate and permeate. As a result, $80-90 \%$ of water is recovered compared to $100 \%$ in dead-end filtration. Furthermore, since the solids are carried away from the membrane surface in the retentate, membranes operating with a 
cross flow filtration regime can usually run at higher fluxes and for longer periods of time.

\subsubsection{Membrane Operational Parameters}

The flow through the membrane can be described by Darcy's law which states that the flow through a porous medium is directly proportional to the pressure gradient across that medium and the permeability of the medium (MWH, 2005). So, in the case of a porous membrane, the permeate flux $(\mathrm{J})$ through the membrane can be obtained by using equation 2.1. Transmembrane pressure (TMP) is the driving force behind the filtration process and can be defined as the difference in pressure between the feed and permeate side of a membrane. TMP measurement varies for pressure driven and submerged membranes. In pressure driven membranes, water is pushed through a membrane unit using pressure pump located on the feed side of the membrane (positive pressure value). On the other hand, in submerged membranes, water is pulled from the membrane by applying vacuum pressure (negative suction pressure value) using pressure pump located on the permeate side of a membrane. TMP measurement is important because it describes how much force is needed to push or pull water through a membrane. A low transmembrane pressure indicates a clean, well-functioning membrane. On the other hand, a high transmembrane pressure indicates fouled membrane with reduced filtering abilities.

In UF membranes, fouling results in a decrease of the membrane permeability over time. This decrease in permeability over time means that less water can be filtered at a given pressure or that higher pressures have to be generated to maintain the permeate 
flux. Either of these two effects is undesirable to the sustainable use of membrane filters to treat surface waters. The water flux $(\mathrm{J})$ can be used to determine the recovery $(\mathrm{R})$ of a membrane filtration System. The recovery is defined as the ratio of treated water flow rate (permeate) to feed water flow Rate (Metcalf and Eddy, 2011).

$$
J=\frac{Q}{A}=\frac{\Delta P}{\mu \cdot R}
$$

Where

$\mathrm{J}:$ permeate flux $\left(\mathrm{L} / \mathrm{m}^{2} \cdot \mathrm{h}\right)$

$\mathrm{Q}:$ is the permeate flow rate $\left(\mathrm{m}^{3} / \mathrm{s}\right)$

$A:$ is the membrane surface area $\left(\mathrm{m}^{2}\right)$

$\Delta \mathrm{P}:$ is the pressure across the membrane or transmembrane pressure (bar)

$\mu:$ is the viscosity of water, $\mathrm{kg} / \mathrm{m} \cdot \mathrm{s}$

$R:$ is the membrane resistance coefficient, $(1 / \mathrm{m})$

\subsection{Ultrafiltration application in water treatment}

In recent years, surface water treatment with UF membranes has become an attractive alternative to conventional methods (Wang et al., 2008). The advantages of UF treatment compared to other conventional treatment techniques are include good quality treated water, good removal efficiency towards microorganisms, less production of sludge, and less need of chemical agents during treatment (Nakatsuka et al., 1996). Also, UF can effectively remove turbidity, microorganism, natural organic matter (NOM), dissolved organic matter (DOM), disinfection by-products (DBPs), and other components (Zularisam et al., 2006). The main UF membrane modules are used in drinking water 
treatment include hollow fiber, tubular and flat sheet membranes (Li et al., 2008; Lesjean et al., 2004).

Hollow fiber membranes are one of the most common UF modules used in drinking water treatment. The membrane fibers have an outside diameter varying from 0.5 to $3 \mathrm{~mm}$. One of the main limitations of hollow fiber membranes is membrane fouling. Pumping water with high suspended solids would lead to sever plugging because of the narrow inner diameter of fibers (Chen et al., 2007). As a result, extensive pretreatment is usually applied prior the membrane process when hollow fiber membranes are used for the treatment of water or any other liquid mixtures (Chen et al., 2007). Cleaning of hollow fiber membranes is usually done by physical means (i.e. backwash and air scouring) and chemical means (i.e. using chemical agents) (Wef. 2011). Membrane physical and chemical cleaning are discussed in sections 2.4.2 and 2.4.3 respectively.

Tubular membranes, on the other hand, are large diameter tubes with an inner diameter ranging from 5 to $13 \mathrm{~mm}$. These tubular modules are known of their ability to control membrane fouling because to their diameter large size (Strathmann, et al., 2011). As a result, these membranes can be operated at a higher operational flux and higher suspended solids. However, the tubular modules have high production cost. Therefore, the use of these modules is limited in applications where feed solutions with high solids contents have to be treated (Strathmann, et al., 2011).

Flat sheet membranes have an overall thickness between 5 to $13 \mathrm{~mm}$. These types of membranes are usually operated at moderate to high operational flux because of their 
moderate tendency to clog. Cleaning efficiency depends on chemical cleaning and air scouring only (Wef. 2011). As a result, the cost and the energy consumption of these membranes are moderate compared to other modules (Wef. 2011).

\subsection{Membrane Fouling}

Membrane fouling is caused by accumulation of feed water constituents on the surface of the membrane (cake formation), in the membrane matrix (Pore constriction) or adsorption within the pores of the membrane (pore blocking) (Van der Marel et al., 2010). Fouling phenomena is considered as a major issue in UF membranes for more than a decade with an increase in published articles that deals with fouling (Drews et al., 2010). UF membranes' fouling is classified into two categories reversible and irreversible fouling (Hiroshi et al., 2007). Reversible fouling is the fouling that can be removed by physical cleaning such as backwashing, and air scouring. On the other hand, irreversible fouling refers to fouling that cannot be removed by physical means and the only way to be removed is by chemical cleaning. Membrane fouling affects the membrane lifetime, the quality of water produced, increases the energy required for aeration, and the operation cost (Zularisam et al., 2006; Peiris et al., 2010). The source of fouling can be classified into organics, inorganic, colloidal, and biofouling.

\subsubsection{Organic fouling}

Organic fouling is due to the accumulation and adsorption of natural organic matter (NOM) on the membrane surface or within pore structure. NOM in water is a 
complex mixture of humic substances, fatty acids, and proteins (Thurman et al., 1985). Several studies of UF with surface, lake, and river waters have identified (NOM) as one of the major foulants during UF membranes processes. Zularism et al., (2011) classified NOM into hydrophobic fraction which includes humic substances and hydrophilic fraction which includes fatty acids and proteins. Removal of NOM is important since they act as the precursors to disinfection by-products (DBPs) such as trihalomethane (THM) and haloacetic acids (HAA) which are known to be carcinogenic and hazardous to human health (Lowe et al., 2008).

\subsubsection{Inorganic fouling}

Inorganic fouling is caused by the accumulation of inorganic precipitates such as clay minerals, calcium carbonate, calcium sulphate, silicon dioxide, and aluminum hydroxides on membrane surface or in membrane matrix (Shirazi et al, 2010). In nonporous membranes, inorganic particulate fouling is caused by the accumulation of particles on the membrane surface resulting in the formation of cake layer, which creates a hydraulic resistance to permeate flow through the membrane (Zhu et al., 1997). On the other hand, in porous membranes, pore plugging by particulate matters smaller than the membrane pore size is an important mechanism for particulate fouling, in addition to the formation of cake on the membrane surface (Zhu et al., 1997). Also, the presence of inorganic particles can also affect the fouling behaviours of organic substances. Zularisam et al., (2006) studied the behavior of NOM fouling in the presence of clay minerals. It was found clay minerals helped to increase of sorption of NOM onto the membrane and hence decrease membrane permeability. 


\subsubsection{Colloidal fouling}

Colloids are defined as any organic or inorganic components are between $1 \mathrm{~nm}$ and $1 \mu \mathrm{m}$ of size (Buffle and Leppard, 1995). Organic colloids include microorganisms, polysaccharides, humic acids, and fulvic acids. Inorganic colloids include clay, and calcium carbonate (Buffle and Leppard, 1995). Membrane reversible fouling caused by colloids was thought to be not the case because they can be removed by physical cleaning during backwashing and air scrubbing. However, those colloids can cause irreversible fouling due to their smaller size relative to membrane pore size.

\subsubsection{Biofouling fouling}

Biofouling is a result of formation of biofilms on membrane surface due to the presence of bacteria in the membrane system. Once the bacteria enter the membrane system, they use organic matter as a source of energy resulting in biological growth at the membrane surface or within the membrane matrix. Once bacteria attach to the membrane, they start to produce extracellular polymeric substances (EPS) to form a viscous, slimy, hydrated gel (Ishigake et al., 2000). The main compositions of EPS are protein, carbohydrate, humic substances, DNA and RNA. Due to their ability to remove bacteria, many researches have suggested using UF membranes in order to prevent biofilm buildup on membranes.

\subsection{Fouling control in UF membranes}

As previously mentioned, fouling in UF membranes affects the membrane performance on producing high quality treated water as well as the membrane lifetime. 
As a result, a variety of approaches have been used to control this phenomenon. Some of these approaches include feed water pretreatment, physical cleaning, and chemical cleaning.

\subsubsection{Fouling control through feed water pretreatment}

Pretretment approach can change the physical, chemical, and biological properties of feed water and improve the performance of the membrane. Feed water pretreatment involves coagulation, oxidation and biological processes (Hilal et al., 2005).

Coagulation, as a pretreatnent process, is the most successfully used due to its easy operation and low cost compared to other pretreatment processes (Hilal et al., 2005). Pretreatment coagulants include organic and inorganic salts. In drinking water production, the use of inorganic coagulants, such as aluminum and ferric salts, is more commonly than organic coagulants. Gao et al., (2011) showed that the using of coagulation prior UF enhanced the removal of contaminants and reduced the formation of disinfection by-product. Also, a combination of these two processes is capable of removing both turbidity and dissolved organics (Howe et al., 2006). However, one significant limitation to the coagulation process is that the efficiency of the coagulation process may vary between different types of DOC. Carroll et al., (2000) found that coagulation of NOM characterized as hydrophilic was poor relative to other types of NOM. Also, Geo et al., (2011) found that coagulation is not efficient in the removal of NOM that cause irreversible fouling (i.e. fatty acids and proteins). 
Oxidants used in water treatment are usually ozone, permanganate, and chlorine. Oxidants can reduce the growth of microorganisms or change the structure and properties of the NOM. Kim et al., (2008) investigated the effect of ozone on the performance of UF membranes. He found that membrane fouling decreased and TOC removal increased when ozone dosage was applied. Also, peroxidation using low doses of ozone has been found to alter the size distribution of effluent organic matter, and hence, their contribution to membrane fouling. Permanganate and chlorine, on the other hand, are able to oxidize inorganic ions, such as manganese, and account for less fouling of UF membranes (Liang et al., 2008). Chen et al., (2005) studied the mechanism of potassium permanganate on algae removal. It was reported that permanganate could promote the aggregation of algal cells.

Biological processes such as biofiltration; are used to remove biodegradable contaminants to reduce biofilm formation (Uhl et al., 2003). Jimenez and Basu et al., (2008) examined the effect of bio-filter, as a pretreatment option, on the performance of ultrafiltration applying to the treatment of humic acid water, and found that combination of bio-filter presented lower fouling rate than ultrafiltration alone.

\subsubsection{Fouling control through membrane physical cleaning}

Another approach for controlling membrane fouling in UF membranes is through physical cleaning which includes backward flush and air scouring. As it mentioned previously, fouling mechanism in UF membranes is formed due to the interaction between water impurities and membrane surface or membrane matrix. When backwashing is applied, the pores are flushed inside out. The pressure on the permeate 
side of the membrane is higher than the pressure within the membranes, causing the pores to be cleaned. However, in some cases, backwashing may not be effective for cleaning some foulants. Katsoufidou et al., (2008) investigated the effect of backwashing on fouling in UF membranes by using two different organic substances humic acid and sodium alginate. It was found that different organics have different fouling mechanisms and that backwashing was more effective for sodium alginate fouling than for humic acid fouling. Furthermore, backwash efficiency depends on backwash duration, backwash interval, and backwash flux (Wu et al., 2007).

Air scouring is another physical technique to control fouling. Air scouring provides a shear force on the membrane surface preventing the foulants from accumulating on the membrane surface. Air scouring is often coupled with backwashing and used periodically or continuously. Psoch et al., 2006 indicated that air scouring and backwashing applications can co-exist to reduce external and internal fouling respectively. Also, Qaisrani et al., (2011) investigated the potential effect of air scouring and backwashing for membranes. They have found that the combination of air scouring and backwashing is the best method for improving membrane performance in term of fouling control.

\subsubsection{Fouling control through membrane chemical cleaning}

Various cleaning chemicals can be used to remove fouling materials from the membrane matrix and enhance the membrane performance. Gao et al., (2011) categorized the common chemicals used for cleaning UF membranes in water industry into three categories: acids which are responsible for the control of inorganic fouling, alkalis which 
are relatively effective for the reduction of organic fouling, and biocides, which are added when the bio-fouling is formed. Chemical cleaning can be carried out in various ways: directly immersing the fouled membranes in the chemicals, (clean-in-place (CIP)) or cleaning in conjunction with the physical cleaning step, (a chemical enhanced backwash (CEB)) (Chun et al., 2010).

However, there are some factors that might affect the chemical cleaning efficiency. These factors include cleaning time, chemicals concentration, and temperature. Van der Bruggen et al., (2003) investigated the effect of cleaning time on membranes. He found that frequent usage of chemical cleans can damage the membrane as well as shorten the membrane lifetime. To support this finding, Siavash et al., (2000) studied the effects of chemical concentration and cleaning time on ultrafiltration membrane. Two chemical agents were used in their study, $\mathrm{HCl}$ and $\mathrm{NaOH}$. It was found the cleaning efficiency for both chemical agents increased with increasing the cleaner concentration and decreased afterwards. His explanation to this finding was the used of high chemical concentration affected the membrane by altering its permeability which resulted in less cleaning efficiency. Therefore, increasing the concentration of cleaning agent up to the optimum concentration provided highest cleaning efficiency. It means that there is no benefit to use concentrated chemicals.

The effect of temperature on cleaning efficiency was investigated by Ang et al., (2006). He found that temperature had a significant impact on the efficiency of membrane cleaning, by changing the reaction equilibrium, by enhancing the reaction kinetics, and by increasing the solubility of solutes. 


\subsection{The impacts of raw water characteristics and support media on UF membranes fouling}

Ultrafiltration is considered as one of the most successful technique in drinking water treatment. The efficiency of UF membranes to produce high quality treated water depends on the ability to control and minimize membrane fouling to a reasonable degree (Sutzkover et al., 2010). As discussed previously, fouling phenomena in UF membranes can be controlled through pretreatment as well as physical and chemical cleanings. However, raw water characteristics such as the concentration of organics, inorganics and $\mathrm{pH}$ level and the use of support media can have a significant impact on membrane performance and the degree of fouling.

\subsubsection{Effect of organics}

NOM is considered as the main source of fouling in ultrafiltration. NOM is divided into two groups: non-humic substances (hydrophilic fraction) and humic substances (hydrophobic fraction) (Sutzkover et al., 2010). Non humic substances such as proteins, waxes, and fats are considered less important than humic substances because of their simple structures and low molecular weight. Compared to non-humic substances, humic substances (HS) are considered as major components of the NOM in water. It was reported that a major fraction of NOM from humic substances represent $60-70 \%$ of total organic carbon (TOC) in soils and $60-90 \%$ of dissolved organic carbon (DOC) in most natural waters, ( Zularisam et al., 2007).

Humic substances, which are coloured from yellowish to dark brown, are complex mixtures formed by biochemical and chemical reactions during the decay of 
plant and microbial remains (Jeffrey et al., 1996). Domany et al., (2002) classified humic substances according to their solubility and molecular weight to: fulvic acids (FA), humins, and humic acids (HA). Fulvic acids are soluble in water under all $\mathrm{pH}$ conditions and have a molecular weight less than $2000 \mathrm{Da}$ (Dalton). They are dark brown to black in color. Humins, on the other hand, are insoluble at any $\mathrm{pH}$ conditions and they are black in color. Humic acids are insoluble at $\mathrm{pH}$ values less than 2 and soluble at higher $\mathrm{pH}$ values. Humic acids, which have a molecular weight between 2000 to $5000 \mathrm{Da}$, are the major component of soil humic substances and they are dark brown in color.

In general, humic substances are not believed to be harmful to human health. However, they can cause problems to water body such as taste problem and unpleasant odour. Also, humic substances can adsorb a variety of organic substances. Many metals present in drinking water can also react with humic substances in water, which can increase the concentration of metals in the water (Shao et al., 2011). In addition, humic acids can lead to further complications such as disinfection by product formation such as trihalomethane (THM) and haloacetic acids (HAA) during water treatment processes such as chlorination which are known to be carcinogenic to human health (Lowe et al., 2008). Therefore, the removal of HAs is very important to meet DBPs regulations and providing safe drinking water (Shao et al., 2011).

The application of membranes in water treatment has shown potential for treatment of humic acid and other organic matter. Nevertheless, Compared to the size of humic acids, UF membranes with comparatively larger pore size are not very effectively to remove humic acid. In addition, humic acid has been recognized as one of the main 
foulants that causes flux decline during water treatment using UF membrane process. Yuan et al., (1999) studied humic acid fouling and found that HA was responsible for the initial stage of fouling due to deposition and pore adsorption. Also, Schafer et al., (2001), observed that HA caused up to $78 \%$ decline in flux and have a great impact on membrane performance.

As previously mentioned, the hydrophilic components of NOM were thought to impact water quality less than the humic fraction. However, several studies were done on the hydrophilic fraction of NOM. Caroll et al., (1999), investigated the effect of hydrophilic materials on membrane fouling. It was found that the major cause of fouling was due to the non humic substances, and not the humic substances. This finding was supported by Speth et al., (2000) who found that hydrophilic materials fouled more than hydrophobic materials. Also, Jarusutthirak et al., (2002) studied the effect of organic matter on UF membranes and found that the hydrophilic fraction represented the highest fouling. It was found that the high molecular weight of the hydrophilic component was responsible as the initial contributor to NOM fouling.

Studies related to the effect of organics on membrane fouling and membrane performance are summarized in Table 2.1 . 
Table 2.1- Effect of organics on membrane fouling and performance

\begin{tabular}{|c|c|c|c|c|c|}
\hline Researchers & $\begin{array}{l}\text { Membrane } \\
\text { Type/ material }\end{array}$ & Effect studied & Feed & $\begin{array}{l}\text { Organic studied / } \\
\text { concentration }\end{array}$ & Results / findings \\
\hline $\begin{array}{l}\text { Jones et al } \\
\quad(2001)\end{array}$ & $\begin{array}{l}\mathrm{UF} / \\
\text { regenerated } \\
\text { cellulose }\end{array}$ & $\begin{array}{l}\text { The behavior of } \\
\text { NOM on } \\
\text { membrane } \\
\text { fouling }\end{array}$ & $\begin{array}{l}\text { Distilled } \\
\text { water and } \\
\text { humic acid } \\
\text { solution }\end{array}$ & $\begin{array}{l}\text { humic acid } \\
25 \mathrm{mg} / \mathrm{L}\end{array}$ & $\begin{array}{l}\text {-Severe flex decline was related to the } \\
\text { size of humic acid molecules. The } \\
\text { size of humic acid molecules is small, } \\
\text { causing diffusivity to be increased, } \\
\text { allowing for humic acid to be easily } \\
\text { diffuse into the membrane pores and } \\
\text { adsorb. }\end{array}$ \\
\hline $\begin{array}{l}\text { Zularisam et al } \\
\qquad(2011)\end{array}$ & $\begin{array}{l}\text { UF/ Hollow } \\
\text { fiber / } \\
\text { Polysulfone }\end{array}$ & $\begin{array}{c}\text { Fouling potential } \\
\text { of NOM }\end{array}$ & $\begin{array}{l}\text { Synthetic } \\
\text { water } \\
\text { which } \\
\text { contains } \\
\text { humic acid }\end{array}$ & $\begin{array}{l}\text { Humic acid } \\
10 \mathrm{mg} / \mathrm{L}\end{array}$ & $\begin{array}{l}\text { - Flux decline was observed at the } \\
\text { beginning of the filtration caused by } \\
\text { humic acid deposition on membrane } \\
\text { surface. } \\
\text { - Membrane fouling caused by humic } \\
\text { acid was higher before inorganic } \\
\text { addition. }\end{array}$ \\
\hline $\begin{array}{l}\text { Jermann et al } \\
\quad(2007)\end{array}$ & $\begin{array}{l}\text { UF /flat sheet/ } \\
\text { polyethersulfon } \\
\text { e }\end{array}$ & $\begin{array}{l}\text { The effect of } \\
\text { molecular } \\
\text { interactions } \\
\text { between humic } \\
\text { and Alginate on } \\
\text { UF fouling } \\
\text { mechanisms }\end{array}$ & $\begin{array}{l}\text { Deionized } \\
\text { water, } \\
\text { humic acid } \\
\text { and } \\
\text { Alginate } \\
\text { solutions }\end{array}$ & $\begin{array}{l}\text { Humic acid } \\
2 \mathrm{mg} \mathrm{C} / \mathrm{L} \\
\text { Alginate } \\
1 \mathrm{mg} \mathrm{C} / \mathrm{L}\end{array}$ & $\begin{array}{l}\text { - Irreversible fouling occurred due to } \\
\text { humic acid adsorption. } \\
\text { - Reversible fouling occurs after the } \\
\text { addition of alginate } \\
\text { - Formation of a heterogeneous } \\
\text { alginate cake with humic acid } \\
\text { incorporated, adsorption of mainly } \\
\text { humic acid onto the membrane. }\end{array}$ \\
\hline $\begin{array}{c}\text { Crazes et al } \\
\text { (1993) }\end{array}$ & $\begin{array}{l}\text { UF/ hollow } \\
\text { fiber / } \\
\text { cellulosic } \\
\text { derivative }\end{array}$ & $\begin{array}{l}\text { The effect of } \\
\text { organic matter } \\
\text { adsorption on } \\
\text { ultrafiltration } \\
\text { membrane }\end{array}$ & $\begin{array}{l}\text { Synthetic } \\
\text { water and } \\
\text { tannic acid } \\
\text { solution }\end{array}$ & $\begin{array}{l}\text { Tannic acid } \\
15 \mathrm{mg} / \mathrm{L}\end{array}$ & $\begin{array}{l}\text {-Severe fouling caused by tannic acid. } \\
-80 \text { percent loss of initial flux was } \\
\text { observed after only three hours of } \\
\text { filtration. }\end{array}$ \\
\hline
\end{tabular}




\subsubsection{Effect of inorganics}

Surface waters may contain significant concentrations of inorganic particles and their ability to cause fouling of various membranes has been the subject of a number of studies. Inorganics fouling usually is caused by the accumulation of clay minerals and inorganic salts on the membrane surface or within membrane pores. For inorganic particles, the type of membrane system used, dead-end or cross flow, may impact membrane fouling significantly. In a dead-end filtration design, these particles are rejected at the membrane surface and form a cake. In contrast, in cross flow filtration, these particles can be transported away from the membrane surface, (Lahoussine et al., 1990). Particles accumulation depends on several back transport mechanisms (e.g., shear induced diffusion, lateral migration), (Lahoussine et al., 1990).

Several studies have indicated that cakes composed of inorganic particles do not cause significant fouling of ultrafiltration membranes (Kim et al., 1993; Waite et al., 1999). However, Crozes et al., (1993) study has reported significant fouling of an ultrafiltration membrane by kaolin clay. Inorganic particles can also affect the fouling behaviours of organic substances. The presence of inorganic particles such as clay minerals in surface water created a significant competition between NOM and inorganic particles to adsorb onto the membrane surface or in the pores, (Zularisam et al., 2006).

Studies related to the effect of inorganics on membrane fouling and membrane performance are summarized in Table 2.2. 
Table 2.2- Effect of Inorganics on membrane fouling and performance

\begin{tabular}{|c|c|c|c|c|c|}
\hline Researchers & $\begin{array}{c}\text { Membrane } \\
\text { Typel } \\
\text { material }\end{array}$ & Effect studied & Feed & $\begin{array}{l}\text { Inorganic } \\
\text { studied }\end{array}$ & Results / findings \\
\hline $\begin{array}{l}\text { Zularisam et al } \\
\qquad(2011)\end{array}$ & $\begin{array}{c}\text { UF/ Hollow } \\
\text { fiber / } \\
\text { Polysulfone }\end{array}$ & $\begin{array}{l}\text { The fouling } \\
\text { potential of } \\
\text { inorganic } \\
\text { colloidal } \\
\text { components }\end{array}$ & $\begin{array}{c}\text { Synthetic } \\
\text { water, humic } \\
\text { acid and } \\
\text { Kaolin }\end{array}$ & Kaolin & $\begin{array}{l}\text { - High flux decline was observed after Kaolin } \\
\text { addition. } \\
\text { - Inorganic particles can act as an adsorbent of } \\
\text { humic acid, thus increasing humic acid } \\
\text { adsorption onto the membrane surface and } \\
\text { consequently resulting in high flux decline. }\end{array}$ \\
\hline $\begin{array}{l}\text { Jermann et al } \\
\quad(2008)\end{array}$ & $\begin{array}{c}\text { UF / flat } \\
\text { sheet/ } \\
\text { polyethersulf } \\
\text { one }\end{array}$ & Flux decline & $\begin{array}{l}\text { Deionized } \\
\text { water, humic } \\
\text { acid solution, } \\
\text { alginate } \\
\text { solution, and } \\
\text { Kaolinite }\end{array}$ & Kaolinite & $\begin{array}{l}\text {-A combination of humic acid and Kaolinite } \\
\text { resulted in a significant flux decrease }\end{array}$ \\
\hline $\begin{array}{c}\text { Kim et al } \\
(1993)\end{array}$ & $\begin{array}{c}\text { UF/ } \\
\text { polysulfone }\end{array}$ & $\begin{array}{l}\text { The effect } \\
\text { of varying salt } \\
\text { concentrations } \\
\text { on the fouling } \\
\text { and flux decline }\end{array}$ & $\begin{array}{c}\text { Distilled water } \\
\text { and Silver sols } \\
\text { solution }\end{array}$ & $\begin{array}{c}\text { Colloidal } \\
\text { silver sols }\end{array}$ & $\begin{array}{l}\text {-High salt concentrations limited flux decline } \\
\text { by precipitating the salt at the membrane } \\
\text { surface. } \\
\text {-Moderate salt concentrations compressed } \\
\text { double layers within the membrane pores, } \\
\text { allowing particles to travel deeper into the } \\
\text { membrane porous structure and lowering their } \\
\text { rejection while slightly increasing the extent } \\
\text { of flux decline. }\end{array}$ \\
\hline $\begin{array}{l}\text { Crazes et al } \\
\quad(1993)\end{array}$ & $\begin{array}{c}\text { UF/ hollow } \\
\text { fiber / } \\
\text { cellulosic } \\
\text { derivative }\end{array}$ & $\begin{array}{l}\text { The effect of } \\
\text { organic and } \\
\text { inorganic matter } \\
\text { adsorption on } \\
\text { ultrafiltration } \\
\text { membrane }\end{array}$ & $\begin{array}{l}\text { Synthetic } \\
\text { water, tannic } \\
\text { acid solution } \\
\text { and Kaolin } \\
\text { clay }\end{array}$ & $\begin{array}{l}\text { Kaolin } \\
\text { clay }\end{array}$ & $\begin{array}{l}\text { - A significant fouling by kaolin } \\
\text { Clay. } \\
\text { - The fouling was associated with the } \\
\text { formation of a cake but this cake was easily } \\
\text { removed by backwash. }\end{array}$ \\
\hline
\end{tabular}




\subsubsection{Effect of Solution pH}

Feed solution $\mathrm{pH}$ has a definite impact on membrane fouling potential, (Nanda et al., 2010). Many studies investigated the effect of feed solution $\mathrm{pH}$ in order to optimize the membrane performance, permeability, and service life span. Some of membranes are unable to resist extreme acidic or alkaline conditions. Exposure to these extreme conditions may have a great impact on membrane performance such as membrane structure damage and irreversible fouling.

Nanda et al., (2010) investigated the impact of $\mathrm{pH}$ on fouling potential of calcium sulfate. It was found that the fouling potential of calcium sulfate increased with increasing acidity of the feed solution. Another study on membrane fouling was conducted by (Korbutowicz et al., 1999), using humic substances. It was reported that the increase of $\mathrm{pH}$ from 4.6 to 7.0 in the solution reduced membrane fouling and increased the efficiency of organic retention. This finding can be supported by Wang et al, (2001) who studied the impact of $\mathrm{pH}$ on humic acid diffusivity. He found that the diffusivity of humic acid depends on $\mathrm{pH}$ level. The diffusivity of humic acid increased with decreasing $\mathrm{pH}$.

Studies on the effect of solution $\mathrm{pH}$ on membrane fouling and membrane performance are summarized in Table 2.3. 
Table 2.3 - Effect of $\mathrm{pH}$ on membrane fouling and performance

\begin{tabular}{|c|c|c|c|c|c|}
\hline Researchers & $\begin{array}{l}\text { Membrane } \\
\text { Type/ material }\end{array}$ & Effect studied & $\begin{array}{l}\text { Feed/, } \\
\text { concentration }\end{array}$ & pH studied & Results / findings \\
\hline $\begin{array}{l}\text { Jones et al } \\
\quad(2001)\end{array}$ & $\begin{array}{l}\text { UF/ regenerated } \\
\text { cellulose }\end{array}$ & $\begin{array}{l}\text { Humic acid } \\
\text { adsorption / } \\
\text { Flux decline }\end{array}$ & $\begin{array}{l}\text { Distilled water } \\
\text { and humic acid } \\
\text { solution } \\
25 \mathrm{mg} / \mathrm{L}\end{array}$ & 4.7 and 10 & $\begin{array}{l}\text { - Humic acid adsorption } \\
\text { decreased as the } \mathrm{pH} \text { increased } \\
\text { from } 4.7 \text { to } 10 . \\
\text { - Electrostatic interactions } \\
\text { affected fouling resistance. }\end{array}$ \\
\hline $\begin{array}{l}\text { Yuan et al } \\
(2000)\end{array}$ & UF/ polysulfone & Flux decline & $\begin{array}{l}\text { Humic acid } \\
\text { solution } \\
2 \mathrm{mg} / \mathrm{L}\end{array}$ & 3 and 7 & $\begin{array}{l}\text { - Flux decline was significantly } \\
\text { higher at the low } \mathrm{pH} \text {. }\end{array}$ \\
\hline $\begin{array}{l}\text { Wang et al } \\
\quad(2011)\end{array}$ & UF/ hollow fiber & $\begin{array}{l}\text { Membrane } \\
\text { permeability }\end{array}$ & $\begin{array}{l}\text { Domestic } \\
\text { wastewater }\end{array}$ & $\begin{array}{l}6.7 \text { and } 5.8 \\
6.7 \text { and } 7.9\end{array}$ & $\begin{array}{l}\text { - Membrane permeability } \\
\text { increased as } \mathrm{pH} \text { value decreased } \\
\text { from } 6.7 \text { to } 5.8 \\
\text { - Increasing } \mathrm{pH} \text { value from } 6.7 \\
\text { to } 7.9 \text { resulted in a significant } \\
\text { decrease in membrane } \\
\text { permeability. }\end{array}$ \\
\hline $\begin{array}{l}\text { Kulovaara et al } \\
\text { (1999) }\end{array}$ & $\begin{array}{l}\text { UF/ flat-sheet / } \\
\text { polysulfone }\end{array}$ & $\begin{array}{c}\text { Fouling } \\
\text { potential / Flux } \\
\text { decline }\end{array}$ & $\begin{array}{c}\text { Natural water } \\
20 \mathrm{mg} / \mathrm{L} \\
\text { reference } \\
\text { Humic acid }\end{array}$ & 4.5 and 6.5 & $\begin{array}{l}\text { - Fouling Rate and flux decline } \\
\text { were significantly higher at low } \\
\text { pH. }\end{array}$ \\
\hline
\end{tabular}




\subsubsection{Impact of Support Media on membrane fouling}

Support media is usually associated with submerged membrane bioreactor (SMBR) which combines membrane system and biological treatment processes into a single unit. A number of studies were conducted to investigate the effect of support media on minimizing the fouling of SMBR.

The impact of support material on an integrated bio-filter membrane system was investigated by Basu and Huck, (2005). It was found that the fouling of the support medium system was at least two times slower than the non-support system. In their study, the support medium was made of high density polyethylene. Also, a study on submerged membrane by Aryal et al., (2010) using anthracite granules was resulted in a significant reduction in transmembrane pressure (TMP) and flux decline. Aryal's finding can be support it by Krause et al., (2008) study using granular material in the membrane reactor. The granular material resulted in the enhancement of scouring of the membrane surface, therefore, lower TMP and less flux decline.

Studies on the effect of support media on membrane fouling and membrane performance are summarized in Table 2.4 . 
Table 2.4 - Effect of Support Media on membrane fouling and performance

\begin{tabular}{|c|c|c|c|c|c|}
\hline Researchers & $\begin{array}{l}\text { Membrane } \\
\text { Type/ material }\end{array}$ & Effect studied & $\begin{array}{c}\text { Feed/ } \\
\text { concentration }\end{array}$ & $\begin{array}{c}\text { Type of support } \\
\text { media }\end{array}$ & Results / findings \\
\hline $\begin{array}{l}\text { Pradhan et al. } \\
\text { (2012) }\end{array}$ & $\begin{array}{c}\text { Submerged MF/ } \\
\text { flat sheet } \\
\text { membrane }\end{array}$ & $\begin{array}{l}\text { the combined } \\
\text { effect of air } \\
\text { flow and use of } \\
\text { support media } \\
\text { on membrane } \\
\text { fouling } \\
\text { reduction }\end{array}$ & $\begin{array}{l}\text { A suspension of } \\
\text { kaolin clay (10 } \\
\mathrm{g} / \mathrm{L} \text { ) mixed with } \\
\text { tap water }\end{array}$ & $\begin{array}{c}\text { Granular } \\
\text { Activated } \\
\text { Carbon (GAC) }\end{array}$ & $\begin{array}{l}\text {-A reduction of TMP was obtained } \\
\text { by adding granular medium instead } \\
\text { of doubling air flow rate. } \\
\text {-Adding granular medium in the } \\
\text { suspension (mechanical scouring) } \\
\text { with air flow (air scouring) could } \\
\text { be a sustainable alternative to } \\
\text { applying high air flow in } \\
\text { submerged membrane systems. }\end{array}$ \\
\hline $\begin{array}{l}\text { Siembida et al. } \\
\text { (2010) }\end{array}$ & $\begin{array}{c}\text { Polyethersulphon } \\
\text { (PES) flat sheet } \\
\text { membrane }\end{array}$ & $\begin{array}{l}\text { fouling } \\
\text { reduction and } \\
\text { permeability } \\
\text { loss in } \\
\text { membrane } \\
\text { bioreactors } \\
\text { (MBRs) }\end{array}$ & $\begin{array}{l}\text { Synthetic } \\
\text { wastewater }\end{array}$ & $\begin{array}{l}\text { Granular } \\
\text { Material }\end{array}$ & $\begin{array}{l}\text { - The use of granular material has } \\
\text { an overall positive effect on } \\
\text { membrane operation, as less } \\
\text { cleaning is necessary and higher } \\
\text { flux rates are realizable }\end{array}$ \\
\hline $\begin{array}{l}\text { Johir et al. } \\
\text { (2011) }\end{array}$ & $\begin{array}{l}\text { flat sheet } \\
\text { membrane / } \\
\text { polyvinylidene } \\
\text { fluoride } \\
\text { (PVDF) }\end{array}$ & $\begin{array}{l}\text { the effect of } \\
\text { support } \\
\text { materials } \\
\text { on membrane } \\
\text { process } \\
\text { efficiency } \\
\text { without the } \\
\text { need to } \\
\text { increase } \\
\text { aeration rate }\end{array}$ & $\begin{array}{c}\text { Domestic } \\
\text { wastewater }\end{array}$ & $\begin{array}{c}\text { Granular } \\
\text { Activated } \\
\text { Carbon (GAC) }\end{array}$ & $\begin{array}{l}\text { - A significant reduction in TMP } \\
\text { was observed after the addition of } \\
\text { support medium. } \\
\text { - GAC had an effect on organic } \\
\text { removal possibly by adsorption. } \\
\text { Some of the organic molecules } \\
\text { were adsorbed by the GAC. }\end{array}$ \\
\hline
\end{tabular}




\section{CHAPTER 3 - MATERIALS AND METHODS}

\subsection{Experimental Setup}

\subsubsection{Membrane Module}

Two bench scale hollow fiber membrane filtration setups were used throughout the research phases. The membrane module used for all experiments was a ZeeWeed ZW-1 hollow fiber module, which is commonly used in drinking water treatment. This type of membranes is ideal for fouling studies and has been used for filtration of different sources of water. The membranes are made of polyvinylidene fluoride (PVDF) and have a nominal pore size of $0.04 \mu \mathrm{m}$ and an effective surface area of $0.047 \mathrm{~m}^{2}$. Membrane specifications can be seen in Appendix (A).

\subsubsection{Process Configuration}

The two bench scale filtration setups were identical and featured three flow lines (for each filtration setup). The flow lines were feed flow line, permeate flow line, and an air flow line. A schematic representation of the two bench scale membrane filtration setups can be seen in Figure 3.1.

The feed line made use of a Nalgene heavy-duty cylindrical tank, which had a volume of $50 \mathrm{~L}$ and used to store the feed water during experimental period. An overhead mechanical stirrer was used to continuously mix the feed water to maintain the homogeneity of the feed water and to prevent any chemical settling during experimental 
period. A Masterflex peristaltic pump (model \# 7024-20) and Cole Parmer tubing were used to supply the feed water continuously to a $3 \mathrm{~L}$ plexiglass cylindrical membrane reactor tank during experiments. The overflow from the membrane reactor tank was directed continuously to the feed tank.

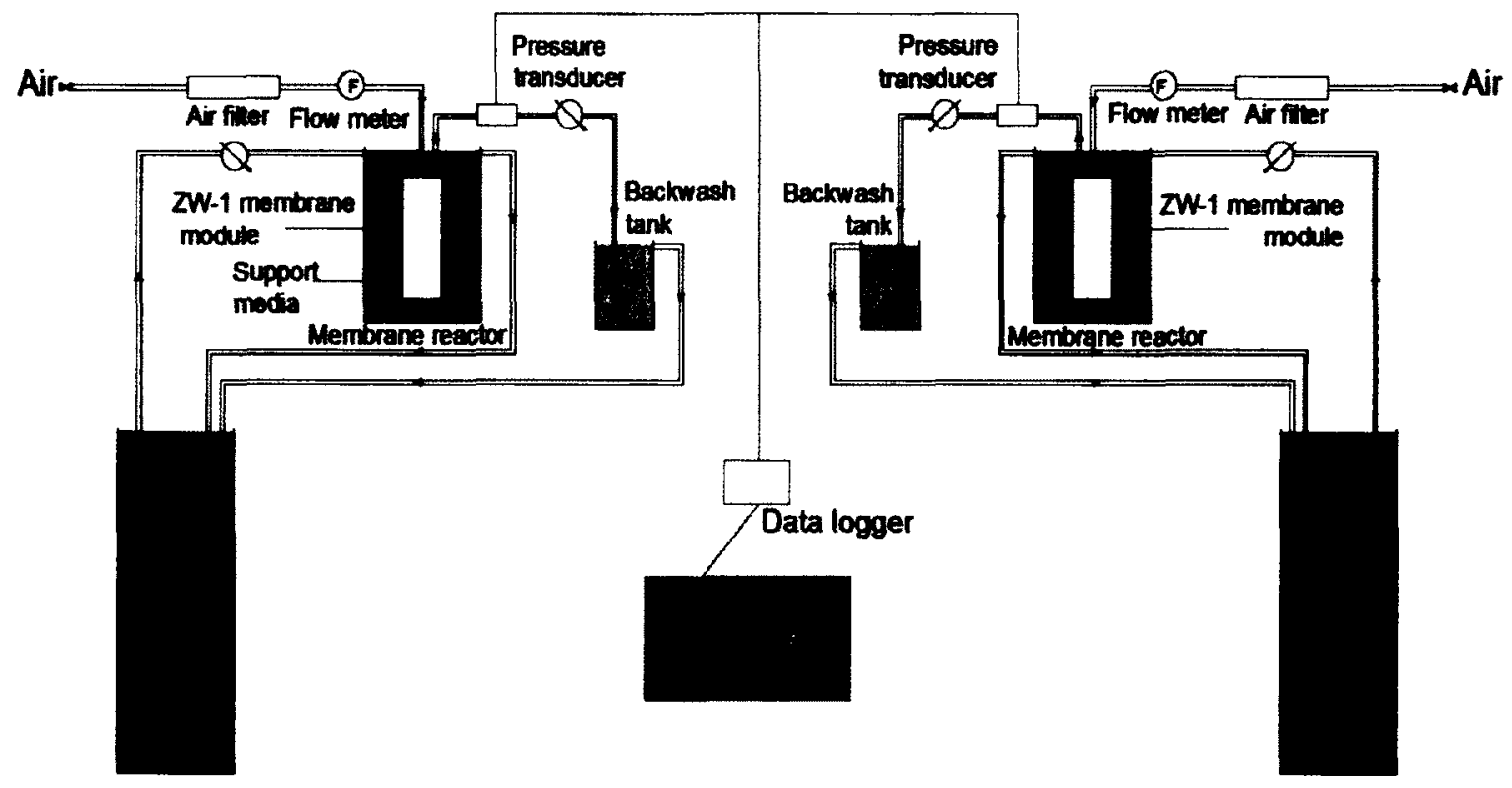

Figure 3.1 A schematic representation of the two bench scale membrane filtration setups

The permeate flow line featured a Masterflex L/S digital peristaltic pump (model \# 77800-62) to provide the required suction from the membrane to produce permeate (filtered water). The digital pumps were connected to a computer using a USB to serial converter. The flow rate and direction of the permeate was controlled using a software WinLIN. Additional Information regarding the programming of WinLIN software can be find in De Souza, 2012. 
The operational conditions, forward filtration, backwash duration, relaxation interval and relaxation duration were also controlled using this software. The permeate component was directed to a $1 \mathrm{~L}$ backwash tank during filtration and was used during backwash periods. Any overflow from the backwash tank was directed back to the feed tank. A differential pressure transducer (Cole Parmer high accuracy $\pm 0.25 \%$ ) was installed between the membrane module and the digital pump in both setups and was used to measure the transmembrane pressure during experiments. The pressure transducers were connected to a computer where the data were recorded using Operation Flux 2.0 program. Additional Information regarding Operation Flux 2.0 program can be find in De Souza, 2012.

Air flow line featured an electronic flow meter with a digital readout which was used to measure the flow rate during experiments, a flow modulator, a Whatman HEPAVENT which was used to filter the air, a plastic valve, and Cole Parmer tubing. Compressed air was used to scour the membrane surface during experiments. In addition, a flexible air curtain $(20 \mathrm{~cm})$ was installed around the base of the membrane to provide air bubbles to ensure that the membrane surface was scoured during experiments. The air from the curtain was controlled using a valve. The electronic flow meters used in both setups were also connected to a computer via a USB to serial convertor where the data were recorded using Operation Flux 2.0 program. The flow meters were connected to the computer using ADAM -4019+ and ADAM -4561+ convertors.

The feed line, permeate line and air flow line materials can be seen in Appendix (B). 


\subsection{Experimental Design}

\subsubsection{Preliminary Study Phase}

\subsubsection{Feedwater Characteristics}

In the preliminary phase experiments, synthetic river water was used which was made up of distilled water, organic mixture of Sigma Aldrich humic acid and Sigma Aldrich cellulous which represent the dissolved organic particles and organic particulates respectively, inorganic component measured as turbidity (Kaolin Clay), and hardness chemicals sodium bicarbonate and calcium sulphate. The characteristics of the feed water including the required amount of all chemicals used in the preliminary study are presented in Table 3.1. The main reason for using synthetic river water, which contains humic acid, was because many researchers have identified humic acid as the main source of fouling in membranes (Yuan et al., 1999; Schafer et al., 2001; Zularisam et al., 2011). In addition, the tested water was mainly used to represent surface water which has an average $\mathrm{DOC}$ range from $1 \mathrm{mgC} / \mathrm{L}-6 \mathrm{mgC} / \mathrm{L}$ (Peiris et al., 2010).

Humic acid and cellulous concentrated solution was prepared one day prior to the start of any experiment by mixing them in $2 \mathrm{~L}$ of a $50 \mathrm{ppm}$ sodium hydroxide $(\mathrm{pH} 10)$ to ensure that humic acid and cellulose were dissolved completely before any experimental run. The amount of humic acid and cellulose required to obtain the required amount of total organic carbon in the feed solution was determined by performing two different analysis, TC and TOC analysis using SHIMADZU TOC-VCPH/ CPN total organic carbon analyzer. The purpose of conducting these two methods of analysis was to ensure that the TOC-VCPH/ CPN unit was able to measure the carbon content caused by humic 
acid and cellulose in solution. Humic acid and cellulose were known for their sensitivity to $\mathrm{pH}$ level as well as other parameters. For this reason, $\mathrm{TC}$ analysis and $\mathrm{TOC}$ analysis were performed to determine the required amount of humic acid and cellulose required to obtain the required amount of carbon in feed water solution and to compare the results from each method of analysis. Results from TC test of humic acid were found to be similar to the results from TOC test. Thus, results from the TOC were used to determine the amount of humic acid required to obtain the required amount of TOC in the feed solution. On the other hand, identifying the amount of cellulose required to obtain the required amount of carbon in the feed solution was difficult due to the nature of cellulose. In order to measure the carbon content caused by cellulose in solution, cellulose has to be in suspension during sampling. Results from TOC test of cellulose were two to three times lower than the TC test. In this case, it was believed that the TOC analysis was not suitable for measuring the carbon content cause by cellulose. As a result, the results from TC test were used to determine the required amount of cellulose to obtain the required amount of carbon in feed solution. Humic acid and cellulose calibration curves can be seen in Appendix (C).

The organic concentrated solution and the required amount of kaolin clay and hardness chemicals were added to distilled water in the feed tank on the day of experiment and were mixed continuously at $370 \mathrm{rpm}$ during the experimental run duration. 
Table 3.1 Characteristics of feed water used in the Preliminary Study Phase

\begin{tabular}{|c|c|c|c|c|}
\hline \multicolumn{5}{|c|}{ Distilled water } \\
\hline \multirow{3}{*}{ Organics } & \multicolumn{2}{|c|}{$\begin{array}{l}\text { Sigma Aldrich humic acid } \\
\text { (3 mg/L TOC) }\end{array}$} & \multicolumn{2}{|c|}{$\begin{array}{l}\text { Sigma Aldrich cellulose } \\
\text { (3 mg/L TOC) }\end{array}$} \\
\hline & $1 \mathrm{~L}$ & $8.4 \mathrm{mg}$ & $1 \mathrm{~L}$ & $7.8 \mathrm{mg}$ \\
\hline & $50 \mathrm{~L}$ & $420 \mathrm{mg}$ & $50 \mathrm{~L}$ & $390 \mathrm{mg}$ \\
\hline \multirow{3}{*}{ Inorganic } & \multicolumn{4}{|c|}{ Kaolin Clay ( 20 NTU) } \\
\hline & \multicolumn{2}{|c|}{$1 \mathrm{~L}$} & \multicolumn{2}{|c|}{$28.6 \mathrm{mg}$} \\
\hline & \multicolumn{2}{|c|}{$50 \mathrm{~L}$} & \multicolumn{2}{|c|}{$1600 \mathrm{mg}$} \\
\hline \multirow{3}{*}{ Hardness } & \multicolumn{2}{|c|}{$\begin{array}{c}\text { Sodium bicarbonate } \\
\text { ( NaHCO3) } \\
\text { (75 } \mathrm{mg} / \mathrm{L} \text { as } \mathrm{CaCO3} \text { ) }\end{array}$} & \multicolumn{2}{|c|}{$\begin{array}{c}\text { Calcium sulfate } \\
\text { (CaSO4) } \\
\text { (75 mg/L as CaCO3) }\end{array}$} \\
\hline & $1 \mathrm{~L}$ & $67.01 \mathrm{mg}$ & $1 \mathrm{~L}$ & $129.13 \mathrm{mg}$ \\
\hline & $50 \mathrm{~L}$ & $3350.25 \mathrm{mg}$ & $50 \mathrm{~L}$ & $6456.5 \mathrm{mg}$ \\
\hline pH & \multicolumn{4}{|c|}{$7-8$} \\
\hline
\end{tabular}

\subsubsection{Operational Conditions}

The objectives of the preliminary study were to investigate the impact of support media at different fill fractions on membrane fouling reduction and membrane performance. In order to achieve these objectives, the two membranes were operated at the same operation parameters (i.e. flux, backwash duration, relaxation period and duration, and aeration rate) with continuous flow at $80 \%$ recovery. The operational parameters are presented in Table 3.2. These operational parameters were applied based on previous work by De Souza, 2012 in order to ensure that fouling occurred and to identify any significant impact of support media on membrane in terms of fouling reduction and water quality parameters. 
Table 3.2 Operational parameters used in the Preliminary Experiments*

\begin{tabular}{|c|c|c|}
\hline Parameter & Flow & Duration \\
\hline Forward flux & $30 \mathrm{ml} / \mathrm{min}(38 \mathrm{LMH})$ & 15 minutes \\
\hline Backwash & $30 \mathrm{ml} / \mathrm{min}(38 \mathrm{LMH})$ & 20 seconds \\
\hline Air flow rate & $5 \mathrm{LPM}$ & continuously \\
\hline Relaxation & $0 \mathrm{ml} / \mathrm{min}$ & 5 mins. every 4 hrs. interval \\
\hline
\end{tabular}

*The operational parameters were adapted from (De Souza, 2012)

\subsubsection{Support Media}

KONTAKT 500 high performance carriers were used in all phases of this research study experiments. The carriers were approximately $20 \mathrm{~mm}$ in diameter and made of highdensity polyethylene (HDPE). This type of carries is ideal for MBBR (Moving Bed Biological Reactor) and IFAS (Integrated Fixed-Film/Activated Sludge) systems because it creates a high percentage of protected surface area for microorganisms to adhere. The characteristics of the support media carries are shown Appendix (D).

The fill fractions of support media investigated in the preliminary study phase were $10 \%, 20 \%$, and $30 \%$ and were compared to the same membrane system without support media $(0 \%)$. The volume of the support media at different fill fractions, Table 3.3, was calculated according to Equation 3.1, (Basu and Huck et. al., 2005). The support media was preconditioned before any experimental run to ensure that the support media would recirculate properly inside the membrane reactor and was added to the membrane reactor 15 to 20 minutes prior to the start of experiment. 
Fill Fraction $=100 \times($ Volume occupied by media $/$ Reactor volume $)$

Equation 3.1

Table 3.3 Volume of Support Media at different fill fraction

\begin{tabular}{|c|c|c|c|c|}
\hline Fill fraction & $\mathbf{0 \%}$ & $\mathbf{1 0} \%$ & $\mathbf{2 0} \%$ & $\mathbf{3 0} \%$ \\
\hline $\begin{array}{c}\text { Volume } \\
\text { occupied by } \\
\text { support } \\
\text { media }\left(\mathbf{c m}^{\mathbf{3}}\right)\end{array}$ & 0 & 300 & 600 & 900 \\
\hline
\end{tabular}

\subsubsection{Water quality monitoring and data recording}

Water quality of the membrane reactors, feed tanks, and permeates was monitored on daily basis for each experimental run in terms of flux, turbidity, and $\mathrm{pH}$. The reason for monitoring water quality parameters was to identify any changes in water quality over 24 hours run. Transmembrane pressure (TMP) was used to measure membrane fouling and was logged every 60 seconds during filtration, and every 5 seconds during backwash cycle, and at 60 second intervals during relaxation steps throughout the 5 days experimental runs. The aeration was applied in the membrane reactor tank continuously throughout the 5 days run and was logged every 60 seconds during forward flow and relaxation period and every 5 seconds during backwashing. 


\subsubsection{Preliminary Phase Experiments Analysis}

As previously mentioned, membrane fouling was measured in terms of TMP (psi). In order to compare between TMP graphs all backwash and relaxation data points were filtered from the recorded data using a filtering macro in Excel (macro code is shown in Appendix (E)). Then, the change in fouling ( $\triangle \mathrm{TMP}$ ) was calculated as the difference between the lowest TMP observed during the first and final 15 minutes of filtration for each experiment. The $\triangle \mathrm{TMP}$ values resulted from each experiment were then used for results analysis and comparison to identify any significant impact of the support media on membrane fouling reduction. The results from these experiments were analyzed using a statistical hypothesis test (T-test) to determine whether membrane fouling at different fill fractions of support media were statistically different.

\subsection{T-Test}

T-test is a statistical method used to investigate whether the mean of two groups are statistically different from each other. The T-test compares the actual difference between two means in relation to the variation in the data (expressed as the standard deviation of the difference between the means). The $T$ - test equation for two groups of data can be seen in Equation 3.2, (Devore, J, 2010).

This test reports two important parameters, T-value and P-value. These two parameters are used as indicators to determine the level of significance between two groups of data or more. 


$$
\mathrm{T}=\frac{\mathrm{x}_{1}-\mathrm{X}_{2}}{\sqrt{\frac{\mathrm{s}_{1}^{2}}{\mathrm{n}_{1}}}+\sqrt{\frac{\mathrm{s}_{2}^{2}}{\mathrm{n}_{2}}}}
$$

Where

$\mathrm{X}_{1}$ : mean of group 1

$\mathrm{X}_{2}$ : mean of group 2

$\mathrm{S}_{1}$ : variance of group 1

$\mathrm{S}_{2}:$ variance of group 1

$\mathrm{n}_{1}:$ number of subjects in group 1

$\mathrm{n}_{2}:$ number of subjects in group 2

The statistical analysis of the preliminary study experiments results were performed using Microsoft Excel software which allows estimating the degree of significance between different groups of data by performing data analysis using a specific function (TTEST).

The results from the preliminary study phase and the statistical analysis of the results are presented in chapter 4 . 


\subsubsection{Phase A Study: The influence of different organic and inorganic concentrations on membrane fouling in the presence or absence of support media}

A $2^{3}$ factorial experiments were conducted during phase A study and were employed to investigate the impact of different organics and inorganics concentrations on membrane fouling in the presence or absence of support media. For the support media, the findings from the preliminary study phase was taking into account, thus, $10 \%$ fill fraction of the same type of support media was used as a design parameter in all experiments. Also, the operational parameters discussed in section 3.2.1.2, (i.e. flux, backwash duration, relaxation period and duration, and aeration rate as well as the $\%$ recovery) used during the preliminary study phase were also used in these experiments. The factorial design of these experiments can be seen in Table 3.4.

Table 3.4 Phase A Study Experiments Factorial Design

\begin{tabular}{|c|c|c|c|}
\hline \multirow{2}{*}{ Run } & \multicolumn{3}{|c|}{ Factors } \\
\cline { 2 - 4 } & Fill fraction (\%) & $\begin{array}{c}\text { Organic (Humic acid) } \\
\text { (mg/L TOC) }\end{array}$ & $\begin{array}{c}\text { Inorganic (Kaolin Clay) } \\
\text { (NTU) }\end{array}$ \\
\hline $\mathbf{2}$ & - & - & - \\
\hline 3 & + & - & - \\
\hline 4 & - & + & - \\
\hline 5 & + & + & - \\
\hline 6 & - & - & + \\
\hline 7 & + & - & + \\
\hline 8 & - & + & + \\
\hline
\end{tabular}


Note that:
Fill fraction:
$(-) 0 \%$
(+) $10 \%$
Organic (Humic acid):
(-) $1.5 \mathrm{mg} / \mathrm{L} \mathrm{TOC}$
(+) $3 \mathrm{mg} / \mathrm{L} \mathrm{TOC}$
Inorganic (Kaolin Clay):
$(-) 5$ NTU
(+) $20 \mathrm{NTU}$

\subsubsection{Feedwater Characteristics}

In Phase A, synthetic water was composed of organic component (humic acid), inorganic component measured as turbidity (kaolin clay), and hardness chemicals, (sodium bicarbonate and calcium sulphate). As previously mentioned, the main objectives of the Phase A study were to investigate the impact of different organics and inorganics concentrations in the presence or absence of support media on membrane fouling. Therefore, to fulfil these objectives, the organic compound (humic acid) in the feed solution was varied from $1.5 \mathrm{mg} / \mathrm{L}$ TOC and $3 \mathrm{mg} / \mathrm{L}$ TOC. The level of turbidity in the feed solution was also varied from 5 NTU and 20 NTU. The amount of humic acid required to obtain $1.5 \mathrm{mg} / \mathrm{L}$ TOC and $3 \mathrm{mg} / \mathrm{L}$ TOC was obtained using the same humic acid calibration curve used in the preliminary study phase (shown in Appendix (C)).

For turbidity measurements, the amount of kaolin clay required to obtain 5 NTU and 20 NTU turbidity level in the feed solution was determined manually by making different solutions with different amount of kaolin clay. Then, the relationship between the amount of kaolin clay and water volume was identified by diluting these solutions and measuring the turbidity level. The characteristics of the feed water including the required amount of all chemicals used in the phase A experiments are presented in Table 3.5. 
Table 3.5 Characteristics of feed water used in the Phase A experiments

\begin{tabular}{|c|c|c|c|c|}
\hline \multicolumn{5}{|c|}{ Distilled water } \\
\hline \multirow{4}{*}{ Organic } & \multicolumn{4}{|c|}{ Sigma Aldrich humic acid } \\
\hline & \multicolumn{2}{|c|}{$1.5 \mathrm{mg} / \mathrm{L} \mathrm{TOC}$} & \multicolumn{2}{|c|}{$3 \mathrm{mg} / \mathrm{L}$ TOC } \\
\hline & $1 \mathrm{~L}$ & $4.2 \mathrm{mg}$ & $1 \mathrm{~L}$ & $8.4 \mathrm{mg}$ \\
\hline & $50 \mathrm{~L}$ & $210 \mathrm{mg}$ & $50 \mathrm{~L}$ & $420 \mathrm{mg}$ \\
\hline \multirow{4}{*}{ Inorganic } & \multicolumn{4}{|c|}{ Kaolin Clay } \\
\hline & \multicolumn{2}{|c|}{$5 \mathrm{NTU}$} & \multicolumn{2}{|c|}{$20 \mathrm{NTU}$} \\
\hline & $1 \mathrm{~L}$ & $7.2 \mathrm{mg}$ & $1 \mathrm{~L}$ & $28.6 \mathrm{mg}$ \\
\hline & $50 \mathrm{~L}$ & $400 \mathrm{mg}$ & $50 \mathrm{~L}$ & $1600 \mathrm{mg}$ \\
\hline \multirow{3}{*}{ Hardness } & \multicolumn{2}{|c|}{$\begin{array}{c}\text { Sodium bicarbonate } \\
\text { ( NaHCO3) } \\
\text { (75 mg/L as CaCO3) }\end{array}$} & \multicolumn{2}{|c|}{$\begin{array}{c}\text { Calcium sulfate } \\
\text { (CaSO4) } \\
\text { (75 mg/L as CaCO3) }\end{array}$} \\
\hline & $1 \mathrm{~L}$ & $67.01 \mathrm{mg}$ & $1 \mathrm{~L}$ & $129.13 \mathrm{mg}$ \\
\hline & $50 \mathrm{~L}$ & $3350.25 \mathrm{mg}$ & $50 \mathrm{~L}$ & $6456.5 \mathrm{mg}$ \\
\hline$\overline{\text { pH }}$ & \multicolumn{4}{|c|}{$7-8$} \\
\hline
\end{tabular}

\subsubsection{Water quality monitoring and data recording}

Water quality assessment of the membrane reactors, feed tanks, and permeates were also monitored on daily basis for each experimental run in terms of flux, turbidity, and $\mathrm{pH}$. Also, COD measurements of the membrane reactors, feed solutions, and permeates were taking every 24 hours to identify any significant changes in water quality that may affect fouling. 
Transmembrane pressure (TMP) was also used to measure membrane fouling during the $2^{3}$ factorial experiments and was logged every 60 seconds during filtration, and every 5 seconds during backwash cycle, and at 60 second intervals during relaxation steps throughout the 5 days experimental runs. The aeration was applied in the membrane reactor tank continuously throughout the 5 days run and was logged every 60 seconds during forward flow and relaxation period and every 5 seconds during backwashing.

\subsubsection{Phase B Study: The relationship between natural source water organic types and membrane fouling in the presence or absence of support media}

A $2^{3}$ factorial experiment was conducted during Phase B which investigated the relationship between organic types and membrane fouling in the presence or absence of support media. A fill fraction of $10 \%$ of support media was also used as design parameter in these experiments. Also, the operational parameters discussed in section 3.2.1.2, (i.e. flux, backwash duration, relaxation period and duration, and aeration rate as well as the $\%$ recovery) used during the preliminary study phase were also used in these experiments. The factorial design of these experiments can be seen in Table 3.6. 
Table 3.6 Phase B Study Experiments Factorial Design

\begin{tabular}{|c|c|c|c|}
\hline \multirow{2}{*}{ Run } & \multicolumn{3}{|c|}{ Factors } \\
\cline { 2 - 4 } & Fill fraction (\%) & Organics (mg/L TOC) & $\begin{array}{c}\text { Inorganic (Kaolin Clay) } \\
\text { (NTU) }\end{array}$ \\
\hline 1 & - & - & - \\
\hline 2 & + & - & - \\
\hline 3 & - & + & - \\
\hline 4 & + & + & - \\
\hline 5 & - & - & + \\
\hline 6 & + & - & + \\
\hline 7 & - & + & + \\
\hline 8 & + & + & + \\
\hline
\end{tabular}

\section{Note that:}

Fill fraction: $\quad(-) 0 \% \quad(+) 10 \%$

Organics: $\quad(-) 3 \mathrm{mgC} / \mathrm{L}$ of cellulose $(+) 3 \mathrm{mgC} / \mathrm{L}$ of humic acid Inorganic (Kaolin Clay): (-) 5 NTU (+) 20 NTU

\subsubsection{Feedwater Characteristics}

In phase B of this research study, a synthetic water was also used which was made up of organic components, inorganic component measured as turbidity (kaolin clay), and hardness chemicals, (sodium bicarbonate and calcium sulphate). As previously mentioned, the main objectives of the phase B experiments were to investigate the impact of organics type on fouling with or without support media. Therefore, to achieve these objectives, two organic compounds were studied, $3 \mathrm{mgC} / \mathrm{L}$ of humic acid and $3 \mathrm{mgC} / \mathrm{L}$ of cellulose. Each of these organic compounds was tested separately to study their 
influence on membrane fouling and membrane performance. The level of turbidity in the feed tank was varied from 5 NTU and 20 NTU. The amount of humic acid and cellulose required to obtain $3 \mathrm{mg} / \mathrm{L}$ TOC were identified using the same humic acid and cellulose calibration curves used in the preliminary study phase (shown in Appendix (C)). Also, the amount of kaolin clay required to obtain 5 NTU and 20 NTU turbidity level in feed solution was determined using the same measurements mentioned in section 3.2.2.1. The characteristics of the feed water including the required amount of all chemicals used in phase B experiments are presented in Table 3.7.

Table 3.7 Characteristics of feed water used in the Phase B experiments

\begin{tabular}{|c|c|c|c|c|}
\hline \multicolumn{5}{|c|}{ Distilled water } \\
\hline \multirow{3}{*}{ Organics } & \multicolumn{2}{|c|}{$\begin{array}{c}\text { Sigma Aldrich humic acid } \\
\text { (3 mg/L TOC) }\end{array}$} & \multicolumn{2}{|c|}{$\begin{array}{l}\text { Sigma Aldrich cellulose } \\
\text { ( } 3 \mathrm{mg} / \mathrm{L} \text { TOC) }\end{array}$} \\
\hline & $1 \mathrm{~L}$ & $8.4 \mathrm{mg}$ & $1 \mathrm{~L}$ & $7.8 \mathrm{mg}$ \\
\hline & $50 \mathrm{~L}$ & $420 \mathrm{mg}$ & $50 \mathrm{~L}$ & $390 \mathrm{mg}$ \\
\hline \multirow{4}{*}{ Inorganic } & \multicolumn{4}{|c|}{ Kaolin Clay ( 20 NTU) } \\
\hline & \multicolumn{2}{|c|}{$5 \mathrm{NTU}$} & \multicolumn{2}{|c|}{$20 \mathrm{NTU}$} \\
\hline & $1 \mathrm{~L}$ & $7.2 \mathrm{mg}$ & $1 \mathrm{~L}$ & $28.6 \mathrm{mg}$ \\
\hline & $50 \mathrm{~L}$ & $400 \mathrm{mg}$ & $50 \mathrm{~L}$ & $1600 \mathrm{mg}$ \\
\hline \multirow{3}{*}{ Hardness } & \multicolumn{2}{|c|}{$\begin{array}{c}\text { Sodium bicarbonate } \\
\text { ( } \mathrm{NaHCO3)} \\
\text { (75 } \mathrm{mg} / \mathrm{L} \text { as } \mathrm{CaCO3})\end{array}$} & \multicolumn{2}{|c|}{$\begin{array}{c}\text { Calcium sulfate } \\
\text { (CaSO4) } \\
\text { (75 mg/L as CaCO3) }\end{array}$} \\
\hline & $1 \mathrm{~L}$ & $67.01 \mathrm{mg}$ & $1 \mathrm{~L}$ & $129.13 \mathrm{mg}$ \\
\hline & $50 \mathrm{~L}$ & $3350.25 \mathrm{mg}$ & $50 \mathrm{~L}$ & $6456.5 \mathrm{mg}$ \\
\hline pH & \multicolumn{4}{|c|}{$7-8$} \\
\hline
\end{tabular}




\subsubsection{Water quality monitoring and data recording}

Water quality assessment of the membrane reactors, feed tanks, and permeates were also monitored on daily basis for each experimental run in terms of flux, turbidity, and $\mathrm{pH}$. Also, total organic carbon (TOC) measurements for feed solutions, and permeates were also taking every 24 hours to identify any significant changes in water quality and carbon removal that may affect fouling. In addition, UV absorbance at 254 $\mathrm{nm}$ for feed solutions, and permeates were also measured every 24 hours.

Transmembrane pressure (TMP) was also used to measure membrane fouling

during the $2^{3}$ factorial experiments and was logged every 60 seconds during filtration, and every 5 seconds during backwash cycle, and at 60 second intervals during relaxation steps throughout the 5 days experimental runs. The aeration was applied in the membrane reactor tank continuously throughout the 5 days run and was logged every 60 seconds during forward flow and relaxation period and every 5 seconds during backwashing.

\subsubsection{Phase A / Phase B Experiments Analysis}

\subsubsection{Fouling measurement during Phase $\mathrm{A} /$ Phase B experiments}

Membrane fouling during phase A and phase B experiments was also measured in terms of TMP (mbar). For better comparison, all backwash and relaxation data points were also filtered from the recorded data using a filtering macro in Excel (shown in Appendix (E)). Then, the change in fouling ( $\triangle \mathrm{TMP}$ ) was calculated as the difference between the lowest TMP observed during the first and final 15 minutes of filtration for 
each experiment. The $\triangle \mathrm{TMP}$ values resulted from each experiment were then used for results analysis.

\subsubsection{Phase A / Phase B results analysis: Regression analysis}

Regression analysis was conducted for the analysis of the results from the $2^{3}$ factorial design of experiments used in phase A and Phase B experiments. Regression analysis is a statistical method usually used to model the relationship between a dependent variable $(\mathrm{Y})$ and one or more independent variables $(\mathrm{X})$. The dependent variable is sometimes also called the predictand, and the independent variables the predictors. Regression analysis allows the investigation of the effects of one or more factors on response variables and identifying the possible interaction effects of factors on the response. The $2^{3}$ factorial design of experiments was represented using the regression model presented in Equation 3.3.

$$
\begin{aligned}
Y= & \beta_{0}+\beta_{1} X_{1}+\beta_{2} X_{2}+\beta_{3} X_{3}+\beta_{12} X_{1} X_{2}+\beta_{13} X_{1} X_{3} \\
& +\beta_{23} X_{2} X_{3}+\beta_{123} X_{1} X_{2} X_{3}
\end{aligned}
$$

Equation 3.3

Where:

Y: response variables (TMP)

$X_{1}$ : represents the support media with values of +1 and -1 for the high and low levels respectively

$\mathrm{X}_{2}$ : represents the organics with values of +1 and -1 for the high and low levels respectively 
$\mathrm{X}_{3}$ : represents the inorganics (turbidity) with values of +1 and -1 for the high and low levels respectively

$\mathrm{B}_{0:}$ Intercept or regression constant.

$\beta_{1}, \beta_{2}, \beta_{3}$ : represent main factor effect of support media, organics, and inorganics respectively

$\beta_{12}, \beta_{13}, \beta_{23}$ : represent two factors interactions

$\beta_{123}$ : represent three factors interactions

$\beta$ parameters represent the regression coefficients which usually are estimated using least square estimation method. The least square estimation for 8 regression coefficients can be performed by matrix algebra using Equation 3.4 (Neter, J., Wasserman, W., and Kutner, M., 1990).

$$
\beta=\left(X^{\prime} X^{-1} X^{\prime} Y\right.
$$

Where :

$$
\boldsymbol{\beta}=\left|\begin{array}{l}
\beta_{0} \\
\beta_{1} \\
\beta_{2} \\
\beta_{3} \\
\beta_{12} \\
\beta_{13} \\
\beta_{23} \\
\beta_{123}
\end{array}\right|
$$




$$
\mathbf{Y}=
$$

$$
\begin{aligned}
& Y-1,-1,-1 \\
& Y+1,-1,-1 \\
& Y-1,+1,-1 \\
& Y+1,+1,-1 \\
& Y-1,-1,+1 \\
& Y+1,-1,+1 \\
& Y-1,+1,+1 \\
& Y+1,+1,+1
\end{aligned}
$$

$\mathbf{X}=\left|\begin{array}{rrrrrrrr}+1 & -1 & -1 & -1 & +1 & +1 & +1 & -1 \\ +1 & +1 & -1 & -1 & -1 & -1 & +1 & +1 \\ +1 & -1 & +1 & -1 & -1 & +1 & -1 & +1 \\ +1 & +1 & +1 & -1 & +1 & -1 & -1 & -1 \\ +1 & -1 & -1 & +1 & +1 & -1 & -1 & +1 \\ +1 & +1 & -1 & +1 & -1 & +1 & -1 & -1 \\ +1 & -1 & +1 & +1 & -1 & -1 & +1 & -1 \\ +1 & +1 & +1 & +1 & +1 & +1 & +1 & +1\end{array}\right|$

Regression is based on least squares: the model is fit such that the sum-of-squares of residual (SSR) of differences of observed and predicted values is minimized. Calculation of the residual $(\mathrm{E})$ is presented in Equation 3.5. 


$$
\mathbf{E}=\mathbf{Y}-\hat{\mathbf{Y}}
$$

\section{Equation 3.5}

Where

$\mathrm{Y}=$ Experimental results (TMP)

$\hat{Y}=$ Predicted results (TMP)

The statistical software SPSS 20.0 by IBM was used to perform a regression analysis for results from phase A and phase B experiments to identify main effects and interaction effects of parameters. First, $X_{1}, X_{2}$, and $X_{3}$ variables were forced into the model to estimate the parameters for main effects and interactions. Then, since 8 parameters were estimated using results for 8 experiments, the data were found to fit perfectly to the model resulting in $\left(\mathrm{R}^{2}\right)$ equal to 1 . Therefore, the model was tested by performing stepwise regression to simplify the model by including only important parameters representing main or interaction effects. In stepwise regression, a number of models were developed which $X_{1}, X_{2}$, and $X_{3}$ variables were added or deleted from the model sequentially based on their contribution to the model. The addition or deletion from the model was based on their degree of significance represented as $F$ value. Once unimportant parameters were identified in each sequence, they were excluded from the main model resulting in the best model possible by including only important parameters that had a significant influence on fouling.

A number of experiments were conducted in replicates during Phase A and Phase B studies and used to confirm the results of some experiments. Replicate experiments can be seen in Appendix (G). 
The results from phase A / phase B studies and the statistical analysis of the results are presented in chapter 5 .

\subsection{Cleaning Procedure}

Membrane chemical cleaning was performed following every 5 day experiment to restore the membrane permeability. At the end of any experimental run, the membrane module was soaked in warm distilled water for 30 minutes. During this duration, a frequent backwashing was applied to remove foulants from the surface of the membranes. Then, the membrane was allowed to soak in a sodium hypochlorite solution (200 ppm) for 20 hours. After that, the membrane was put through another 30 minutes soak in distilled water which periodic backwashing was applied. Then, the membrane was allowed to soak in citric acid for 20 hours. After the citric acid soak, the membrane was soaked in distilled water until the start of next experiment. When chemical cleaning of the membrane was found to be ineffective to restore the membrane permeability ( $85 \%$ of the original value), the membrane module was replaced with new membrane module.

The feed tank, membrane tank, and backwash tank were also cleaned before every experiment with water and detergent. Tubing used in the feed and the permeate line were also cleaned or sometimes were replaced to ensure a high performance of the tubing before every experiment. In addition, clean water flux tests were conducted after membrane chemical cleaning step and prior the start of new experiment to ensure that membranes were able to achieve the required flux before any experimental run and to ensure membranes were the same in terms of permeate flux and transmembrane pressure. 


\section{CHAPTER 4 - PRELIMINARY STUDY PHASE RESULTS}

The influence of support media at different fill fractions on the fouling of submerged membrane reactor was investigated in the preliminary phase experiments. Three different fill fractions of support media were added to the membrane reactor, $10 \%$, $20 \%$, and $30 \%$ and were compared to the same membrane reactor without support media $(0 \%)$. Each of these fill fractions was examined in triplicate for statistical analysis. Transmembrane pressure graphs and values resulted from the preliminary study experiments can be seen in section 4.1. The results from the statistical analysis (T-test) are presented in section 4.2. Also, water quality assessment of the membrane reactors, feed tanks, and permeates can be seen in section 4.3.

\subsection{TMP graphs and TMP values}

Membrane fouling at $10 \%, 20 \%$, and $30 \%$ fill fraction of support media compared to membrane system without support media $(0 \%)$ are represented in terms of transmembrane pressure in figures $4.1,4.2$, and 4.3 . As previously mentioned, the change in fouling ( $\triangle \mathrm{TMP}$ ) was calculated as the difference between the lowest TMP observed during the first and final 15 minutes of filtration for each experiment. The $\triangle$ TMP values resulted from the preliminary phase experiments at different fill fractions of support media are shown in Table 4.2. A representation of $\triangle \mathrm{TMP}$ at $0 \%, 10 \%, 20 \%$, and $30 \%$ fill fractions can be seen in Figure 4.4. 


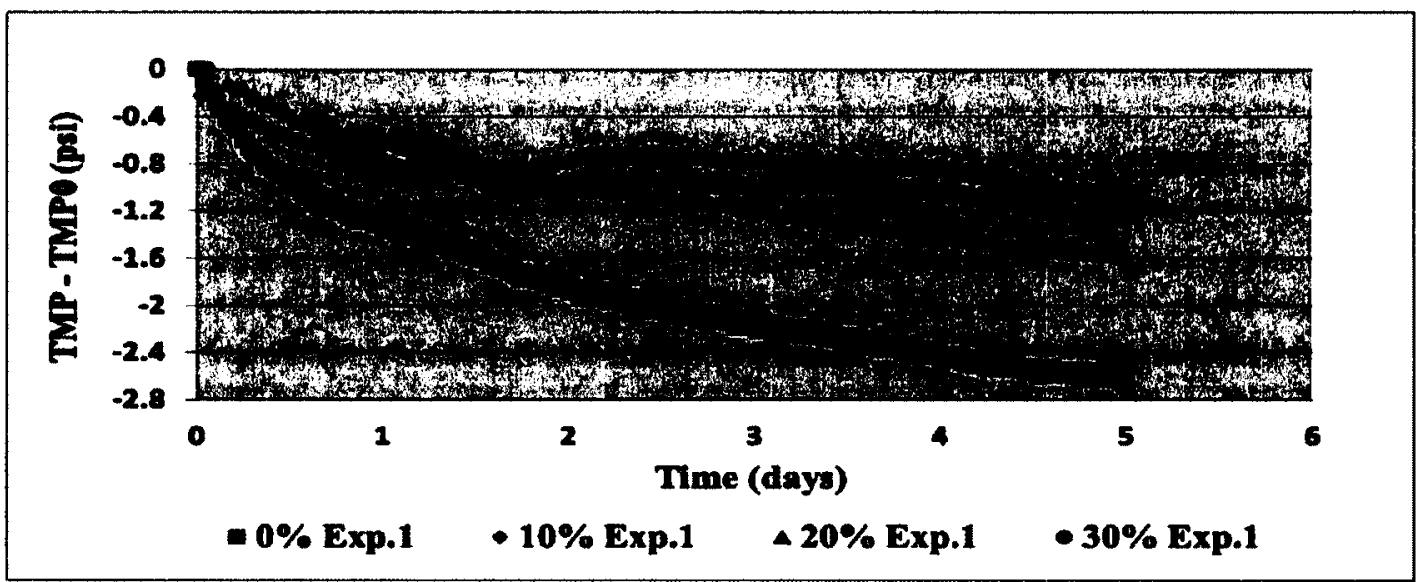

Figure 4.1 TMP graphs for membrane system with different fill fractions of support media compared to membrane system without support media (Trial \#1)

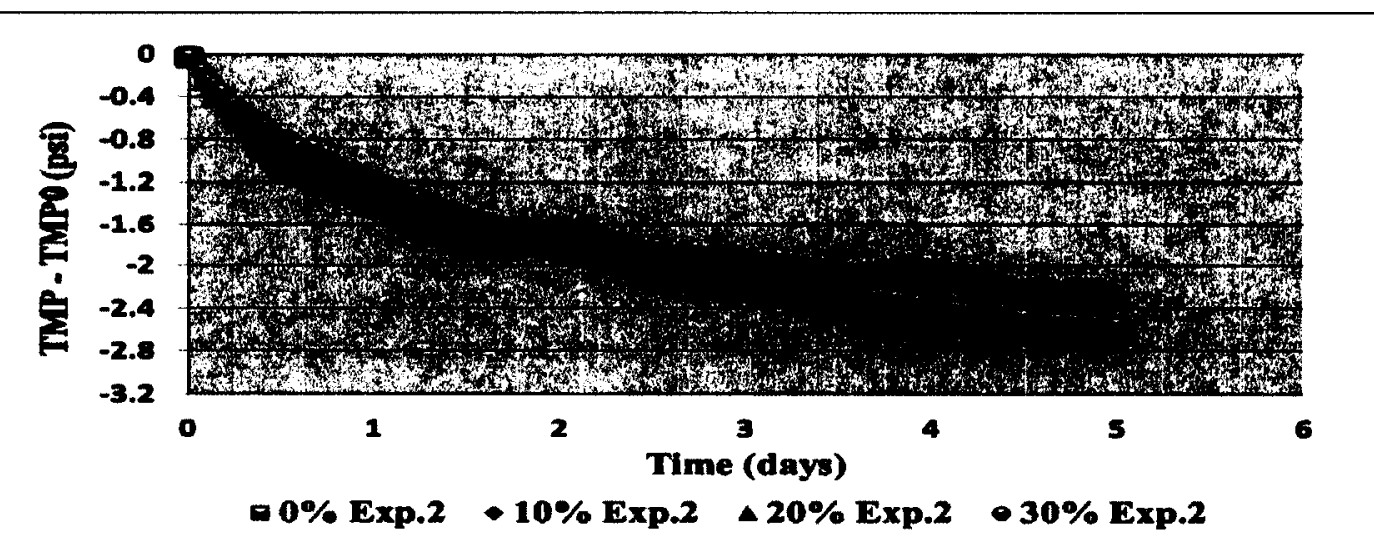

Figure 4.2 TMP graphs for membrane system with different fill fractions of support media compared to membrane system without support media (Trial \#2)

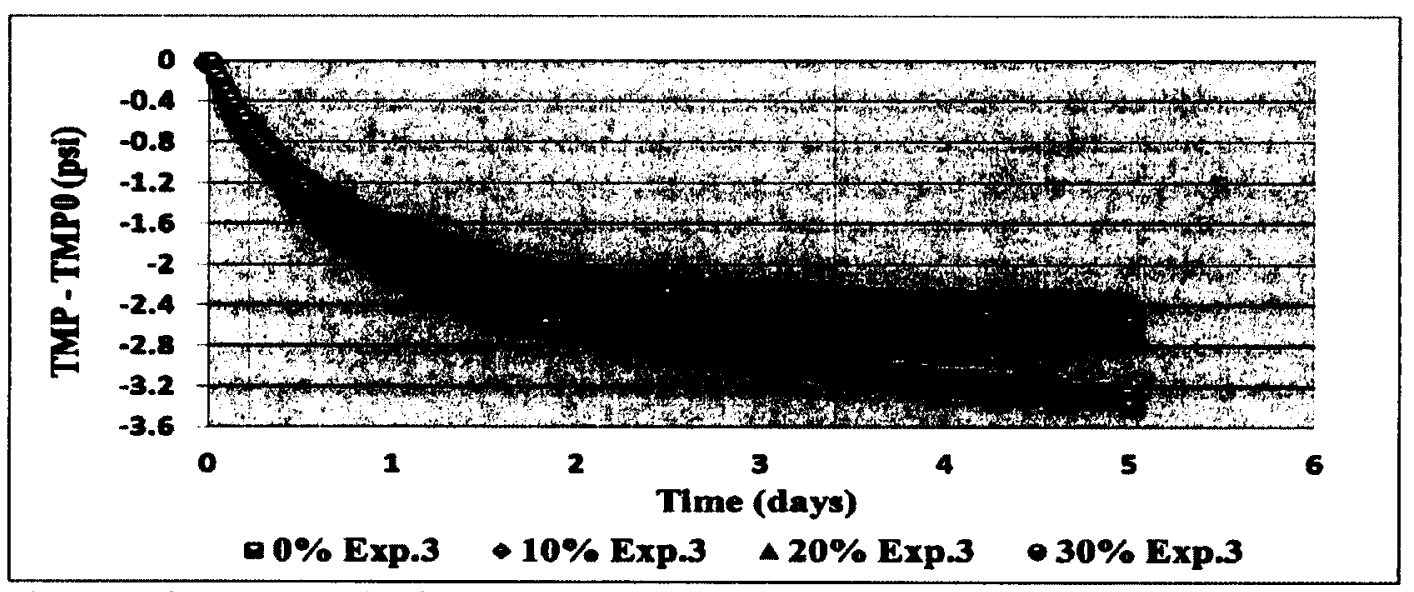

Figure 4.3 TMP graphs for membrane system with different fill fractions of support media compared to membrane system without support media (Trial \#3) 


\subsubsection{General observation}

By looking at TMP graphs from these experiments, the use of support media at three different conditions $10 \%, 20 \%$, and $30 \%$ was able to reduce TMP at different levels. In all experiments, the TMP in the membrane system without support media ( $0 \%)$ was always higher than the same membrane system with different fill fractions of support media.

In Trial \#1 (Figure 4.1), 10\% fill fraction was able to reduce $40 \%$ of the TMP and count for less fouling (-1.62 psi) compared the system with no support media $(-2.65 \mathrm{psi})$. On the other hand, the use of $20 \%$ and $30 \%$ fill fractions showed the best results in term of TMP reduction( -1.04 and $-1.20 \mathrm{psi}$, respectively) and were able to lower about $60 \%$ of TMP compared to no support media.

Trial \#2 (Figure 4.2), showed less significant differences in fouling between all conditions. Fouling in the system without support media was almost the same as the first experiment $(-2.60 \mathrm{psi})$ and was still higher than fouling in the system with support media. For the system with $10 \%$ and $20 \%$ fill fraction, TMP was only $15 \%$ lower than the system with no support media $(-2.20$ and $-2.30 \mathrm{psi}$, respectively) while the use of $30 \%$ fill wasn't effective in lowering fouling.

In Trial \#3 (Figure 4.3), fouling in the system with no support media increased to $(-3.30 \mathrm{psi})$ and was still higher than the system with support media. However, for the system with $10 \%$ fill fraction, TMP remained almost the same as the second experiment $(-2.30 \mathrm{psi})$ but in this case TMP was almost $30 \%$ lower than TMP of the system with no support media. On the other hand, for the system with $20 \%$ fill, TMP value resulted was 
higher than the TMP value resulted from second experiment at the same condition; however, TMP was $20 \%$ lower than the system with no support media. For the system with $30 \%$ fill fraction, TMP was still the same as the second experiment but in this case TMP was $20 \%$ lower than the system without support media. Table 4.1 summarized the $\%$ reduction in TMP observed at different fill fractions of support media.

Table 4.1 A summary of \% reduction in TMP at different fill fractions of support media

\begin{tabular}{|c|c|c|c|}
\hline \multirow{2}{*}{$\%$ Fill } & \multicolumn{3}{|c|}{$\%$ Reduction in TMP compared to membrane system without support media } \\
\hline \multirow{2}{*}{$10 \%$} & Experiment \#1 & Experiment \#2 & Experiment \#3 \\
\cline { 2 - 4 } & $40 \%$ & $15 \%$ & $30 \%$ \\
\hline \multirow{2}{*}{$20 \%$} & & & \\
\cline { 2 - 4 } & $60 \%$ & $15 \%$ & $20 \%$ \\
\hline \multirow{2}{*}{$30 \%$} & Experiment \#1 & Experiment \#2 & Experiment \#3 \\
\cline { 2 - 4 } & $60 \%$ & $0 \%$ & $20 \%$ \\
\hline
\end{tabular}


Table 4.2 $\triangle T M P$ values resulted from the Preliminary Study Phase Experiments at different fill fractions of Support Media

\begin{tabular}{|c|c|c|c|}
\hline & & $\begin{array}{c}\Delta \text { DTMP value } \\
\text { observed for each } \\
\text { experiment }\end{array}$ & Average $\Delta \mathrm{TMP}$ \\
\hline \multirow{3}{*}{$\begin{array}{l}\text { No support } \\
\text { media }(0 \%) \\
\text { fill fraction }\end{array}$} & Experiment \#I & -2.65 & \multirow{3}{*}{-2.85} \\
\hline & Experiment \#2 & -2.60 & \\
\hline & Experiment \#3 & -3.30 & \\
\hline \multirow{3}{*}{$\begin{array}{l}10 \% \text { fill } \\
\text { fraction }\end{array}$} & Experiment \#1 & -162 & \multirow{3}{*}{-2.04} \\
\hline & Experiment $\# 2$ & -2.20 & \\
\hline & Experiment \#3 & -2.30 & \\
\hline \multirow{3}{*}{$\begin{array}{l}20 \% \text { fill } \\
\text { fraction }\end{array}$} & Experiment \#1 & -1.04 & \multirow{3}{*}{-2.01} \\
\hline & Experiment \#2 & -2.30 & \\
\hline & Experiment \#3 & -2.70 & \\
\hline \multirow{3}{*}{$\begin{array}{l}30 \% \text { fill } \\
\text { fraction }\end{array}$} & Experiment \#I & -1.20 & \multirow{3}{*}{-2.14} \\
\hline & Experiment \#2 & -2.62 & \\
\hline & Experiment \#3 & -2.60 & \\
\hline
\end{tabular}

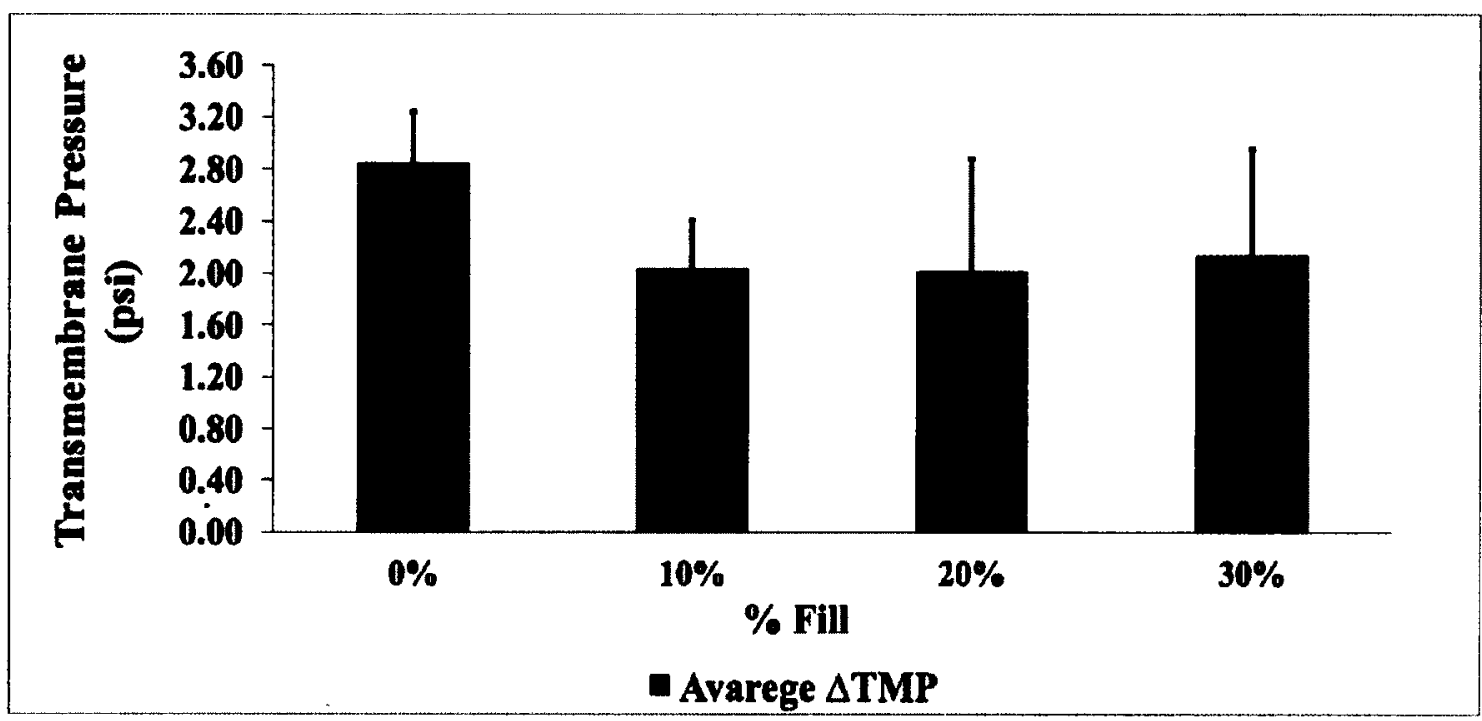

Figure 4.4 A representation of average $\triangle \mathrm{TMP}$ at $0 \%, 10 \%, 20 \%$, and $30 \%$ fill fraction 
The presence or absence of support media was observed to have an impact on the degree of fouling. However, different fill fractions resulted in different fouling results. Not surprising, fouling in the membrane system with no support media was always higher compared to other system with different fill fractions of media. On the other hand, $10 \%$ fill fraction was observed to have more influence of fouling compared to $20 \%$ and $30 \%$. Based on visual inspection, $10 \%$ fill fraction of media was observed to circulate very smoothly inside the membrane reactor whereas the support media with $20 \%$ and $30 \%$ were packed inside the membrane reactor and did not provide the required scouring for the membrane unit. As a result, it was thought that $10 \%$ fill fraction was the optimum for the system tested. In addition, some of the variation and inconsistency in results between experiment trials was thought to be related to exposing the membrane unit to different fill fractions. For this reason, a statistical analysis test ( $\mathrm{T}$ - test) was performed to identify the best fill fraction in terms of fouling reduction.

\subsection{T-test}

Based on the general observation of the results, the use of support media resulted in minimizing TMP and count for less membrane fouling in all experiments. However, in order to identify which fill fraction of support media was the best in terms of fouling reduction, the results from this study were analyzed by performing $\mathrm{T}$-test. The parameters used in the statistical analysis can be seen in Table 4.3. For each of the four conditions $0 \%, 10 \%, 20 \%$, and $30 \%$ fill fractions, $\Delta \mathrm{TMP}$ values were averaged and then used in the 
statistical analysis. An acceptable significance level of 0.05 (95\% confidence interval) was used. The results from T-test are shown in Table 4.4 .

Table 4.3 Parameters used for T-test

\begin{tabular}{|c|c|c|c|}
\hline \% Fill & Average $\Delta$ TMP & Standard deviation & $\begin{array}{c}\text { Number of } \\
\text { experiments (n) }\end{array}$ \\
\hline $\mathbf{0 \%}$ & 2.85 & \pm 0.39 & 3 \\
\hline $\mathbf{1 0} \%$ & 2.04 & \pm 0.37 & 3 \\
\hline $\mathbf{2 0} \%$ & 2.01 & \pm 0.87 & 3 \\
\hline $\mathbf{3 0} \%$ & 2.14 & \pm 0.81 & 3 \\
\hline
\end{tabular}

Table 4.4 T-test results

\begin{tabular}{|c|c|c|c|}
\hline$\%$ Fill & Average $\triangle T M P$ & T-value & $P$ - value \\
\hline $0 \%$ & $2.85 \pm 0.39$ & \multirow{2}{*}{2.62} & \multirow{2}{*}{0.05} \\
\hline $10 \%$ & $2.04 \pm 0.37$ & & \\
\hline & & & \\
\hline$\overline{0 \%}$ & $2.85 \pm 0.39$ & \multirow{2}{*}{1.53} & \multirow{2}{*}{0.22} \\
\hline $20 \%$ & $2.01 \pm 0.87$ & & \\
\hline & & & \\
\hline $0 \%$ & $2.85 \pm 0.39$ & \multirow{2}{*}{1.37} & \multirow{2}{*}{0.26} \\
\hline $30 \%$ & $2.14 \pm 0.81$ & & \\
\hline
\end{tabular}




\subsubsection{T-test results discussion}

The results from T- test showed that the differences in TMP values between the membrane systems with $0 \%$ and $10 \%$ fill fractions were the most significant $(\mathrm{P}-$ value $=$ $0.05)$ from the $20 \%(\mathrm{P}-$ value $=0.22)$ and $30 \%(\mathrm{P}-$ value $=0.26)$. In other words, the degree of significance between the membrane system with no support media and the membrane system with $10 \%$ fill fraction was an indicator that $10 \%$ fill fraction was the most effective in minimizing TMP, hence, decreasing fouling compared to $20 \%$ and $30 \%$ fill fractions. It was reported in literature that the use of support materials was effective in membrane fouling rate reduction. (Basu and. Huck, 2005) study reported that the membrane fouling rate in the system without support media was at least twice as high as in the system without support media. However, in their study, $40 \%$ fill fraction and different size of support media as well as different water type were used.

\subsection{Water Quality Assessment}

As mentioned previously, water quality of the membrane reactors, feed tanks, and permeates were monitored on daily basis in terms of flux, turbidity, and $\mathrm{pH}$ for all experiments. The main reasons of monitoring these parameters were to identify any changes over 24 hours and to determine any impact of support media on water quality parameters. Water quality assessment of all preliminary study phase experiments can be seen in Appendix (F). 
Turbidity was slightly different between two membranes systems. The turbidity in the membrane reactor with support media was slightly lower than the membrane reactor without support media but it was not very significant. However, for the system without support media the permeate flux decreased gradually. The gradual decrease was caused by the formation of cake layer on the membrane surface as well as fouling caused by small particles. For the system tested with support media, the decrease in permeate flux was lower than the system without support media. In addition, the visual inspection would indicate that more irreversible fouling occurred on the system without support media. Cleaning of the membrane with support media was easier than the membrane without support media. Most of fouling materials on the membrane with support media were mostly removed by soaking in sodium hypochlorite only while the membrane without support media required frequent cleaning by soaking as well as backwashing. A comparison of membrane cleaning time between the two membrane systems will be discussed in chapter 5 . The $\mathrm{pH}$ level was similar in both membrane systems. 


\subsection{Preliminary Study Phase Conclusion}

The influence of support media on membrane fouling reduction and water quality parameters were investigated in the preliminary study phase. The support media were added to the membrane reactor at different conditions $10 \%, 20 \%$, and $30 \%$, and were compared to the same membrane rector without support media $0 \%$ in terms of transmembrane pressure (TMP) and water quality parameters (i.e. flux, turbidity, and $\mathrm{pH})$.

The results from statistical analysis (T-test) showed that, for the system tested, 10 $\%$ fill fraction of support media was able to reduce TMP and count for less membrane fouling than $20 \%$ and $30 \% .10 \%$ fill fraction was very effective in lowering the degree of fouling compared to the system with no support media under the same operational conditions.

The water quality assessment for the two membrane systems showed that the difference in turbidity and $\mathrm{pH}$ level were not significantly different $(\mathrm{p}=0.05)$ between the two membrane systems. However, because of the presence of the support media in the membrane reactor, it was observed that permeate flow was always better than the same membrane system with no support media. 


\section{CHAPTER 5 - Membrane Fouling with Different Organic and Inorganic Matter Content in the Presence or Absence of Support Media}

Chapter 5 presents the results of the main experiments conducted in this research and was broken into two sections; Phase A and Phase B. Phase A focused on the related effect of different organic and inorganic concentrations on membrane fouling and performance in a submerged UF membrane reactor in the presence or absence of support media. The relationship between different natural source organics and membrane fouling and performance in submerged UF membrane reactor in the presence or absence of support media was investigated in Phase B. In both Phase A and Phase B experiments, the main findings from the preliminary study were taken into account, as a result, a fill fraction of $10 \%$ of support media was incorporated into the experimental trials.

Membrane performance during these experiments was analyzed in terms of fouling and water quality measurements including flux, turbidity, and $\mathrm{pH}$. COD measurements were also taken during phase A experiments while TOC samples and UV absorbance measurements were taken during phase B experiments.

Stepwise regression analysis was used to identify the impact of direct and interaction effects from organic and inorganic components on the degree of UF membrane fouling. The regression module was simplified by exclusion/inclusion of parameters based of their significant contribution to the model. 


\subsection{Phase A Study Results: The influence of different organic and inorganic concentrations on membrane fouling in the presence or absence of support media.}

\subsubsection{TMP graphs and TMP values}

Membrane fouling resulted from phase A study experiments are represented in terms of transmembrane pressure in figures $5.1-5.8$. As previously mentioned, the change in fouling ( $\triangle \mathrm{TMP}$ ) was calculated as the difference between the lowest TMP observed during the first and final 15 minutes of filtration for each experiment. The $\Delta \mathrm{TMP}$ values resulted from each experiment were then used for statistical analysis. For experiments that were duplicated, results were found to be reproducible; therefore, they were used to confirm the results. Phase A study replicates experiments can be seen in Appendix (G).

The $\triangle$ TMP values resulted from phase A study experiments are shown in Table 5.1. Note that ( $-\mathbf{M}$ and $+\mathbf{M})$ refers to the membrane system without support media $(0 \%)$ and membrane system with support media $(10 \%)$ respectively. $(-O$ and +0$)$ refers to the low concentration of organic component (humic acid) $1.5 \mathrm{mg} / \mathrm{L}$ TOC and the high level 3 $\mathrm{mg} / \mathrm{L}$ TOC respectively. Also, (-IO and +IO) refers to the low level of inorganic component (turbidity) 5 NTU and the high level 20 NTU respectively. 
Table 5.1 TMP values resulted from phase A experiments at different organics and inorganics concentrations in the presence or absence of support media

\begin{tabular}{|c|c|c|c|c|c|c|}
\hline & $\begin{array}{c}\text { Initial } \\
\text { TMP } \\
\text { (mbar) }\end{array}$ & $\begin{array}{l}\text { TMP at the } \\
\text { end of day } 1 \\
\text { (mbar) }\end{array}$ & $\begin{array}{l}\text { TMP at the } \\
\text { end of day } 2 \\
\text { (mbar) }\end{array}$ & $\begin{array}{l}\text { TMP at the } \\
\text { end of day } 3 \\
\text { (mbar) }\end{array}$ & $\begin{array}{l}\text { TMP at the } \\
\text { end of day } 4 \\
\text { (mbar) }\end{array}$ & $\begin{array}{l}\text { TMP at the } \\
\text { end of day } 5 \\
\text { (mbar) }\end{array}$ \\
\hline $\operatorname{Exp.1}(-M,-0,-I 0)$ & 0 & -39.64 & -55.47 & -65.34 & -67.59 & -69.59 \\
\hline $\operatorname{Exp.2}(+\mathrm{M},-\mathrm{O},-\mathrm{IO})$ & 0 & -16.74 & -21.05 & -25.09 & -29.62 & -34.88 \\
\hline $\operatorname{Exp.3}(-M,+0,-10)$ & 0 & -70.40 & -90.34 & -103.52 & -106.16 & -111.33 \\
\hline $\operatorname{Exp.4(+M,+0,IO)}$ & 0 & -42.25 & -51.89 & -58.82 & -61.39 & -70.05 \\
\hline $\operatorname{Exp.5}(-M,-O,+10)$ & 0 & -34.64 & -51.01 & -61.93 & -72.35 & -80.33 \\
\hline $\operatorname{Exp.6}(+\mathrm{M},-0,+\mathrm{IO})$ & 0 & -29.30 & -41.02 & -45.59 & -46.63 & -46.77 \\
\hline $\operatorname{Exp.7}(-M,+0,+10)$ & 0 & -60.83 & -82.60 & -97.92 & -109.23 & -120.07 \\
\hline $\operatorname{Exp.8}(+M,+0,+I O)$ & 0 & -41.39 & -56.24 & -68.38 & -75.38 & -76.60 \\
\hline
\end{tabular}

${ }^{*} \mathrm{M}=$ media, $\mathrm{O}=$ organic, $\mathrm{IO}=$ inorganic (turbidity) 


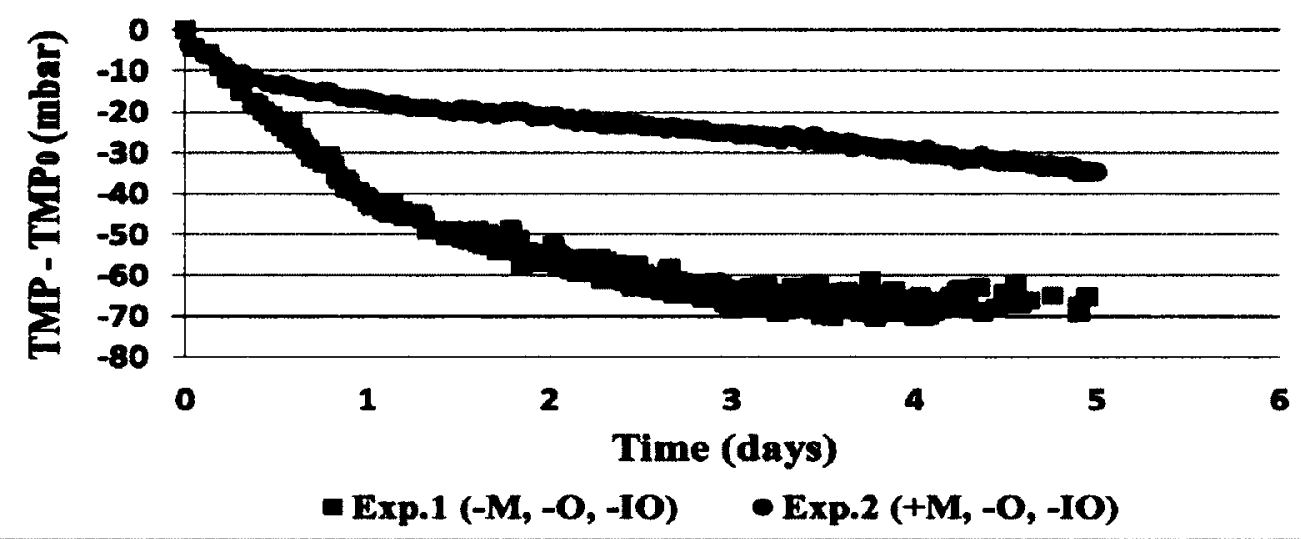

Figure 5.1 Comparison of low organic and inorganic fouling conditions with and without support media

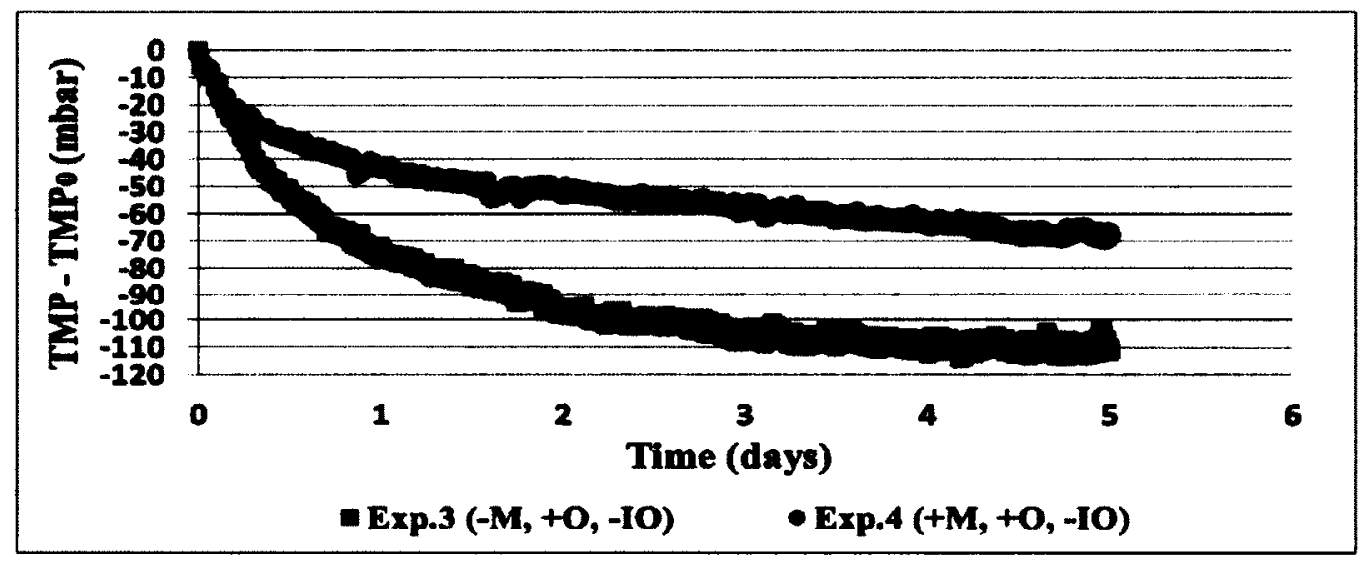

Figure 5.2 Comparison of high organic, low inorganic fouling conditions with and without support media

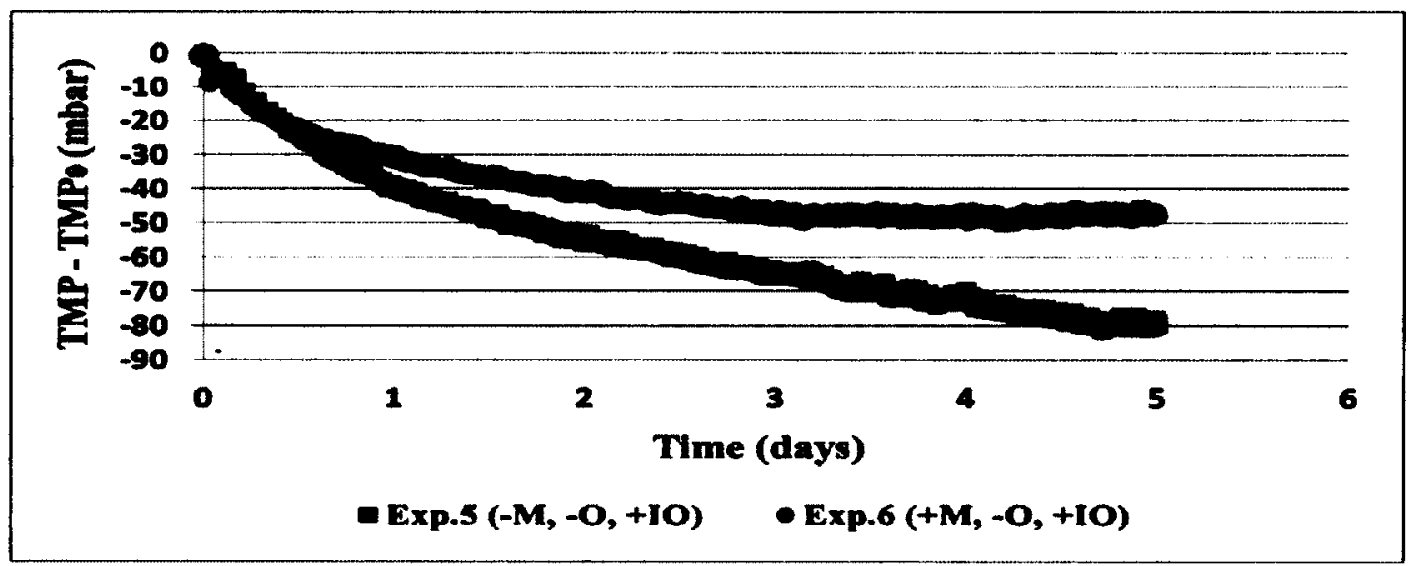

Figure 5.3 Comparison of low organic, high inorganic fouling conditions with and without support media 


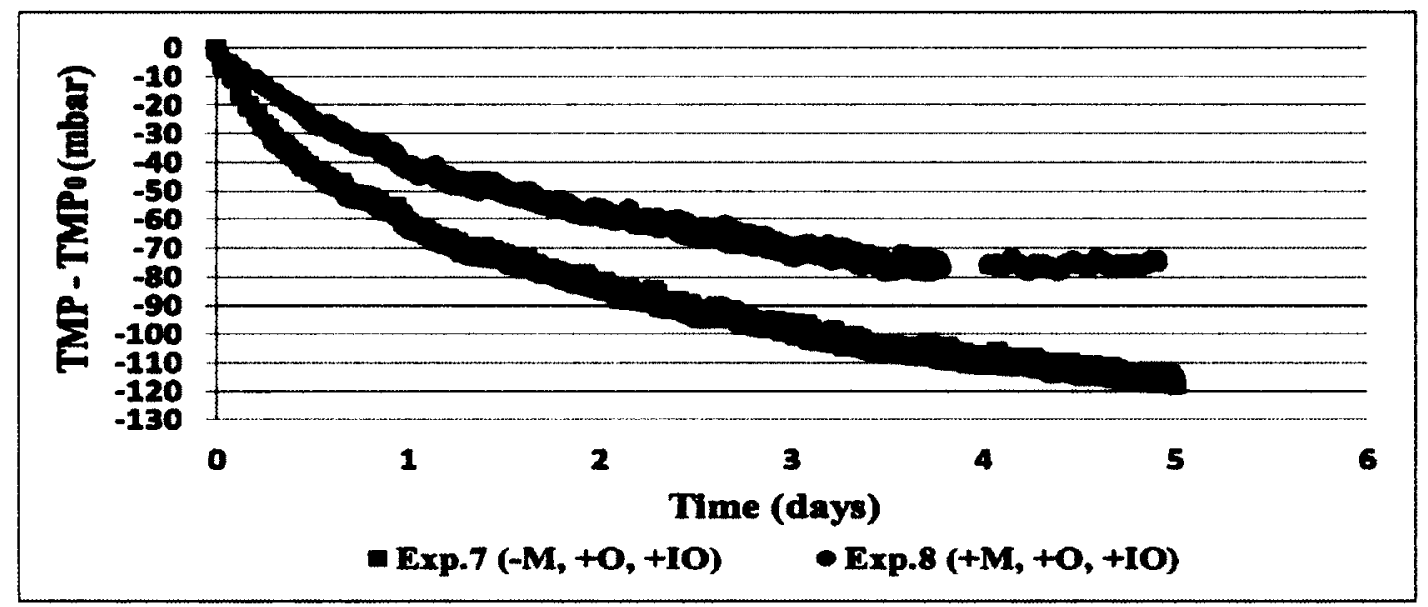

Figure 5.4 Comparison of high organic and inorganic fouling conditions with and without support media

\subsubsection{General observation}

Table 5.1 showed the fouling at the end of each day of the 5 day long experiments. Membrane fouling at the end of day 5 was found to be more sever in the case where high organic (humic acid) and inorganic (turbidity) concentrations were presented in the feed solution (i.e. experiment 7). On the other hand, and as expected, low concentrations of the organic and inorganic components (i.e. experiment 1) resulted in less membrane fouling compared to the high concentrations. However, experiments 3 and 5 results showed that the organic component (humic acid) had more influence on membrane fouling than the inorganic component (Kaolin clay). Nghiem et al. (2006) study showed that, membrane fouling was strongly affected by the organic concentration whereas inorganic concentration had a minimal effect on fouling. Whenever a high organics concentration was presented in the feed solution the more membrane fouling was observed (Figures 5.2 and 5.4). The contribution of inorganic particles to membrane 
fouling was observed to be minimal compared to the organics fraction. This general observation can be supported by (Kim et al., 1993; Waite et al., 1999) studies which showed that inorganic particles did not cause significant fouling of UF membranes. Also, Zularisam et al., (2011) study on UF membrane fouling by humic acid and inorganics particles showed severe membrane fouling related to the presence of humic acid not to inorganics particles.

While membrane fouling was observed to be more severe when high organics and inorganics concentrations were present in the feed solution, the presence of support media in the membrane reactor resulted in a significant reduction in membrane fouling. Whenever the support media was present (i.e. experiments $2,4,6$, and 8 ), fouling was found to be $35 \%-50 \%$ less than fouling in the same membrane system without support media. This observation was an indicator that the fill fraction of $10 \%$ of support media was very effective in reducing the degree of fouling during this research study. For comparison purposes, figure 5.5 shows photo images of membrane fouling from experiment 1 and experiment 2 at low organic and inorganic concentrations in the presence or absence of support media compared to membrane fouling at high organic and inorganic concentrations in the presence or absence of support media (experiment 7 and $8)$. 
a)

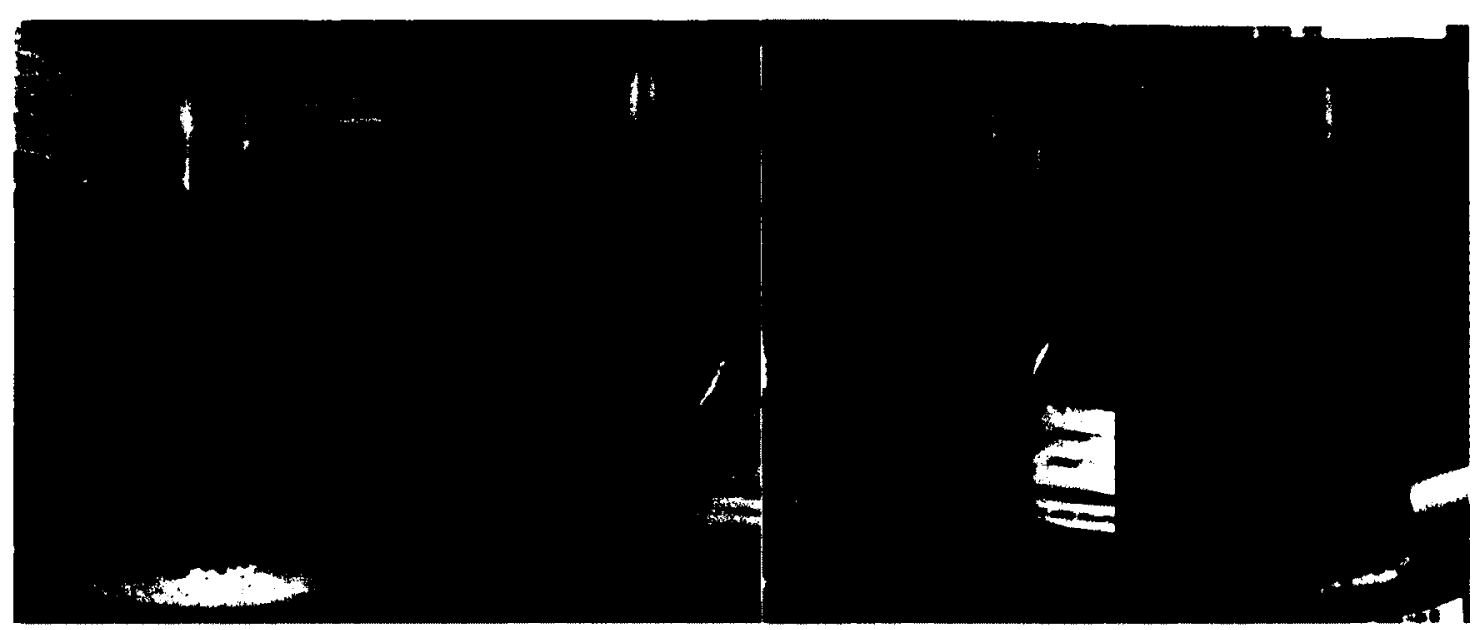

b)

c)

d)

Figure 5.5 Photo images of membrane fouling from: a) low organic and inorganic conditions in the absence of support media, b) low organic and inorganic conditions in the presence of support media, c) high organic and inorganic conditions in the absence of support media, and d) high organic and inorganic conditions in the presence of support media

As can be seen from the photo images, in experiment 7 , the high concentrations of humic acid and turbidity formed a thick cake layer on the membrane surface compared to the low concentrations (experiment 1). On the other hand, the support media used in experiment 2 and 8 was able to minimize the cake layer formation on the membrane surface, hence, lower fouling compared to the same system with no support media.

\subsubsection{Fouling analysis: Main and interaction effects identification}

In addition to TMP observations for fouling analysis, stepwise regression was performed to identify the important main and interactions effects of the three factors (support media, organic component (humic acid) and inorganic component (turbidity)) 
and their possible related impact on membrane fouling. Stepwise regression analysis were performed using SPSS 20.0 by IBM so that each of the three factors was added or deleted from the main model based on its degree of significance and its important contribution to the model. In other words, if there was a strong relationship between the factor and the results, the factor was added to the main model, otherwise, it was deleted. The addition or deletion of the factor was based on probability of $F$ value of 0.05 and 0.1 respectively.

As previously noted, the statistical model for $2^{3}$ factorial designs was represented in the equation below:

$$
\begin{aligned}
Y= & \beta_{0}+\beta_{1} X_{1}+\beta_{2} X_{2}+\beta_{3} X_{3}+\beta_{12} X_{1} X_{2}+\beta_{13} X_{1} X_{3}+\beta_{23} X_{2} X_{3} \\
& +\beta_{123} X_{1} X_{2} X_{3}
\end{aligned}
$$

Equation 5.1

Regression analysis was resulted in estimating the regression coefficients (及) which represented the main and interaction effects of the three parameters (support media, organic, and inorganic) on membrane fouling. (Y) is TMP output at day 5 .

In this model, $\beta_{0}=\left(\mathbf{- 7 6 . 2 0 3 )}\right.$ represents the intercept or regression constant. $\beta_{1=}$ (19.128), $\beta_{2}=(-18.310)$ and $\beta_{3}=(-4.740)$, represent the direct effect of support media, organic component (humic acid), and inorganic component (turbidity as kaolin clay) respectively on membrane fouling. $\beta_{12}=\mathbf{( 2 . 0 6 0 ) ,} \beta_{13}=(\mathbf{0 . 1 3 0}), \beta_{23}=(\mathbf{0 . 9 1 8})$ represent the effect of two factors interactions while $\beta_{123=}(\mathbf{0 . 4 1 8})$ represent the effect of three factors interactions on membrane fouling. Table 5.2 is a summary of main and interaction effects of parameters estimated by linear regression analysis. The complete model for these factorial experiments can be written as follows: 


$$
\begin{aligned}
Y= & -76.203+19.128 X_{1}-18.310 X_{2}-4.740 X_{3}+2.060 X_{1} X_{2} \\
& +0.130 X_{1} X_{3}+0.918 X_{2} X_{3}+0.418 X_{1} X_{2} X_{3}
\end{aligned}
$$

Table 5.2 Main and interaction effects of parameters estimated by linear regression analysis

\begin{tabular}{|c|c|c|}
\hline Main / Interaction effects & $\begin{array}{c}\text { Regression } \\
\text { coefficients for the } \\
\text { linear model }\end{array}$ & Estimated value \\
\hline Intercept / Regression constant & $\beta_{0}$ & -76.203 \\
\hline Support Media (M) & $\beta_{1}$ & 19.128 \\
\hline Organic (Humic Acid) (O) & $\beta_{2}$ & -18.310 \\
\hline Inorganic (Turbidity) (IO) & $\beta_{3}$ & -4.740 \\
\hline $\mathrm{M}^{*} \mathrm{O}$ & $\beta_{12}$ & 2.060 \\
\hline $\mathrm{M}^{*} \mathrm{IO}$ & $\beta_{13}$ & 0.130 \\
\hline $\mathrm{O}^{*} \mathrm{IO}$ & $\beta_{23}$ & 0.918 \\
\hline $\mathrm{M}^{*} \mathrm{O}^{*} \mathrm{IO}$ & $\beta_{123}$ & 0.418 \\
\hline
\end{tabular}

By performing stepwise regression analysis, each one of these three parameters (support media, organic component, and inorganic component) was entered into the model in each sequence and the significance of the model was monitored through $\left(\mathrm{R}^{2}\right)$ value. First, support media was entered into the model and resulted in $\mathrm{R}^{2}$ of $(0.502)$. That means $50.2 \%$ of the variation in the results and difference in fouling between experiments were influenced by the presence or absence of support media. The direct 
influence of support media on the degree of fouling was identified as a positive influence, (19.128). The second parameter (organic component) was then entered into the model and resulted in increasing the significance of the model $\left(R^{2}\right)$ to $(0.962)$. However, organic component was found to have a negative influence on the degree of fouling a value of (-18.310). The higher the concentration of organic component (humic acid), the higher fouling (as noted by an increase in TMP) was expected. The inorganic component (turbidity) was then added to the model and resulted in a slight increase in $\left(R^{2}\right)$ to $(0.993)$ with a negative effect value of $(-4.740)$. This would confirm the finding from the general observation of the results which showed that inorganic fraction (turbidity) had a minimum influence on the degree of fouling compared to the organic fraction.

After the three main parameters were entered into the model and their main contribution to membrane fouling was estimated, second and third interaction terms of these parameters were then entered into the model. Only the interaction between support media $(\mathrm{M})$ and organic component $(\mathrm{O})$, (i.e. $\mathrm{M}^{*} \mathrm{O}$ ) was found to be more significant than other interaction terms, thus, it was added to the model. The other interaction terms, i.e. interaction between support media and inorganic component $\left(\mathrm{M}^{*} \mathrm{IO}\right)$, organic and inorganic components $\left(\mathrm{O}^{*} \mathrm{IO}\right)$, and interaction between the three parameter support media, organic, and inorganic $\left(\mathrm{M}^{*} \mathrm{O}^{*} \mathrm{IO}\right)$ were found to have no effect on the significance of the model due to their low magnitude compared to other parameters therefore; they were excluded from the model. The complete stepwise regression output estimated by SPSS 20.0 can be seen in appendix $(\mathrm{H})$. The simplified model estimated by performing stepwise regression analysis can be written as: 
$Y=-76.203+19.128 X_{1}-18.310 X_{2}-4.740 X_{3}+2.060 X_{1} X_{2} \quad$ Equation 5.3

Table 5.3 compared the 5 day fouling estimated for each $2^{3}$ factorial experiment using full regression model and the simplified regression model as well as the Sum of Squares of Residuals (SSR) for each model. As shown in Table 5.3, the simplified model TMP values provided a good representation of the results from the $2^{3}$ factorial experiments and varied within $5 \%$ of the actual results. This would confirm that the confidence level $(95 \%)$ used for the identification of important main and interaction effects of parameters in stepwise regression resulted in exclusion of parameters of lower importance and inclusion of parameters of higher importance.

Table 5.3 Comparison of the fouling predicted by full and simplified regression models for each experiment and the corresponding Sum of Squares of Residuals

\begin{tabular}{|c|c|c|c|}
\hline Experiment \# & $\begin{array}{c}\text { TMP (mbar) } \\
\text { estimated by the full } \\
\text { regression model }\end{array}$ & $\begin{array}{c}\text { TMP (mbar) } \\
\text { estimated by the } \\
\text { simplified regression } \\
\text { model }\end{array}$ & \% error \\
\hline $\mathbf{1}$ & -69.59 & -70.22 & -0.91 \\
\hline $\mathbf{2}$ & -34.88 & -36.08 & -3.44 \\
\hline $\mathbf{3}$ & -111.33 & -110.96 & 0.33 \\
\hline $\mathbf{4}$ & -70.05 & -68.58 & 2.10 \\
\hline $\mathbf{5}$ & -80.33 & -79.70 & 0.78 \\
\hline $\mathbf{6}$ & -46.77 & -45.56 & 2.59 \\
\hline $\mathbf{7}$ & -120.07 & -120.44 & -0.31 \\
\hline $\mathbf{8}$ & -76.60 & -78.07 & -1.92 \\
\hline $\begin{array}{c}\text { Sum of } \\
\text { Squares of } \\
\text { Residuals } \\
\text { (SSR) }\end{array}$ & 0.000 & 8.264 & \\
\hline
\end{tabular}


Table 5.4 presents the rank of importance of main and interaction effects of support media, organic (humic acid) and inorganic (turbidity) estimated by stepwise regression analysis.

Table 5.4 Identification of Important Main / Interaction effects of Parameters

\begin{tabular}{|c|c|c|}
\hline Rank (Important effects) & Main / Interaction effects & Estimated effect \\
\hline $\mathbf{1}$ & $(\mathrm{M})$ - Support Media & 19.128 \\
\hline 2 & (O) - Organic (Humic Acid) & -18.310 \\
\hline 3 & (IO) - Inorganic (Turbidity) & -4.740 \\
\hline 4 & $\mathrm{M}^{*} \mathrm{O}$ & 2.060 \\
\hline 5 & $\mathrm{O}^{*} \mathrm{IO}$ & 0.918 \\
\hline 6 & $\mathrm{M}^{*} \mathrm{O}^{*} \mathrm{IO}$ & 0.418 \\
\hline 7 & $\mathrm{M}^{*} \mathrm{IO}$ & 0.130 \\
\hline
\end{tabular}




\subsubsection{Discussion}

The use of support media in a submerged membrane reactor was found to be very effective in controlling the degree of fouling physically by removing the fouling materials from the membrane surface. The results from these experiments as well as the statistical analysis confirmed that whenever the support media was present in the membrane reactor, membrane fouling was always lower than the same membrane system with no support media under the same operational condition.

As suspected, the organic component in the feed solution represented by humic acid was found to cause more fouling to the membrane unit compared to the inorganic component represented by kaolin clay. Previous studies on organic and inorganic fouling showed that humic acid deposition on the membrane surface or inside the membrane pores resulted in a sever flux decline during UF process (Turcaud et al., 1990). Whereas, inorganic particle deposition was more easily swept away during backwashing and by air scouring. Also, Peter-Varbanets et al., (2011) study on organic and inorganic fouling showed that flux decline did not depend on the inorganic concentrations, indicating that the resistance of the cake layer formed by inorganic particles is considerably lower than the resistance caused by NOM, as a result, the cake layer formed by inorganic particles was easily removed compared to cake layer formed by NOM.

In this research, humic acid (HA) concentration was found to correlate strongly with membrane fouling which corresponds well with other studies (Nghiem et al., 2006; Zularisam et al., 2011; Jermann et al., 2008). The transmembrane pressure increases rapidly with increasing HA concentration, probably due to the formation of a more compact and denser cake layer. A combination of high organic and inorganic 
concentrations was found to cause more fouling to the membrane unit. Perhaps the inorganic particle adsorbed to the humic acid and increased humic acid adsorption onto the membrane surface, hence, resulting in higher TMP increased. In general, the statistical analysis reflects well on the observed trends and it was clear that the support media did a good job at fouling control at various organic and inorganic conditions.

\subsubsection{Water Quality Assessment}

Water quality monitoring of membrane reactors, feed solutions, and permeates were conducted on daily basis in order to identify any significant changes in in water quality parameters that might affect membrane fouling and membrane performance. During the experimental run duration, turbidity measurements, $\mathrm{pH}$ monitoring, and permeates flow measurements as well as COD samples were taking. Appendix (I) presents water quality assessment for all 8 experiments performed in phase A study.

Turbidity monitoring showed that there weren't any significant differences in turbidity level and turbidity removal between all experiments. However, both membrane units (with or without support media) were very efficient in removing turbidity in all experiments.

By monitoring permeates flow, it was found that high organic and inorganic concentrations (i.e. Experiment 7) resulted in a significant decrease in permeate flow compared to other experiments. In other words, the more fouling that occurred, the larger the decrease in permeate flow was observed. However, in the membrane system where the support media was presented, permeate flow was always better than the same system 
with no support media. This was another indicator that the use of support media was very efficient in controlling the degree of fouling and enhancing membrane productivity throughout this research study. A comparison between the volume of permeates produced during 5 days of filtration for each membrane system can be seen in Table 5.5. High permeate volume was produced during experiment 2 compared to other experiments and that was due to the low feed concentrations of organic and inorganic components as well as the presence of support media. In general, permeate flow was found to be influenced by the degree of fouling of the membrane unit.

While the reduction in permeates flow was found to be associated with the degree of fouling of the membrane unit, in all experiments, both membrane systems with or without support media were very efficient in COD removal. The average COD removal in both systems was $90 \%$ for the system without media and $92 \%$ for the media system. This can be an indication that the fouling removal by the support media was physically not biologically and that the COD removal was mainly done by the membrane unit itself as a physical barrier not the support media. $\mathrm{pH}$ level in the membrane reactors, feed solutions, and permeates were almost the same in all experiments.

Table 5.5 Volume of permeate produced during 5 days of filtration $(\mathrm{L})^{*}$

\begin{tabular}{|c|c|c|c|}
\hline \multicolumn{2}{|c|}{ Membrane system without support media } & \multicolumn{2}{|c|}{ Membrane system with support media } \\
\hline Experiment 1 & 207 & Experiment 2 & 214 \\
\hline Experiment 3 & 201 & Experiment 4 & 212 \\
\hline Experiment 5 & 208 & Experiment 6 & 212 \\
\hline Experiment 7 & 200 & Experiment 8 & 209 \\
\hline
\end{tabular}

*The expected permeate volume during 5 days of filtration if no fouling occurred is $(216 \mathrm{~L})$ 
Water permeability tests were also conducted following each experiment and after chemical cleaning of the membrane units in order to make sure that the membrane units were able to achieve the required flux before the following experiments. As previously mentioned in Chapter 3 (section 3.2.5), cleaning of the membrane units were done by two steps: soaking in a sodium hypochlorite solution for no less than 20 hours followed by soaking in citric acid solution for another 20 hours. Clean distilled water was then ran through the membrane systems with assigned permeate flux of $(30 \mathrm{ml} / \mathrm{min})$ and the membrane permeate flow was measured manually. It was found that, in the membrane system where the support media was used, $98 \%$ of the required flux was recovered after only soaking in sodium hypochlorite while $94 \%$ recovery was achieved in the system that was operated with no support media. As can be seen in Figure 5.6, 99.5\% recovery was achieved in the system with support media after second cleaning while the membrane system with no support media was not able to achieve full flux recovery until third cleaning with sodium hypochlorite was conducted. This finding was an indicator that the use of support media was able to reduce the time required for membrane cleaning. However, more investigation is required to confirm this finding.

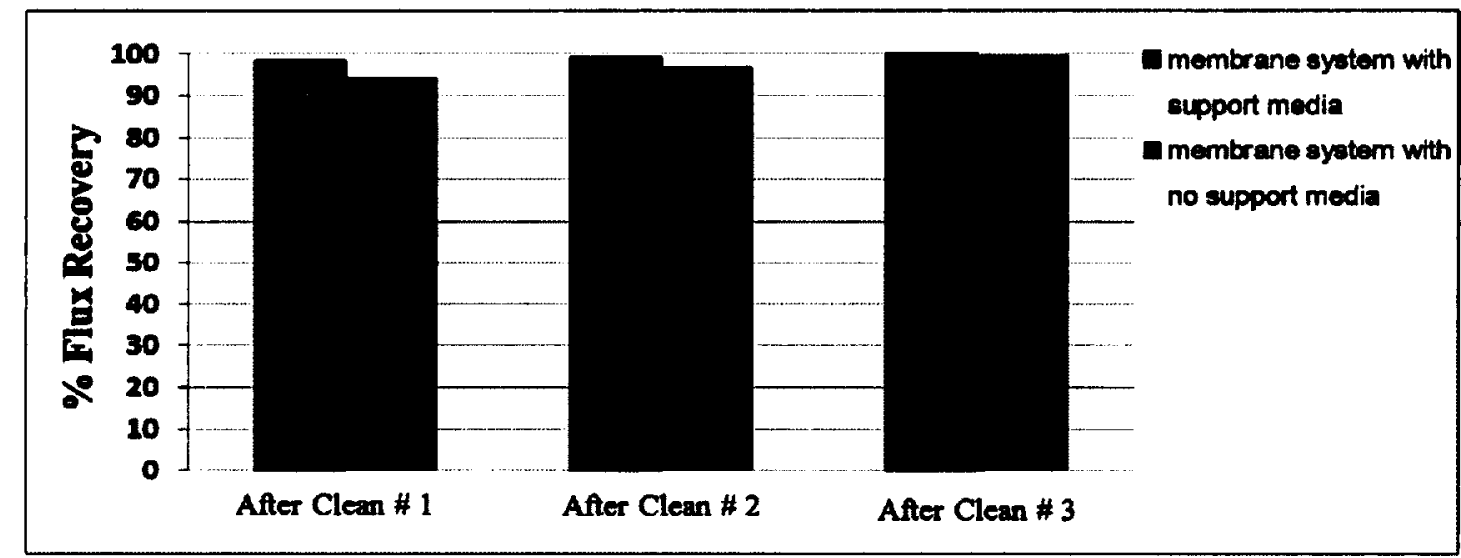

Figure 5.6 Flux recovery comparisons of two membranes systems

* Note: Clean \#1: with sodium hypochlorite (for 18 hrs.), Clean \#2: with citric acid (for 18 hrs.) Clean \#3 with sodium hypochlorite $(5 \mathrm{hrs}$. 


\subsubsection{Phase A conclusion}

The influence of different organic and inorganic concentrations on membrane fouling in the presence or absence of support media was studied by performing a $2^{3}$ factorial experiments.

The results showed that the degree of fouling of the membrane unit was highly influenced by the presence or absence of support media in the membrane reactor. The support media was able to scour the membrane surface effectively and resulted in minimizing the cake layer formation on the membrane surface physically by removing the fouling materials, hence, lower fouling compared to the same membrane system with no support media. In addition, the use of support media was found to be effective in increasing the volume of permeate produced and reducing the cleaning time compared to the system with no media.

Fouling of the membrane unit was found to be influenced by the concentrations of organic (humic acid) and inorganic (turbidity) components presented in the feed solution. Not surprisingly, the higher the concentration of humic acid and turbidity, the higher membrane fouling was occurred. However, the cake layer formed by inorganic particles (kaolin clay) was found to be easily removed by physical cleaning and, as a result, the inorganic particles had a minimal effect on fouling compared to humic acid. Regardless of the concentration of humic acid and the level of turbidity in the feed solution, the presence of support media was able to minimize the degree of fouling of the membrane unit and count for $35 \%-50 \%$ less in fouling compared to the same membrane system with no support media. The most fouling reduction was achieved when the organic 
component (humic acid) and inorganic component (turbidity) were presented in the feed solution at low concentrations in the presence of support media.

Stepwise regression analysis was conducted to identify main and interaction effects of three parameters: fill fraction of support media, organic component (humic acid), and inorganic component (kaolin clay) measured as turbidity. Stepwise regression identified main effects of support media, organic concentration, and inorganic concentration as well as the interaction between support media and organic concentration as important factors that can have influences on the degree of fouling. 


\subsection{Phase B Study Results: The relationship between humic acid and cellulose with membrane fouling in the presence or absence of support media}

Phase A experiments examined fouling of humic acid and turbidity on membrane fouling. This section examines fouling of humic acid and cellulose on membrane fouling. Humic acid and cellulose are both organic compounds present in surface water. However, each of these compounds has different chemical properties (i.e. molecular weight, molecular size distribution, etc.). In addition, each of these different organic compounds is found in different water sources. The presence of humic acid in surface waters is usually associated with microbial degradation of plants and animal matter and agricultural activates. On the other hand, cellulose is usually found in industrial wastewater such as paper, wood, and cotton manufactures. For these reasons, membrane fouling by two different sources of organic matter was investigated in this section.

\subsubsection{TMP graphs and TMP values}

Membrane fouling results from phase B study experiments are represented in terms of transmembrane pressure in figures $5.7-5.10$. As previously mentioned, the change in fouling ( $\triangle \mathrm{TMP}$ ) was calculated as the difference between the lowest TMP observed during the first and final 15 minutes of filtration for each experiment. The $\Delta \mathrm{TMP}$ values resulted from each experiment were then used for statistical analysis. For experiments where humic acid were used (i.e. experiments $3,4,7$, and 8), results were also considered as replicates to the experiments from phase A; therefore, they were used to confirm results. Note that $(-M$ and $+M)$ refers to the membrane system without 
support media ( $0 \%)$ and membrane system with support media (10\%) respectively. Also, (-IO and $+\mathrm{IO}$ ) refers to the low level of inorganic component (turbidity) $5 \mathrm{NTU}$ and the high level 20 NTU respectively. A comparison in membrane fouling by cellulose verses membrane fouling by humic acid is shown in Table 5.6.

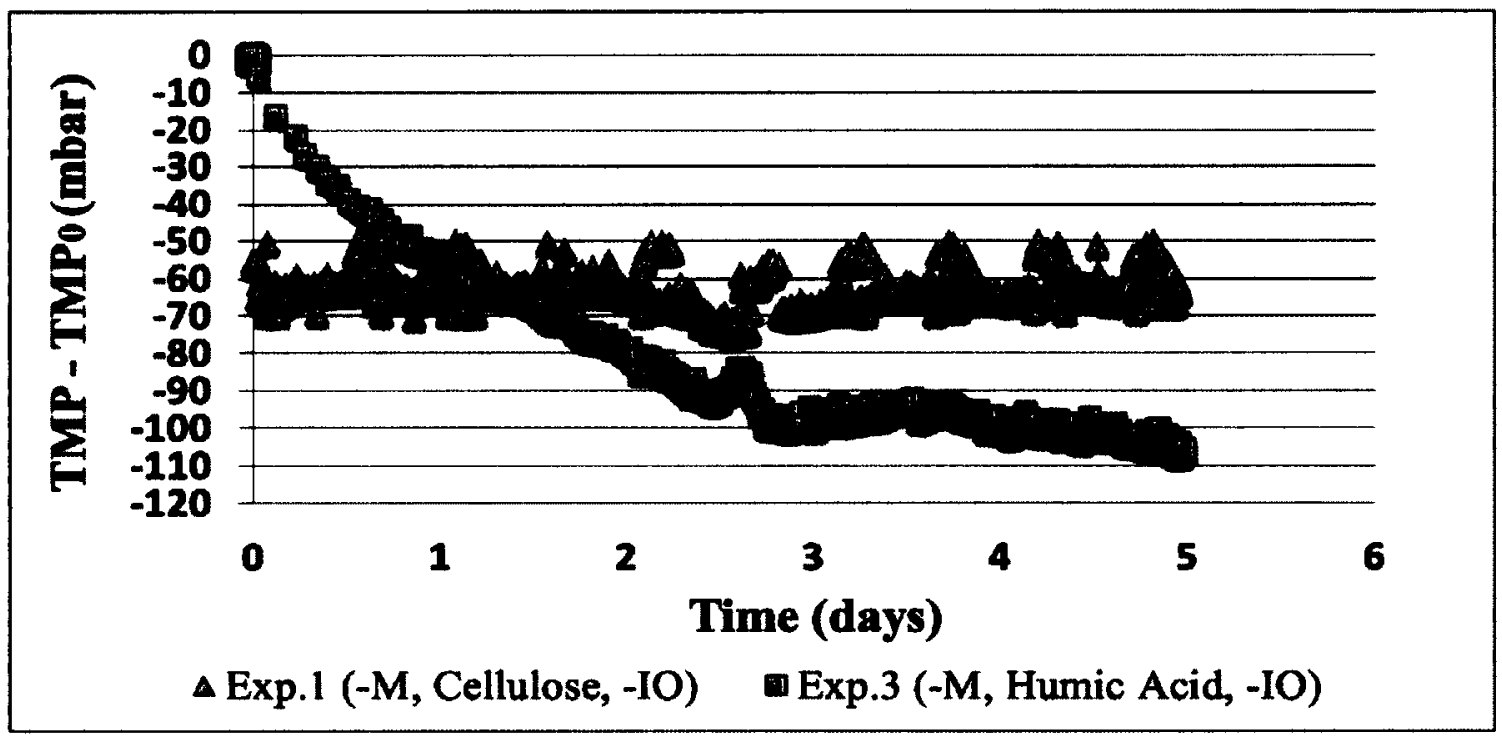

Figure 5.7 Comparison of membrane fouling by cellulose vs. membrane fouling by humic acid without support media at low turbidity

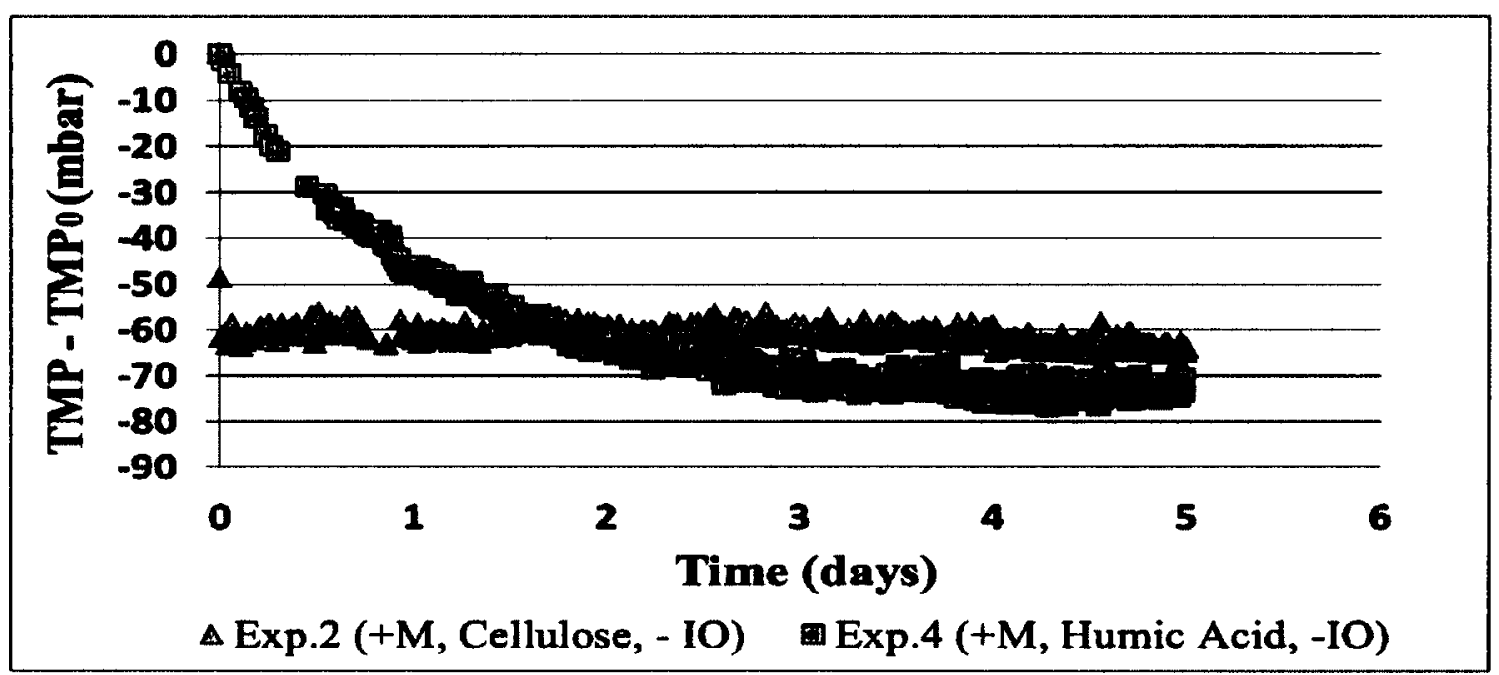

Figure 5.8 Comparison of membrane fouling by cellulose vs. membrane fouling by humic acid with support media at low turbidity 


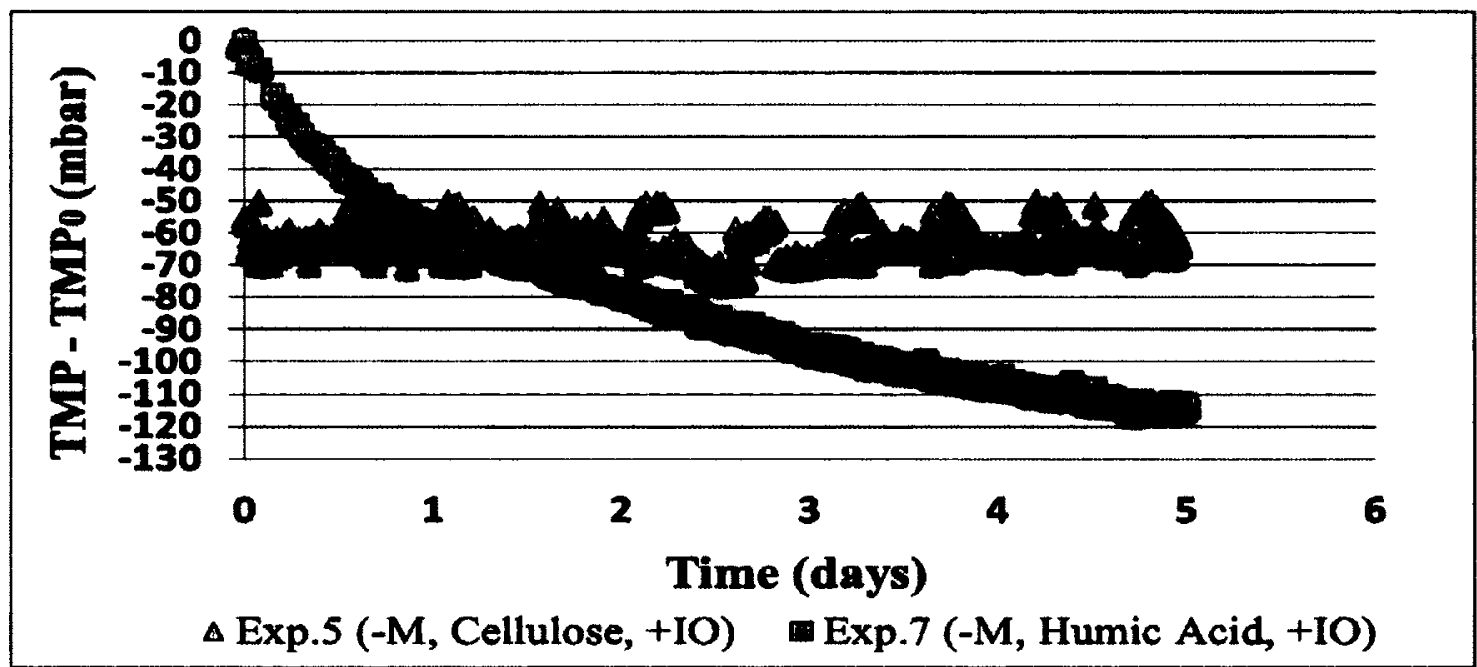

Figure 5.9 Comparison of membrane fouling by cellulose vs. membrane fouling by humic acid without support media at high turbidity

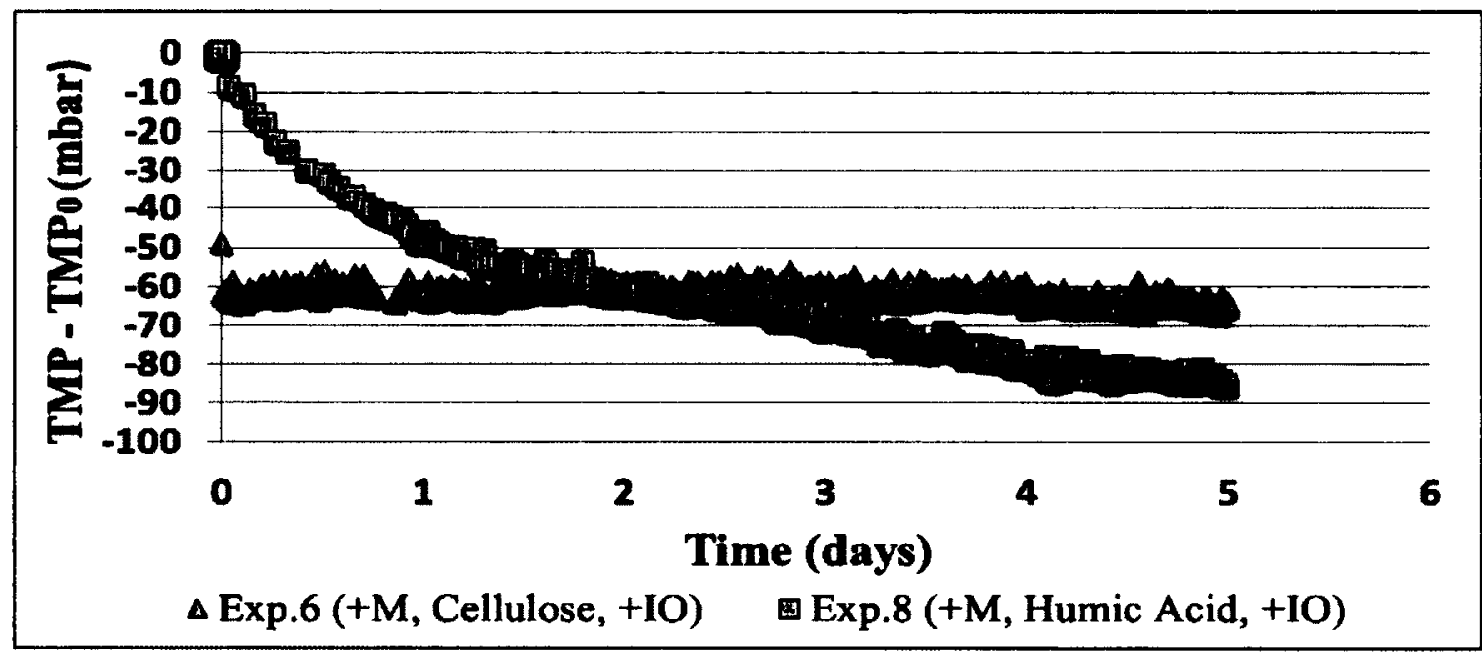

Figure 5.10 Comparison of membrane fouling by cellulose vs. membrane fouling by humic acid with support media at high turbidity

Table 5.6 Membrane fouling by cellulose vs. membrane fouling by humic acid *

\begin{tabular}{|c|c|c|c|}
\hline \multicolumn{2}{|c|}{$\begin{array}{c}\text { Membrane fouling by Cellulose } \\
\left(\Delta \mathbf{M M P}_{\text {day5 }}, \text { mbar) }\right.\end{array}$} & $\begin{array}{c}\text { Membrane fouling by Humic Acid } \\
\left(\mathbf{\Delta T M P}_{\text {day5 }}, \text { mbar) }\right.\end{array}$ \\
\hline Exp. 1 & -65.05 & Exp. 3 & -108.45 \\
\hline Exp. 2 & -64.23 & Exp. 4 & -73.19 \\
\hline Exp. 5 & -65.68 & Exp. 7 & -118.35 \\
\hline Exp. 6 & -64.45 & Exp. 8 & $-\mathbf{- 8 1 . 0 6}$ \\
\hline
\end{tabular}

*Note: experiments $2,4,6$, and 8 with support media whereas experiments $1,3,5$, and 7 without support media 


\subsubsection{General Observation}

As previously noted, membrane fouling with two different natural organic compounds ( $3 \mathrm{mgC} / \mathrm{L}$ of cellulose and $3 \mathrm{mg} \mathrm{C} / \mathrm{L}$ of humic acid) was investigated in phase B of this research study in the presence or absence of support media. The level of turbidity in the feed solution was also varied between 5 NTU and 20 NTU.

TMP graphs and values resulted from these experiments showed the differences of fouling behaviour between the two organic compounds. In experiments $1,2,5$, and 6 where cellulose was used, membrane fouling was consistent and was not affected by the level of turbidity or the presence or absence of the support media. Cellulose fouling curves were almost linear and had TMP value of ( -65 mbar) which remained consistent throughout the experimental run. This was thought to be due to the poor solubility of cellulose in water that was observed during solution preparation noted in Chapter 3. A comparison between cellulose and humic acid fouling during first hour of filtration can be seen in Appendix (J). As shown in Appendix (J), cellulose fouling was immediate and resulted in a large decrease at the start of experiments (within the first 5 minutes) but then stabilized. Perhaps the cake layer formed by cellulose was easily swept away by air scouring. On the other hand, humic acid showed a great influence on membrane fouling compared to cellulose and resulted in a continuous increase in TMP during the experimental run. Also, in experiments 4 and 8 where the support media was added, fouling was almost $35 \%$ lower than the same system with no media (i.e. experiment 3 and 7). 
A Comparison of chemical properties of cellulose and humic can be seen in Table 5.7. As previously noted, these two organic compounds have different chemical properties. The size of cellulose particles are reported to be bigger (range from $2.95 \mu \mathrm{m}-$ $49.1 \mu \mathrm{m})$ than UF membrane pore size diameter $(0.04 \mu \mathrm{m})$ (Nghiem et al., 2006). This implies that cellulose particles can be easily retained by the membrane unit and the cake layer formed by cellulose may not cause any noticeable fouling. In comparison, humic acid is reported to have smaller particles size that can be easily travel through the membrane pores and cause a significant increase in fouling over time.

Table 5.7 Comparison of chemical properties of cellulose vs. humic acid

\begin{tabular}{|c|c|c|}
\hline Formation & Cellulose & Humic acid \\
\hline Molecular Formula & $\mathrm{C}_{6} \mathrm{H}_{12} \mathrm{O}_{5}(1)$ & N/A \\
\hline Solubility & insoluble in water (1) & insoluble at low pH levels $<2$ (2) \\
\hline $\begin{array}{c}\text { Molecular weight } \\
\text { (Dalton) }\end{array}$ & $162(1)$ & range from 2000 to 5000 (2) \\
\hline
\end{tabular}

(1)- Schäfer et al, 2010

(2) - Gutman et al, 2010

\subsubsection{Fouling analysis: Main and interaction effects Identification}

Stepwise regression analysis was performed to identify the important main effects and interactions effects of the three factors: support media ( $0 \%$ and $10 \%$ fill fractions), organic component ( $3 \mathrm{mg} / \mathrm{L}$ TOC of cellulose and $3 \mathrm{mg} / \mathrm{L}$ TOC of humic acid) and inorganic component measured as turbidity (5 NTU and 20 NTU of Kaolin clay) and their possible related impact on membrane fouling. As previously noted, stepwise 
regression analysis were performed using SPSS 20.0 by IBM so that each of the three factors was added or deleted from the main model based on its degree of significance and its important contribution to the model. The addition or deletion of the factor was based on probability of $\mathrm{F}$ value of 0.05 and 0.1 respectively.

Regression coefficients estimated by stepwise regression can be seen in Table 5.8. As observed, type of organic presented in feed solution was found to have different fouling behaviour. Cellulose fouling was observed to be immediate and resulted in a large decrease in TMP and then stabilized and did not affected by the presence or absence of support media. On the other hand, the degree of fouling by humic acid was found to increase over time and can be controlled by the support media. As a result, regression analysis estimated the effect of the organic compound on membrane fouling $\left(\boldsymbol{\beta}_{2}=\mathbf{- 1 5 . 2 0 5}\right)$ as a significant effect compared to other parameters.

As shown in table 5.8, the type of organic material present in the feed solution was estimated to be more important than the support media. This was quite different than what was found from Phase A experiment. Perhaps this was due to the complex fouling trend of cellulose compared to humic acid. In addition, perhaps cellulose absorption on the membrane surface was very low and easily slept away compared to humic acid. However, the presence of support media was observed to be important specifically in those experiments with humic acid and was considered as an important parameter that can influence the degree of fouling. Also, the interaction between the support media and organic was identified to be important. Other parameters such as the main effect of inorganic component, interactions between support media and inorganic component, organic type and inorganic component, and interaction between support 
media, organic type, and inorganic component, were identified as unimportant parameters. The complete stepwise regression output estimated by SPSS 20.0 can be seen in appendix (K). The complete model for Phase B factorial experiments can be written as follows:

$$
\begin{aligned}
Y= & -80.058+9.325 X_{1}-15.205 X_{2}-2.328 X_{3}+8.813 X_{1} X_{2} \\
& +0.305 X_{1} X_{3}-2.115 X_{2} X_{3}+0.202 X_{1} X_{2} X_{3}
\end{aligned}
$$

Table 5.8 Main and interaction effects of parameters estimated by linear regression analysis

\begin{tabular}{|c|c|c|}
\hline Main / Interaction effects & $\begin{array}{c}\text { Regression } \\
\text { coefficients for the } \\
\text { linear model }\end{array}$ & Estimated value \\
\hline Intercept / Regression constant & $\beta_{0}$ & -80.058 \\
\hline Support Media (M) & $\beta_{1}$ & 9.325 \\
\hline Organic type (O) & $\beta_{2}$ & -15.205 \\
\hline Inorganic (Turbidity)(IO) & $\beta_{3}$ & -2.328 \\
\hline $\mathrm{M}^{*} \mathrm{O}$ & $\beta_{12}$ & 8.813 \\
\hline $\mathrm{M}^{*} \mathrm{IO}$ & $\beta_{13}$ & 0.305 \\
\hline $\mathrm{O}^{*} \mathrm{IO}$ & $\beta_{23}$ & -2.115 \\
\hline $\mathrm{M}^{*} \mathrm{O}^{*} \mathrm{IO}$ & $\beta_{123}$ & 0.202 \\
\hline
\end{tabular}

The simplified model estimated by performing stepwise regression analysis can be written as:

$$
Y=-80.058+9.325 X_{1}-15.205 X_{2}+8.813 X_{1} X_{2} \quad \text { Equation 5.5 }
$$


Table 5.9 compared the 5 day fouling estimated for each $2^{3}$ factorial experiment using full regression model and the simplified regression model as well as the Sum of Squares of Residuals (SSR) for each model. As shown in Table 5.9, TMP values predicted by the simplified model vary within $5 \%$ of the actual TMP results.

Table 5.9 Comparison of the fouling predicted by full and simplified regression models for each experiment and the corresponding Sum of Squares of Residuals

\begin{tabular}{|c|c|c|c|}
\hline Experiment \# & $\begin{array}{c}\text { TMP (mbar) } \\
\text { estimated by the full } \\
\text { regression model }\end{array}$ & $\begin{array}{c}\text { TMP (mbar) } \\
\text { estimated by the } \\
\text { simplified regression } \\
\text { model }\end{array}$ & \% error \\
\hline 1 & -65.05 & -65.37 & -0.48 \\
\hline 2 & -64.23 & -64.34 & -0.17 \\
\hline $\mathbf{3}$ & -108.45 & -113.40 & -4.56 \\
\hline $\mathbf{4}$ & -73.19 & -77.13 & -5.38 \\
\hline $\mathbf{5}$ & -65.68 & -65.37 & 0.48 \\
\hline $\mathbf{6}$ & -64.45 & -64.34 & 0.17 \\
\hline 7 & -118.35 & -113.40 & 4.18 \\
\hline $\mathbf{8}$ & -81.06 & -77.13 & 4.85 \\
\hline $\begin{array}{c}\text { Sum of } \\
\text { Squares of } \\
\text { Residuals } \\
\text { (SSR) }\end{array}$ & 0.000 & 80.20 & \\
\hline
\end{tabular}

Table 5.10 presents the rank of importance of main and interaction effects of support media, organic type and inorganic (turbidity) estimated by stepwise regression analysis. 
Table 5.10 Identification of Important Main / Interaction effects of Parameters

\begin{tabular}{|c|c|c|}
\hline Rank (Important effects) & Main / Interaction effects & Estimated effect \\
\hline $\mathbf{1}$ & Organic type (O) & -15.205 \\
\hline $\mathbf{2}$ & Support Media (M) & 9.325 \\
\hline $\mathbf{3}$ & $\mathrm{M}^{*} \mathrm{O}$ & 8.813 \\
\hline $\mathbf{4}$ & Inorganic (Turbidity) (IO) & -2.328 \\
\hline $\mathbf{5}$ & $\mathrm{O}^{*} \mathrm{IO}$ & -2.115 \\
\hline $\mathbf{6}$ & $\mathrm{M}^{*} \mathrm{IO}$ & 0.305 \\
\hline $\mathbf{7}$ & $\mathrm{M}^{*} \mathrm{O} * \mathrm{IO}$ & 0.202 \\
\hline
\end{tabular}

\subsubsection{Discussion}

The type of organic material present in the feed solution was found to have different influences on both the rate and extent of fouling. The differences in chemical properties (i.e. molecular weight, particles size. etc.) of cellulose and humic acid resulted in different fouling behavior. It was reported that, humic acids in solution exist in the shape of loose aggregates which show the characteristics of colloidal particles which can be easily absorbed onto membrane surface and into membrane pores ( $\mathrm{Na}$ et al., 2012).

On the other hand, as previously noted the poor solubility of cellulose caused immediate membrane fouling but limited long term impact. Cellulose as an organic compound was reported to have a linear polysaccharide chain consisting of hundreds to thousands of D anhydroglucopyranose linked together b-glycosidic bonds (Carlmark et 
al. 2012). In addition, cellulose molecules are often large and bulky, and cellulose is relatively inert to chemical interactions (Schäfer et al. 2010). Due to these characteristics, membrane fouling and the cake layer formed by the accumulation of cellulose on the membrane surface was thought to be very porous and caused short term fouling compared to humic acid.

The use of support media was also found to be very effective in minimizing humic acid fouling compared to cellulose. Humic acid was thought to be easily absorbed onto the surface of support media while cellulose absorption was relatively low.

\subsubsection{Water Quality Assessment}

During phase B experiments, water quality monitoring was conducted on daily basis in order to identify any significant changes in water quality that might affect membrane fouling. Permeates flow measurements, turbidity and $\mathrm{pH}$ readings were taken from the membrane reactors, feed solutions, and permeates. As previously noted, TOC and UV absorbance at $254 \mathrm{~nm}$ measurements were also taken for feed solutions and permeates.

No significant changes in turbidity removal or $\mathrm{pH}$ level were observed between the two membrane filtration systems of two different organic compounds. A comparison of the permeate flows at the two different organic compounds showed that the membrane productivity decreased over time in those experiments where humic acid was used. In 
contrast, due to lower membrane fouling by cellulose compered to humic acid, the membrane productivity from cellulose experiments was always better.

Total organic carbon analysis was performed using SHIMADZU TOC-VCPH/ CPN total organic carbon analyzer. One sample from the permeate and one sample from the feed were taking from both membrane filtration setups every 24 hours. In addition, UV absorbance was measured for feed solution and permeates. In the UV measurements, the samples were placed in quartz cuvette and UV absorbance values of the samples were measured at a wavelength of $254 \mathrm{~nm}$ using a UV-Visible spectrophotometer. The difference in reading of $U_{254} \mathrm{~nm}$ absorbance between feed and permeate were reported to be an indication of the quantity of rejected organic substance by the membrane (Mozia et al., 2004).

Specific ultraviolet absorbance (SUVA) was then calculated as a ratio of UV at the wavelength of $254 \mathrm{~nm}$ and TOC. In drinking water treatment, SUVA value can provide a good insight into the composition of NOM in the source water. High SUVA means high aromaticity or hydrophobicity of samples in the limited DOC (Zularisam et al. 2006). Also, SUVA can be used as an indicator of the tendency of the NOM in a given water sample to respond to coagulation with metal salts. Specifically, it indicates whether the coagulation process is controlled by the concentration of DOC, which is the ideal situation for NOM removal through coagulation (Edzwald et al., 1993). Tables 5.11 and 5.12 show a summary of the measured TOC and $\mathrm{UV}_{254 \mathrm{~nm}}$ absorbance at the start of day 1 and the end of day 5 for each experiment respectively. The complete water quality assessment for phase B experiments can be seen in Appendix (L). 
Table 5.11 Measured TOC for feed solutions and permeates for each experiment

\begin{tabular}{|c|c|c|c|c|c|c|c|}
\hline \multicolumn{4}{|c|}{ Organic: Cellulose } & \multicolumn{4}{|c|}{ Organic: Humic Acid } \\
\hline \multicolumn{4}{|c|}{$\mathrm{TOC}(\mathrm{mg} \mathrm{C} / \mathrm{L})$} & \multicolumn{4}{|c|}{ TOC $(\mathrm{mg} \mathrm{C} / \mathrm{L})$} \\
\hline & & Feed & Permeate & & & Feed & Permeate \\
\hline \multirow{2}{*}{ Exp.1 } & Initial & 1.710 & 0.880 & \multirow{2}{*}{ Exp. 3} & Initial & 3.070 & 0.850 \\
\hline & day 5 & 0.410 & 0.310 & & day 5 & 1.220 & 0.580 \\
\hline & & & & & & & \\
\hline \multirow{2}{*}{ Exp.2 } & Initial & 1.380 & 0.680 & \multirow{2}{*}{ Exp. 4} & Initial & 2.980 & 0.650 \\
\hline & day 5 & 0.660 & 0.420 & & day 5 & 1.360 & 0.440 \\
\hline \multirow{2}{*}{ Exp.5 } & Initial & 1.480 & 0.680 & \multirow{2}{*}{ Exp. 7} & Initial & 2.950 & 0.890 \\
\hline & day 5 & 0.510 & 0.380 & & day 5 & 1.790 & 0.350 \\
\hline & & & & & & & \\
\hline \multirow{2}{*}{ Exp.6 } & Initial & 1.330 & 0.550 & \multirow{2}{*}{ Exp. 8} & Initial & 3.050 & 0.750 \\
\hline & day 5 & 0.420 & 0.210 & & day 5 & 1.100 & 0.270 \\
\hline
\end{tabular}

*Note: These experiments have the same feed carbon content $(3 \mathrm{mgC} / \mathrm{L})$. However, as noted in chapter 3 (section 3.2.1.1), due to some issues related to measuring the carbon content caused by cellulose using TOC analysis, the TOC values presented in this table used for comparison purposes.

Table 5.12 Measured $\mathrm{UV}_{254 \mathrm{~nm}}$ absorbance for feed solutions and permeates for each experiment

\begin{tabular}{|c|c|c|c|c|c|c|c|}
\hline \multicolumn{4}{|c|}{ Organic: Cellulose } & \multicolumn{4}{|c|}{ Organic: Humic Acid } \\
\hline \multicolumn{4}{|c|}{$\mathrm{UV}_{254 \mathrm{~nm}}$ absorbance $\left(\mathrm{cm}^{-1}\right)$} & \multicolumn{4}{|c|}{$\mathrm{UV}_{254 \mathrm{~nm}}$ absorbance $\left(\mathrm{cm}^{-1}\right)$} \\
\hline & & Feed & Permeate & & & Feed & Permeate \\
\hline \multirow{2}{*}{ Exp.1 } & Initial & 0.120 & 0.025 & \multirow{2}{*}{ Exp. 3} & Initial & 0.320 & 0.060 \\
\hline & day 5 & 0.027 & 0.004 & & day 5 & 0.110 & 0.015 \\
\hline \multirow{3}{*}{ Exp.2 } & Inition & 0100 & 007 & \multirow{3}{*}{ Exp. 4} & Initio & 0380 & 0041 \\
\hline & Initual & 0.100 & 0.022 & & Initial & 0.380 & 0.041 \\
\hline & day 5 & 0.048 & 0.005 & & day 5 & 0.120 & 0.021 \\
\hline \multirow{3}{*}{ Exp.5 } & & & & & & & \\
\hline & Initial & 0.151 & 0.045 & \multirow{2}{*}{ Exp. 7} & Initial & 0.357 & 0.038 \\
\hline & day 5 & 0.030 & 0.018 & & day 5 & 0.116 & 0.013 \\
\hline \multirow{3}{*}{ Exp.6 } & & & & \multirow{3}{*}{ Exp. 8} & & & \\
\hline & Initial & 0.125 & 0.020 & & Initial & 0.290 & 0.030 \\
\hline & day 5 & 0.026 & 0.006 & & day 5 & 0.060 & 0.008 \\
\hline
\end{tabular}


As previously noted in Chapter 3 (section 3.2.1.1), TOC analysis was found to be not suitable for measuring the total carbon content caused by cellulose in a solution and was thought to be related to the inability of the TOC analyzer to maintain the cellulose in suspension during sampling and the poor solubility of cellulose. However, TOC analysis for cellulose was performed for comparison purposes to humic acid. As shown in Table 5.11 and 5.12, in all experiments, high TOC removal and UV reduction was achieved throughout the 5 days of experimental run. TOC removal and UV reduction was almost consistent over time for both membrane systems. However, it was found that total organic carbon of permeates were slightly higher than what was expected and it was thought to be due to possible contamination of TOC unit or permeate flow line. In general, there was no significant difference in terms of TOC removal or UV reduction between the membrane system with support media and the membrane system without support media. Estimated Specific ultraviolet absorbance (SUVA) values can be seen in Table 5.13. Also, a representation of SUVA reduction for all experiments is shown in Figures 5.11 and 5.12.

Table 5.13 SUVA values for feed solutions and permeates for each experiment

\begin{tabular}{|c|c|c|c|c|c|c|c|}
\hline \multicolumn{4}{|c|}{ Organic: Cellulose } & \multicolumn{4}{|c|}{ Organic: Humic Acid } \\
\hline \multicolumn{4}{|c|}{ SUVA value ( $\mathrm{L} / \mathrm{mgC} \mathrm{m})$} & \multicolumn{4}{|c|}{ SUVA value (L / mgC m) } \\
\hline & & Feed & Permeate & & & Feed & Permeate \\
\hline \multirow{2}{*}{ Exp.1 } & Initial & 8.018 & 2.841 & \multirow{2}{*}{ Exp. 3} & Initial & 11.423 & 7.059 \\
\hline & day 5 & 6.585 & 1.290 & & day 5 & 9.016 & 2.586 \\
\hline \multirow{2}{*}{ Exp.2 } & Initial & 11.043 & 3.235 & \multirow{2}{*}{ Exp. 4} & Initial & 11.752 & 6.308 \\
\hline & day 5 & 7.273 & 1.190 & & day 5 & 8.824 & 4.773 \\
\hline \multirow{2}{*}{ Exp.5 } & Initial & 10.203 & 6.618 & \multirow{2}{*}{ Exp. 7} & Initial & 12.102 & 4.270 \\
\hline & day 5 & 5.882 & 4.737 & & day 5 & 6.480 & 3.714 \\
\hline \multirow{2}{*}{ Exp.6 } & Initial & 9.398 & 3.636 & \multirow{2}{*}{ Exp. 8} & Initial & 10.508 & 4.000 \\
\hline & day 5 & 6.190 & 2.857 & & day 5 & 5.455 & 2.963 \\
\hline
\end{tabular}




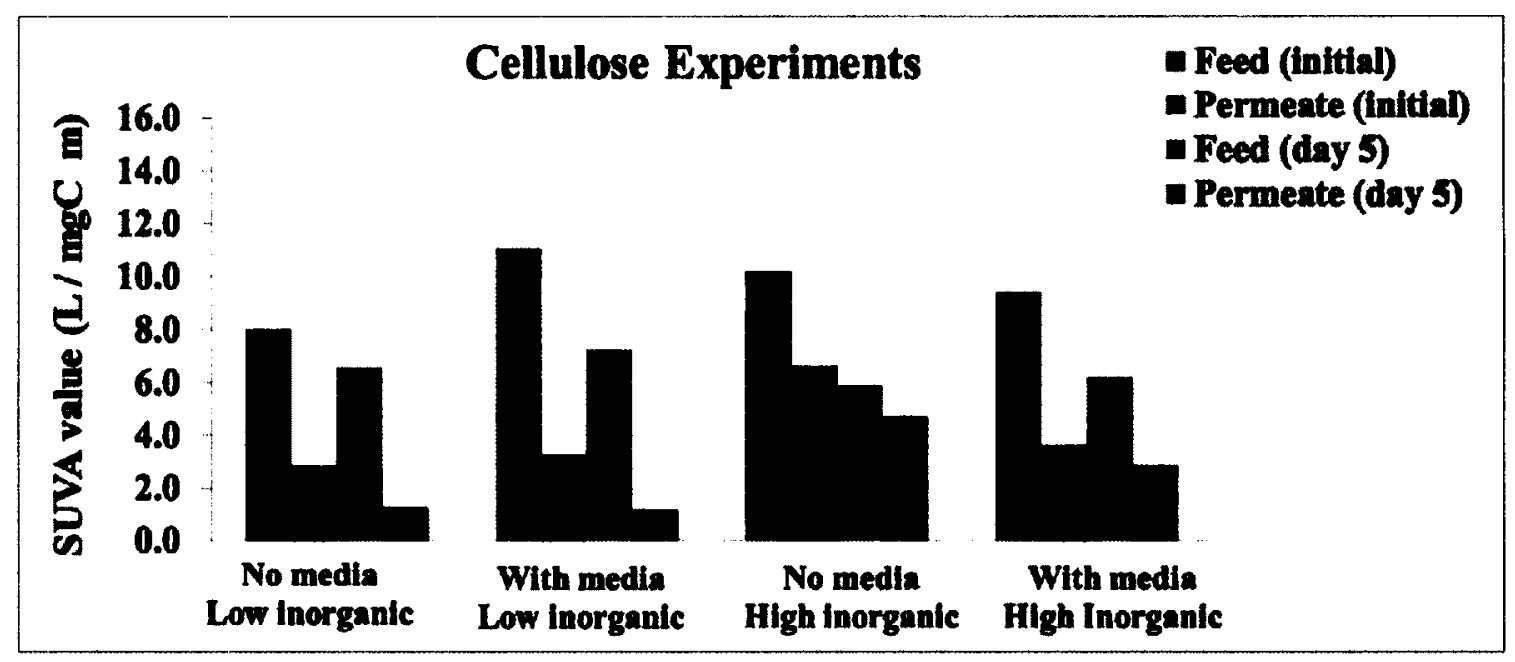

Figure 5.11 SUVA values for feed solutions and permeates of cellulose experiments

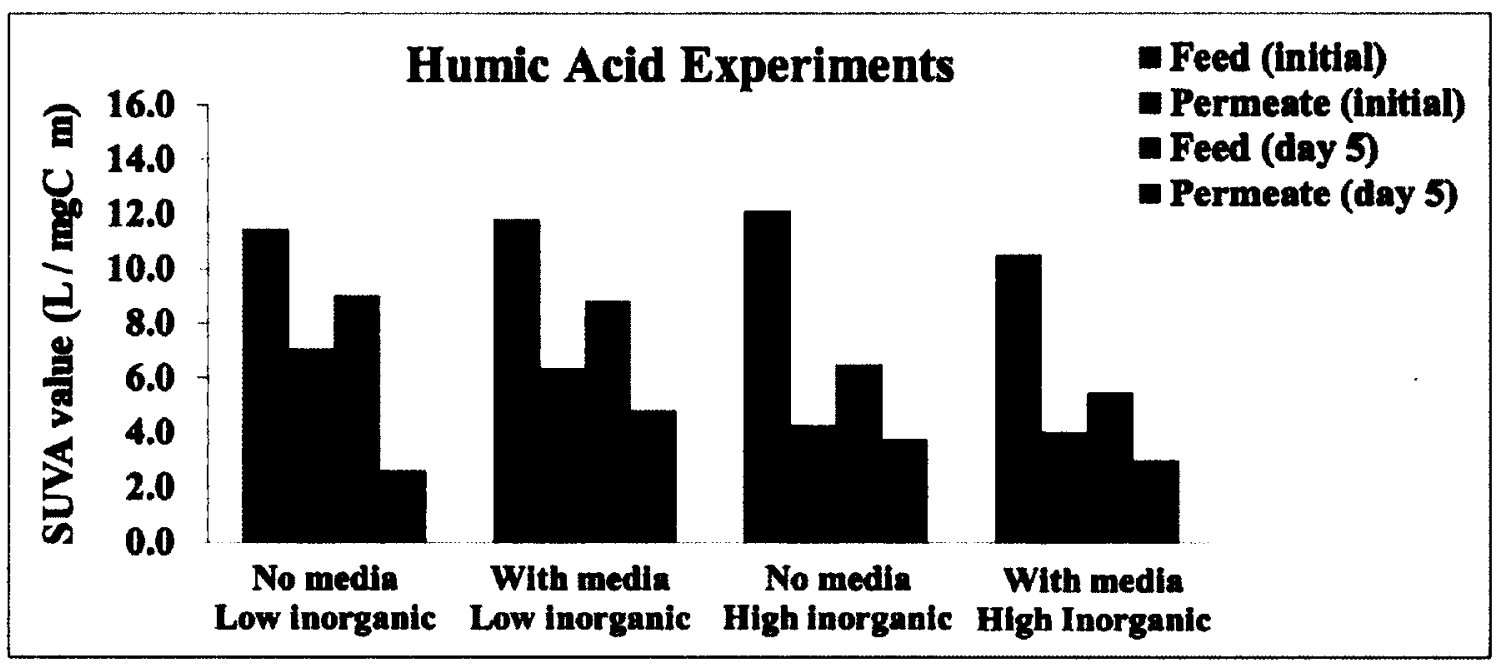

Figure 5.12 SUVA values for feed solutions and permeates of humic acid experiments

As can be seen from SUVA graphs, there is more variability in feed SUVA values in cellulose experiment than humic experiments. This may imply that the poor solubility of cellulose in feed solution compared to humic acid. In general, a reduction in SUVA value was achieved in all experiments. 


\subsubsection{SEM images}

Based on a strictly visual inspection of the membrane surface, it was not possible to observe if there was any damage to the membrane surface from the support media. Therefore, SEM images of the membrane surfaces were taken (Figure $5.13-5.15$ ). The images clearly show visible lines in the system with support media while the system without media shows a smooth unaffected surface. However, it seems that the lines have not affected the membrane integrity and do not appear to have a negative impact or have caused any permanent damage to the integrity of the membrane. However, more studies are required for further evaluation. Additional SEM images of membranes units are included in Appendix (M).

a)

b)

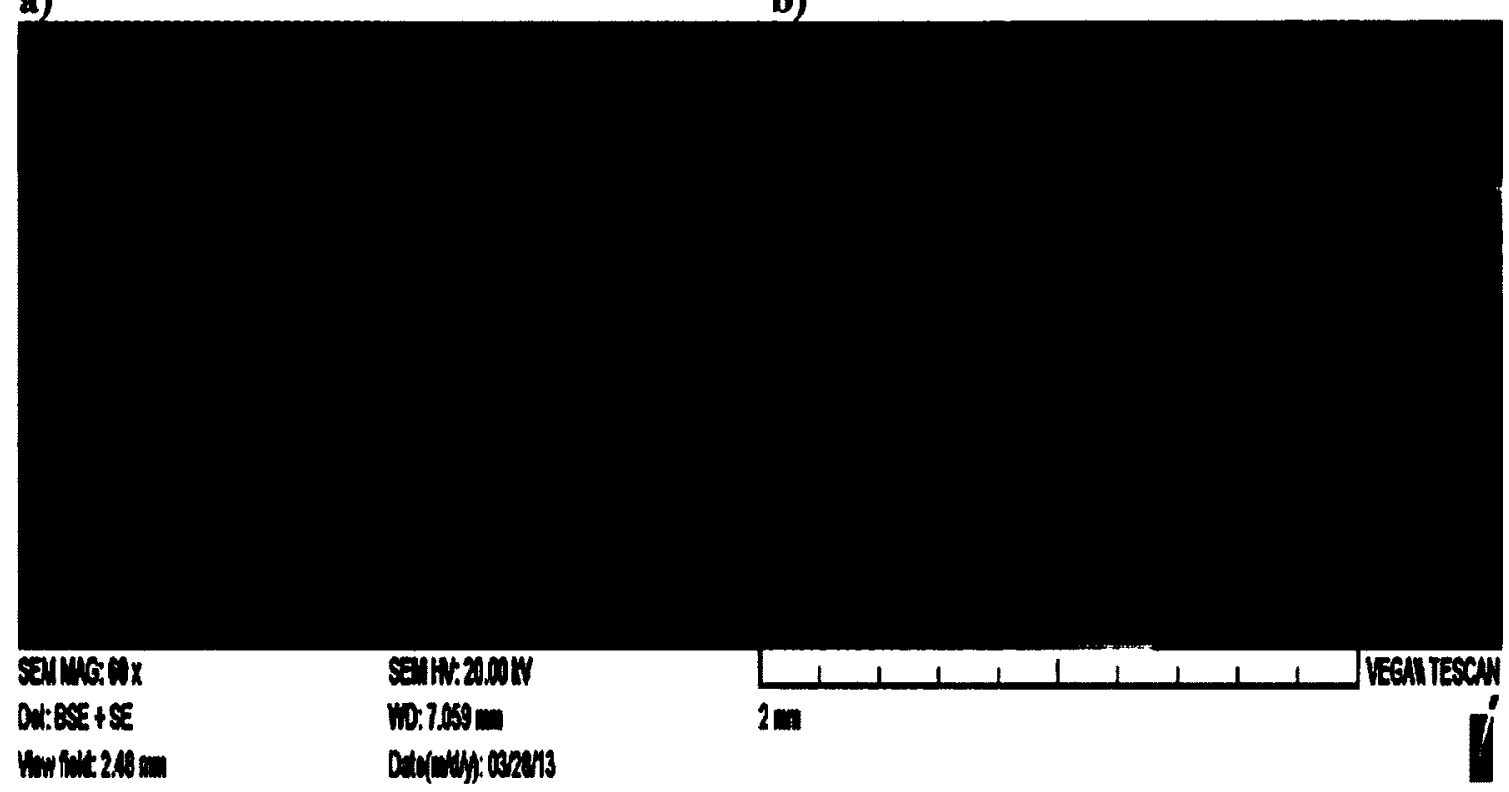

Figure 5.13 SEM images of membranes units, (60x magnification $20 \mathrm{kV}$ ). (a) No visible marking on surface of membrane without support media. (b) Some visible lines on surface of membrane with support media 
a)

b)

\begin{tabular}{|c|c|c|}
\hline 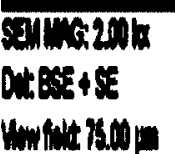 & 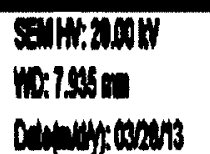 & An \\
\hline
\end{tabular}

Figure 5.14 SEM images of membranes units, ( $2.00 \mathrm{kx}$ magnification $20 \mathrm{kV})$. (a) Smooth unaffected surface of membrane without support media. (b) Arrow indicates some visible marking on surface of membrane with support media

a)

b)

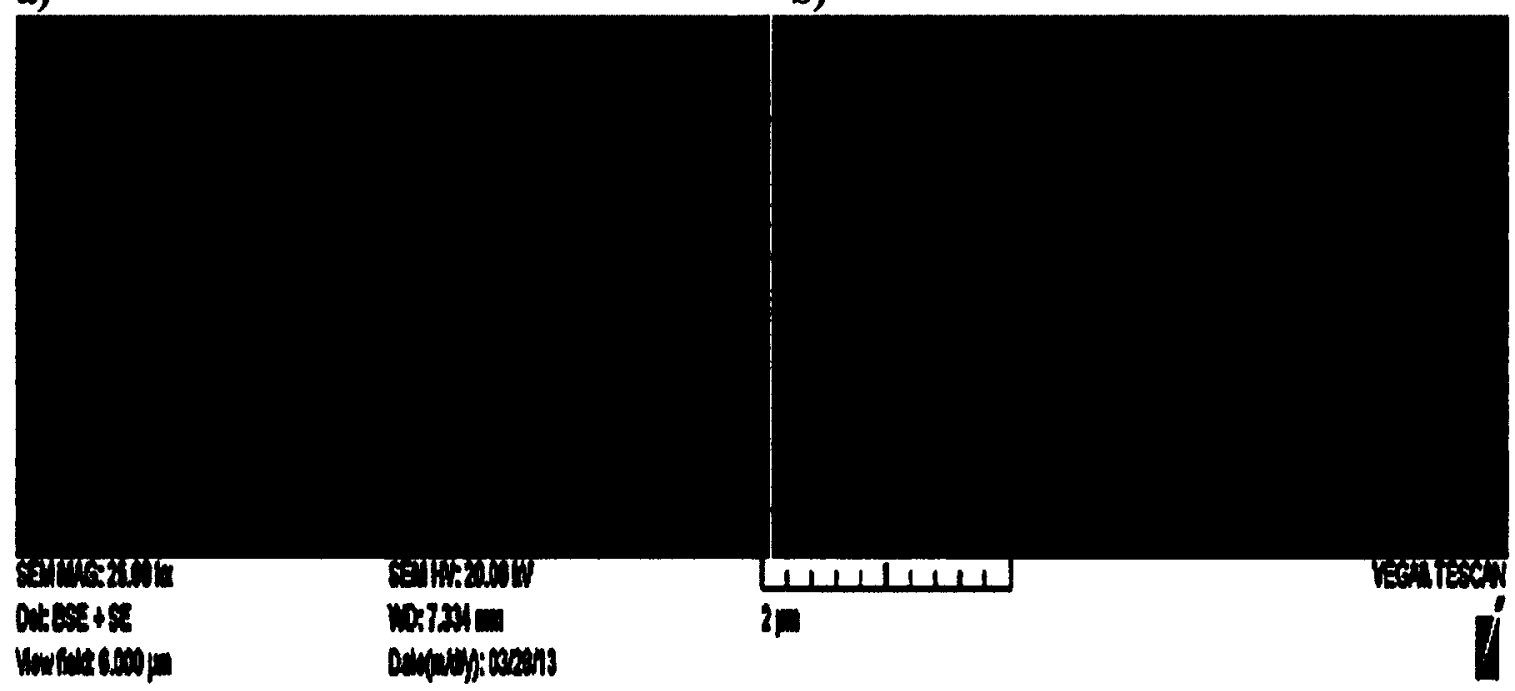

Figure 5.15 SEM images of membranes units, ( $25.00 \mathrm{kx}$ magnification $20 \mathrm{kV})$. (a) Smooth surface of membrane without support media. (b) no defects or damage is shown on surface of membrane with support media 


\subsubsection{Phase B conclusion}

The influence of different natural organic source on membrane fouling in the presence or absence of support media was investigated by performing a $2^{3}$ factorial experiments. Two organic compounds were studied: $3 \mathrm{mgC} / \mathrm{L}$ of cellulose and $3 \mathrm{mgC} / \mathrm{L}$ of humic acid.

The results from these experiments showed that, humic acid fouling was higher and measurable compared to cellulose fouling. Humic acid was found to strongly absorb onto the membrane surface or within membrane pores and caused a significant increase in fouling over time. The use of support media was also very effective in lowering the degree of fouling caused by humic acid which was also considered as an indicator of the significant role of support media on controlling membrane fouling. In contrast, membrane fouling by cellulose was found to be immediate and resulted in large decrease in TMP at the beginning of experiments and then stabilized. The cake layer formed by cellulose was thought to be easily removed by backwashing and air scouring. As a result, did not cause higher measurable fouling increase compared to humic acid.

Regardless of turbidity level, the support media did not help reduce membrane fouling in cellulose experiments compared to humic acid. This implies that, the absorption of cellulose particles on the media surface was relatively low and easily slept away from the media surface compared to humic acid.

Stepwise regression analysis was conducted to identify main and interaction effects of three parameters: fill fraction of support media organic types (humic acid and cellulose), and inorganic component (kaolin clay) measured as turbidity. Stepwise 
regression identified main effect of organic type as important factors that can have influences on the degree of fouling. The use of support media and interaction between media and organics were also found to be important specifically in those experiments with humic acid.

In terms of water quality, high TOC removal and UV absorbance reduction was achieved in all experiments. However, measuring the total amount of carbon caused by cellulose in a solution was found to be difficult due to the poor solubility of cellulose.

SEM images for both membrane units showed that in the system with media, no loss in pore integrity or damage of the membrane was found.

Overall, this study showed the influence of different natural organic source on membrane fouling in the presence or absence of support media. However, more studies on particulate matter fouling specifically cellulose fouling are required. 


\section{CHAPTER 6 - CONCLUSIONS}

\subsection{Overall Summary}

Membrane technology is being increasingly used in drinking water treatment; however, fouling is considered as one of the main aspects for continued optimization of membrane processes. Therefore, the major challenge is the control of membrane fouling and its minimization during operation. Physical cleaning processes such as backwashing and air scouring are commonly used to reduce the fouling of membranes; however, the optimization of these cleaning processes is essential for better membrane performance. While the use of various types of support media such as GAC, high density polyethylene media, and other supporting materials in water treatment have shown a great potential in terms of water impurities reduction and removal, studies on the relative effect of support media with different surface water organic and inorganic components on the degree of fouling in submerged membranes systems for drinking water treatment is limited. Thus, the influence of different organic and inorganic components on membrane fouling in the presence or absence of support media was carried out in this research study.

Two bench scale membrane filtration setups featuring ZeeWeed (ZW-1) hollow fiber membrane module were used for the research. The research study was carried out in three phases; Preliminary Study Phase, Phase A, and Phase B. The impact of different fill fractions of support media on fouling reduction and the selection of the required fill fraction was determined during Preliminary Study Phase. Phase A and Phase B Experiments made use of a $2^{3}$ factorial design of experiments for the purpose of studying 
the influence of support media on membrane fouling reduction with different surface water organic and inorganic components.

\subsection{Preliminary Phase Conclusion}

The impact of different fill fractions of support media on fouling reduction was investigated in the Preliminary Study Phase. Three different fill fractions of support media were investigated; $10 \%, 20 \%$, and $30 \%$. The support media were added to the membrane reactor and were compared to the same membrane system with no support media $(0 \%)$ in terms of fouling and water quality parameters. Each of these fill fractions was examined in triplicate for statistical analysis. Student's T-test was performed and found that, for the system tested a $10 \%$ fill fraction of support media was able to minimize TMP and resulted in less membrane fouling than the $20 \%$ and $30 \%$ fill fractions. Therefore, a fill fraction of $10 \%$ was then selected and incorporated into Phase A and Phase B experimental trials.

\subsection{Phase A Conclusion}

The influence of different organic and inorganic concentrations on membrane fouling in the presence or absence of support media was studied by performing a $2^{3}$ factorial design of experiments. Humic acid and Kaolin clay (measured as turbidity) were selected to represent the organic and inorganic matter contents and their amount were then varied in the feed solution. The main and interaction influences of support media, 
organic component (humic acid), and inorganic component (Kaolin clay) were evaluated using linear regression analysis.

Stepwise linear regression was performed to identify important main and interaction effects of parameters. In the stepwise liner regression a parameter was included when an $F$ value of less than 0.05 was obtained while a parameter was eliminated when $F$ value was greater than 0.05 . The direct effects of support media, organic concentration, and inorganic concentration were identified as important factors that have influences on the degree of fouling. Also, the interaction between support media and organic concentration was also found to be important.

The most significant key findings related to fouling with different organic and inorganic concentrations in the presence or absence of support media were as follows:

1. The degree of fouling of the membrane unit was highly influenced by the presence or absence of support media in the membrane reactor; $35 \%-50 \%$ reduction in fouling was achieved with the addition of support media.

2. Membrane fouling was found to be highly correlated to the concentration of organic and inorganic components presented in the feed solution. That is the higher the concentration of humic acid and turbidity, the higher the membrane fouling.

3. The contribution of the organic component (humic acid) on fouling was found to be more significant compared to the inorganic component (Kaolin clay). Higher fouling was found when the humic acid was highest than when the turbidity was highest. The cake layer formed by inorganic particles was thought to be easily removed during backwashing and air scouring while the organic particles can strongly absorbed onto the membrane surface. 
4. This study showed that, the use of support media was found to be effective in enhancing membrane productivity and reducing the cleaning time compared to the system with no media. $98 \%$ of the required flux was recovered in the membrane system where the support media was used after cleaning with sodium hypochlorite, while $94 \%$ recovery was achieved in the system that was operated with no support media.

\subsection{Phase B Conclusion}

A second $2^{3}$ factorial design of experiments was performed during Phase B study. Membrane fouling with two different natural water organic sources; $3 \mathrm{mgC} / \mathrm{L}$ of cellulose and $3 \mathrm{mgC} / \mathrm{L}$ of humic acid in the presence or absence of support media was investigated during this phase. Kaolin clay (measures as turbidity) was also selected to represent the inorganic component in the feed solution. The main and interaction influences of support media, organic types (humic acid and Cellulose), and inorganic component (Kaolin clay) were identified using linear regression analysis.

Stepwise linear regression, with probability of $F$ value of 0.05 for addition and $F$ value of 0.1 for deletion, was performed to estimate important main and interaction effects of parameters. The main effect of organic type was identified as important factor that can have influences on the degree of fouling. The use of support media was also found to be important specifically in humic acid experiments. 
The most significant key findings related to fouling with different natural surface water organic sources in the presence or absence of support media were as follows:

1. Cellulose fouling was found to be immediate than humic acid fouling. Due to the large size of cellulose particles, the cake layer formed by cellulose was thought to be easily removed by backwashing and air scouring and didn't cause an increase in fouling after an initial rapid decrease. Thus overall, cellulose caused less membrane fouling than humic acid.

2. Humic acid was found to cause an overall higher measurable fouling compared to cellulose. Humic acid was found to be strongly absorbed onto the membrane surface or within membrane pores and caused a significant increase in fouling over time.

3. This study showed that the support media was found to have different behavior with different organic compounds. The support media was very effective in lowering the degree of fouling caused by humic acid compared to cellulose. It is hypothesized that humic acid particles can absorb very strongly onto the media surface whereas cellulose absorption was relatively low and was easily slept away from the media surface.

4. TOC removal and UV absorbance reduction was achieved with or without support media. However, due to the poor solubility of cellulose, it was suggested that more studies on particulate matter fouling are required.

5. SEM images of the membrane with support media showed that no damage or defects caused by the support media to the membrane surface after operation although there were some striations on the membrane surface caused by the support media. However, there was no obvious damage to the membrane integrity. However, further tests on membrane integrity are required in future research. 


\subsection{Significance of results for full scale issues}

Based on the experimental work from bench-scale membrane filtration, the following significance of results for full scale issues is made:

- The use of support media to reduce membrane fouling could be a good alternative to the application of very high air flow and backwash duration in submerged membrane systems. This would help to reduce the cost and the energy required to operate the process.

- The use of support media could be very beneficial in enhancing membrane flux and reducing the time required for chemical cleaning.

- The addition of support media should be considered for successful and longer membrane operation.

\subsection{Future Studies}

The main goal of this study was to investigate the influence of support media on membrane fouling reduction in submerged membrane reactor used to filter different organic and inorganic matter content. The results from this study showed that with low aeration rate and backwash duration and relaxation interval and duration, the degree of fouling can be controlled by the addition of support media into the membrane reactor. Therefore, the following studies are recommended for further studies:

- Identifying the required fill fraction of support media to add based on different parameters such as the reactor volume, the media surface area, etc. should be considered.

- Various types and sizes of support media should be examined for better membrane performance and better fouling reduction. 
- The ability of support media in minimizing fouling with different type of foulants and different type of water should be studied.

- The experiments performed in this study examined the impact of support media on fouling reduction in 5 day long experiments. Therefore, the effectiveness of the support media on fouling reduction in long term operation tests is required for further evaluation. 


\section{References}

1. Ang, W., Lee, S., Elimelech, M., 2006. Chemical and physical aspects of cleaning of organic-fouled reverse osmosis membranes. Journal of Membrane Science, 272 (2006) 198-210

2. Basu, O. D., Huck, P. M., 2005. Impact of support media in an integrated biofilter submerged membrane system. Water Research, 39, (2005) 4220-4228

3. Bellona, C., J.E. Drewes, P. Xu, G. Amy, 2004. Factors affecting the rejection of organic solutes during NF/RO treatment - a literature review. Wat. Res. 38, 27952809

4. Buffle, J., G.G. Leppard, 1995. Characterization of aquatic colloids and macromolecules. Structure and behavior of colloidal material. Environ. Sci. Technol. 29(9), 2169-2175

5. Carroll, T., King, S., Gary, S.R., Bolto, B.A., Booker, N.A., 2000. The fouling of microfiltration membranes by NOM after coagulation treatment. Water research, 34 (2000) 2861-2868

6. Chiemchaisri, C., Passananon, S., Ngo, H.H., Vigneswaran, S., 2008. Enhanced natural organic matter removal in floating media filter coupled with microfiltration membrane for river water treatment. Desalination, 234 (2008) $335-343$

7. Craze, G., Anselmeb, C., Mallevialleb, J., 1993. Effect of adsorption of organic matter on fouling of ultrafiltration membranes. Journal of Membrane Science, 84 (1993) $61-77$

8. De Suza, N., Master's thesis 2012. An investigation of physical cleaning operations for fouling attenuation of hollow fiber membranes in drinking water treatment

9. Domanya, Z., Galambosb, I., Vataib, G., Bekassy-Molnarb, E., 2002. Humic substances removal from drinking water by membrane filtration. Desalination, 145 (2002) 333-337

10. Drews, A., 2010. Membrane fouling in membrane bioreactors-Characterisation, contradictions, cause and cures. Journal of Membrane Science, 363 (2010) 1-28

11. Edzwald, J.K. (1993) Coagulation in drinking water treatment: particles, organics, and coagulants, Water Science and Technology, 27(11), pp. 21-3 
12. Freeman, S., R. Davis, S. Veerapaneni, J. Pressdee, 2006. Integrating lowpressure membranes into water treatment plants. $J A W W A$. 98(12), 26-30

13. Gabelicha, C., Yuna, T., M. Coffey, B., SuEetb, I.H., 2002. Effects of aluminum sulfate and ferric chloride coagulant residuals on polyamide membrane performance. Desalination, 150 (2002) 15-30

14. Gao, W., Liang, H., Ma, J., Han, M., Chen, Z., Han, Z., Li, G., 2011. Membrane fouling control in ultrafiltration technology for drinking water production: a review. Desalination, 272 (2011) 1-8

15. Heng, L., Yanling, Y., Weijia, G., Xing, L., Guibai, L., 2008. Effect of pretreatment by permanganate/chlorine on algae fouling control for ultrafiltration (UF) membrane system. Desalination, 222 (2008) 74-80

16. Hilal, N., Oluwaseun, O., J. Miles, N., Nigmatullin, R., 2005. Methods Employed for Control of Fouling in MF and UF Membranes: A Comprehensive Review. Separation Science and Technology, 40 (2005) 1957-2005

17. Hiroshi Yamamura, Katsuki Kimura, Yoshimasa Watanabe, 2007. Mechanism involve in the evolution of physically irreversible fouling in microfiltration and ultrafiltration membranes used for drinking water treatment, Environ. Sci. Technol. 41 (2007) 6789-6794

18. Huang, H., K. Schwab, J.G. Jacangelo, 2009. Pretreatment for low pressure membranes in water treatment: A review. Environ. Sci. Technol. 43(9), 30113019

19. Huang, H., Lee, N., Young, T., Gary, A., Lozier, J., Jacangelo, J., 2007. Natural organic matter fouling of low-pressure, hollow-fiber membranes: Effects of NOM source and hydrodynamic conditions. Water Research, 41 (2007) 3823 - 3832

20. Jermann, D., Pronk, W., Boller, M., 2008. Mutual influences between natural organic matter and inorganic particles and their combined effect on ultrafiltration membrane fouling. Environ. Sci. Technol., 42 (2008) 9129-9136

21. Jermann, D., Pronk,, W., Meylan, S., Boller, M., 2007. Interplay of different NOM fouling mechanisms during ultrafiltration for drinking water production. Water research, 41 (2007) 1713-1722

22. Johir, M.A.H., Aryal, R., Vigneswaran, S., Kandasamy, J., Grasmick, A., 2011. Influence of supporting media in suspension on membrane fouling reduction in submerged membrane bioreactor (SMBR). Journal of Membrane Science, 374 (2011) 121-128 
23. Jones, K.L., O'Melia, C.R., 2000. Protein and humic acid adsorption onto hydrophilic membrane surfaces: effects of $\mathrm{pH}$ and ionic strength. Journal of Membrane Science, 165 (2000) 31-46

24. Kerry J. Howe, Mark M. Clark, Fouling of microfiltration and ultrafiltration membranes by natural waters, Environ. Sci. Technol. 36 (2002) 3571-3576

25. Kim, K., Chen, V., G. Fane, A., 1993. Ultrafiltration of colloidal silver particles: flux, rejection, and fouling. Journal of colloid and interface science, 155 (1993) $347-359$

26. Koo, C., Mohammad, A., Suja, F., Talib, M., 2012. Review of the effect of selected physicochemical factors on membrane fouling propensity based on fouling indices. Desalination, 287 (2012) 167-177

27. Korbutowicz, M., Nowak, K., Winnicki, T., 1999. Analysis of membrane fouling in the treatment of water solutions containing humic acids and mineral salts. Desalination, 126 (1999) 179-185

28. Kulovaara, M., Metsanuuronen, S., Nystriim, M., 1999. Effects of aquatic humic substances on a hydrophobic ultrafiltration membrane. Chemosphere, 38 (1999) 485-3496

29. Lee, N., Amy, G., Croue, J. P., Buisson, H., 2004. Identification and understanding of fouling in low-pressure membrane (MF/UF) filtration by natural organic matter (NOM). Water Research, 38 (2004) 4511-4523

30. Lesjean, B., Rosenberger, S., Schrotter, J., 2004. Membrane aided biological wastewater treatment - An overview of applied systems. Membrane Technol., 8,5

31. Li, N., Fane, A., Ho, W., 2008. Advanced membrane technology and applications; Wiley \& Sons; Hoboken, New Jersey

32. Lowe, J., Hossain., M., 2008. Application of ultrafiltration membranes for removal of humic acid from drinking water. Desalination, 218 (2008) 343-354

33. Madaeni, S., Sharifnia, S., 2000. Chemical Cleaning of Ultrafiltration Membranes Fouled by Whey. Iranian polymer journal, 9,3,20

34. Marel, P.V.D, Zwijnenburg, A., Kemperman, A., Wessling, M., Temmink, H., Meer, W.V.D., 2010. Influence of membrane properties on fouling in submerged membrane bioreactors. Journal of Membrane Science, 348 (2010) 66-74

35. Metcalf and Eddy, 2003. Wastewater engineering treatment and reuse, Fourth edition, McGraw-Hill, NY, USA 
36. Mosqueda-Jimenez, D., Huck, P. M., Basu, O.D., 2008. Fouling characteristics of an ultrafiltration membrane used in drinking water treatment. Desalination, 230 (2008) 79-91

37. Mozia, S., Tomaszewska, M., 2004. Treatment of surface water using hybrid processes adsorption on PAC and ultrafiltration. Desalination, 162 (2004) 23-31

38. MWH, Montgomery Watson Harza, 2005. Water Treatment: Principles and Design, 2nd Edition,Crittenden, J.C., Trussell, R.R., Hand, D.W., Howe, K.J. and Tchobanoglous, G. eds, Wiley, New Jersey, USA

39. Nada, D., Tung, K., Li, Y., Lin, N., Chuang, C., 2010. Effect of pH on membrane morphology, fouling potential, and filtration performance of nanofiltration membrane for water softening. Journal of Membrane Science, 349 (2010) 411420

40. Neter, J., Wasseman, W., Kutner, M., 1990. Applied linear statistical models. $3^{\text {rd }}$ edition. Boston, MA 1990

41. Nghiem, L., Schafer, A., Oschmann, N., 2006. Fouling in greywater recycling by direct ultrafiltration. Desalination 187 (2006) 283-290

42. Peiris, R., Budman, H., Moresoli, C., Legge, R., 2010. Understanding fouling behaviour of ultrafiltration membrane processes and natural water using principal component analysis of fluorescence excitation-emission matrices

43. Peng, W., C. Escobar, I., B. White, D., 2004. Effects of water chemistries and properties of membrane on the performance and fouling-a model development study. Journal of Membrane Science, 238 (2004) 33-46

44. Porcelli, N., Judd, S., 2010. Chemical cleaning of potable water membranes: A review. Separation and Purification Technology, 71 (2010) 137-143

45. Pradhan, M., Vigneswaran, S., Kandasamy, J., Ben Aim, R., 2012. Combined effect of air and mechanical scouring of membranes for fouling reduction in submerged membrane reactor. Desalination, 288 (2012) 58-65

46. Psoch, C., Schiewer, S., 2006. Anti-fouling application of air sparging and backflushing for MBR. Journal of Membrane Science, 283 (2006) 273-280

47. Qaisran, T.M., Samhaber, W.M., 2011. Impact of gas bubbling and backflushing on fouling control and membrane cleaning. Desalination, 266 (2011) 154-161

48. Shirazi, S., Lin, C., Chen, D., 2010. Inorganic fouling of pressure-driven membrane processes , a critical review. Desalination, 250 (2010) 236-248 
49. Siembida, B., Cornel, P., Krause, S., Zimmermann, B., 2010. Effect of mechanical cleaning with granular material on the permeability of submerged membranes in the MBR process. Water research, 44 (2010) 4037- 4046

50. Strathmann, H., 2011. Introduction to membrane science and technology, Wiley$\mathrm{VCH}$, Boschstr, Germany

51. Sutzkover-Gutman, I., Hasson, D., Semiat, R., 2010. Humic substances fouling in ultrafiltration processes. Desalination, 261 (2010) 218-231

52. V. Lahoussine-Turcaud, M.R. Wiesner and J.-Y. Bottero, Fouling in tangentialflow ultrafiltration: the effect of colloids size and coagulation pretreatment. J. Membr. Sci.,52 (1990) 173

53. Varbanets, M., Margot, J., Traber, J., Pronk, W., 2011. Mechanisms of membrane fouling during ultra-low pressure ultrafiltration. Journal of Membrane Science, 377 (2011) 42-53

54. Wang, L., 2008. Effects of operational conditions on ultrafiltration membrane fouling. Desalination, 229 (2008) 181-191

55. Water environment federation (WEF), 2011. Membrane bioreactors, No.36, McGraw-Hill, NY, USA

56. Xiao, P., Xiao, F., Wang, D., Qin, T., Ping He, S., 2012. Investigation of organic foulants behavior on hollow-fiber UF membranes in a drinking water treatment plant. Separation and Purification Technology, 95 (2012) 109-117

57. Yuan, W., Zydney, A., 2000. Humic acid fouling during ultrafiltration. Environ. Sci. Technol. 34, 5043-5050

58. Zularisam, A.W., Ahmad, A., Sakinah, M., Ismail, A.F., Matsuura, T., 2011. Role of natural organic matter (NOM), colloidal particles, and solution chemistry on ultrafiltration performance. Separation and Purification Technology, 78 (2011) 189-20

59. Zularisam, A.W., Ismail, A.F., Salim, M.R., Sakinah, M., Ozaki, H., 2007. The effects of natural organic matter (NOM) fractions on fouling characteristics and flux recovery of ultrafiltration membranes. Desalination, 212 (2007) 191-208

60. Zularisam, A.W., Ismail, A.F., Salim, R., 2006. Behaviours of natural organic matter in membrane filtration for surface water treatment-a review. Desalination, 194 (2006) 211-231 
APPENDICES 
APPENDIX (A) - Membrane Specifications

\begin{tabular}{|c|c|}
\hline Membrane Material & Polyvinylidene Fluoride (PVDF) \\
\hline Effective Surface Area & $0.047 \mathrm{~m}^{2}$ \\
\hline Nominal Pore Size & $0.04 \mu \mathrm{m}$ \\
\hline Permeate Flow & $5-30 \mathrm{~mL} / \mathrm{min}$ \\
\hline Air Flow Range & $5-30 \mathrm{LPM}$ \\
\hline pH Range & $5-9$ \\
\hline Minimum Membrane Cleaning & $\begin{array}{c}200 \text { ppm of Sodium hypochlorite for } \\
\text { a minimum of } 5 \text { hours }\end{array}$ \\
& $\begin{array}{c}\text { Minimum of } 5 \text { hours Citric Acid } \\
\text { soaking time }\end{array}$ \\
\hline
\end{tabular}


APPENDIX (B) - Feed line, permeate line and air flow line materials

\begin{tabular}{|l|}
\hline \multicolumn{1}{|c|}{ Feed Flow Line Materials } \\
\hline 50 L Nalgene Heavy-Duty Cylindrical Tank \\
\hline Masterflex Peristaltic Pump (model No. 7024-20) \\
\hline Cole Parmer Tubing ( 1/4" D x 3/8" OD) \\
\hline 3 L Glass Cylindrical Membrane Reactor Tank \\
\hline
\end{tabular}

\begin{tabular}{|l|}
\hline \multicolumn{1}{|c|}{ Permeate Flow Line Materials } \\
\hline Membrane Module (ZeeWeed ZW-1) \\
\hline Masterflex L/S Digital Peristaltic Pump - Pump Head 77800-62 \\
\hline Cole Parmer Tubing ( 1/4" ID x 3/8" OD) \\
\hline Cole Parmer Rigid Tubing ( 1/4" ID x 3/8" OD) \\
\hline Cole Parmer Pressure Transducer \\
\hline 1 L Plastic Backwash Tank \\
\hline
\end{tabular}

\begin{tabular}{|l|}
\hline \multicolumn{1}{|c|}{ Air Flow Line Materials } \\
\hline Electronic Flow meter \\
\hline Flow Modulator \\
\hline Whatman HEPA- VENT \\
\hline Cole Parmer Tubing ( $1 / 4^{\prime \prime}$ ID x 3/8" OD) \\
\hline Plastic Valve \\
\hline Flexible Air Curtain $(20 \mathrm{~cm})$ \\
\hline
\end{tabular}


APPENDIX (C) - Humic acid and Cellulose calibration curves

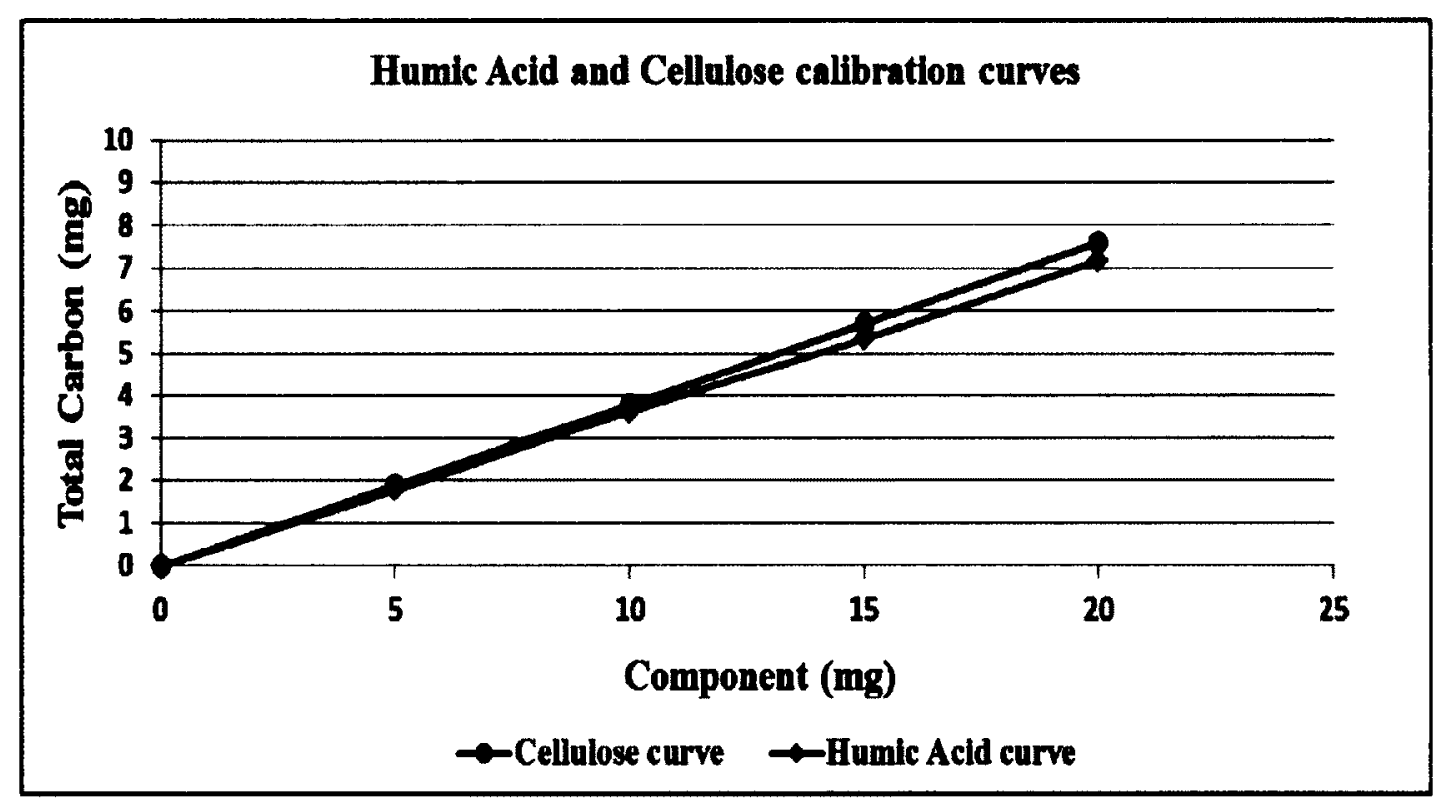


APPENDIX (D) - Support Media Characteristics (Source: Jaeger Environmental products)
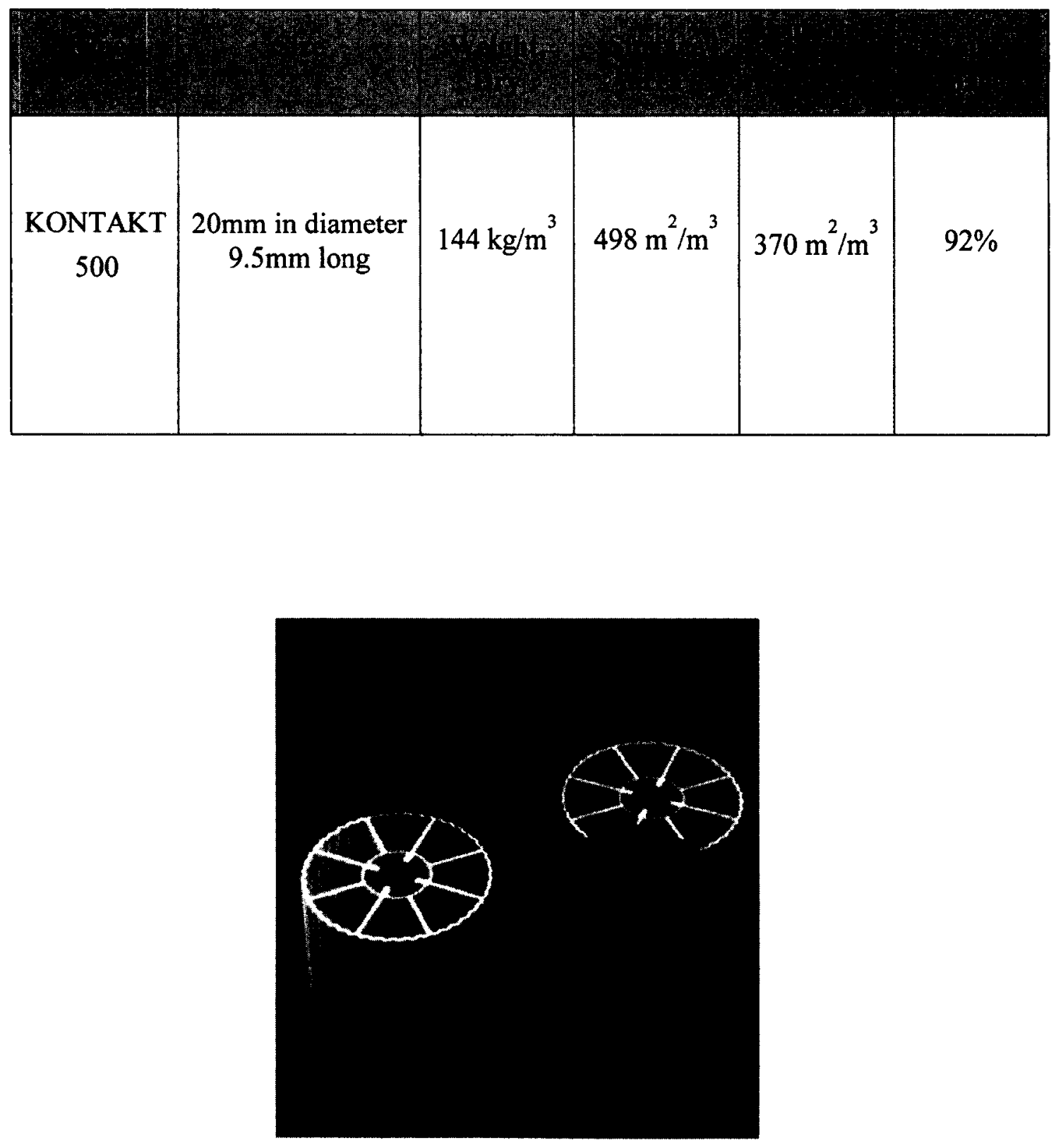


\begin{abstract}
APPENDIX (E) - Macro filter code used in data analysis (created by Kelly Alder and Nigel De Souza)
\end{abstract}

Sub BWRfilt()

I

' BWRfilt Macro

' Authors: Kelly Alder (B.Eng, M.A.Sc) and Nigel De Souza (B.Eng, M.A.Sc)

' Keyboard Shortcut: Ctrl+n

,

'Create a variable to hold the column id

Dim sColumn As String

Dim sColumnHeader As String

'Create a new variable to hold the cell value

Dim nValue As Double

'Create a new variable to hold percent difference

Dim nPercentDiff As Double

'Create a new variable to hold previos value

Dim nPrevValue As Double

'Create a string representation for the Column Id

sColumn $=\operatorname{Chr}($ ActiveCell.Column +64$)+" 1 "$ 
' Go to the top of the selected column

Range(sColumn).Select

' Get the text of the column header

sColumnHeader $=$ ActiveCell. Text

'Trim all leading and trailing whitespaces

sColumnHeader $=$ Trim $($ sColumnHeader $)$

' Make the Column HeEader uppercase

' for case-insensitive comparison

sColumnHeader $=$ UCase $($ SColumnHeader $)$

' Make sure we're looking at a Pressure Reasing Column

If sColumnHeader $=$ "PRESSURE_READING" Then

' Move the selected cell one row down ActiveCell.Offset( 2,0$)$.Select

' Check that we haven't reached the end by checking that it's not blank

While (ActiveCell.Text $\diamond "$ ")

' Get the cell value and previous cell value

nValue $=$ ActiveCell. Value 
' Check to see if a row is positive

If $n$ Value $>0$ Then

' Delete the positive row

Rows(ActiveCell.Row).EntireRow.Delete

Else

' Get the value of the previous cell

nPrevValue $=$ ActiveCell.Offset $(-1,0)$. Value

'Check to see if the cell value is greater than

' the previous value

If $n$ Value $>$ nPrevValue Then

'Calculate percent difference

$\mathrm{nPercentDiff}=(\mathrm{nPrevValue}-\mathrm{nValue}) / \mathrm{nPrevValue} * 100$

' Check to see if percent difference is larger that our tolerance

If $n$ PercentDiff $>5$ Then

' Delete this row, we dont want it

Rows(ActiveCell.Row).EntireRow.Delete

Else 
' Move the selected cell one row down

ActiveCell.Offset( $(1,0)$.Select

End If

Else

' Move the selected cell one row down

ActiveCell.Offset( $(1,0)$.Select

End If

End If

Wend

Else

' Display Warning

MsgBox ("Macro Must Be Run On a PRESSURE_READING Column!")

End If

End Sub 
APPENDIX (F) - Water quality assessment for preliminary study phase experiments

\begin{tabular}{|c|c|c|}
\hline \multicolumn{3}{|c|}{ No support media $(0 \%)$ fill fraction of support media } \\
\hline Sample name & Turbidity (NTU) & $\mathrm{pH}$ \\
\hline \multicolumn{3}{|c|}{ Experiment \#1 } \\
\hline Reactor (initial) & 33.86 & 7.72 \\
\hline Reactor (24 hr.) & 60.34 & 7.68 \\
\hline Reactor (48 hr.) & 75.21 & 7.65 \\
\hline Reactor (72 hr.) & 68.22 & 7.86 \\
\hline Reactor ( $96 \mathrm{hr})$. & 62.88 & 7.91 \\
\hline Reactor (120 hr.) & 61.04 & 7.71 \\
\hline \multicolumn{3}{|c|}{ Experiment \#2 } \\
\hline Reactor (initial) & 31.03 & 7.76 \\
\hline Reactor (24 hr.) & 82.50 & 7.75 \\
\hline Reactor (48 hr.) & 88.12 & 7.77 \\
\hline Reactor (72 hr.) & 73.34 & 7.73 \\
\hline Reactor (96 hr.) & 72.44 & 7.62 \\
\hline Reactor $(120 \mathrm{hr})$. & 70.07 & 7.71 \\
\hline \multicolumn{3}{|c|}{ Experiment \#3 } \\
\hline Reactor (initial) & 30.83 & 7.70 \\
\hline Reactor (24 hr.) & 48.41 & 7.75 \\
\hline Reactor (48 hr.) & 74.53 & 7.81 \\
\hline Reactor (72 hr.) & 81.06 & 7.74 \\
\hline Reactor (96 hr.) & 76.22 & 7.62 \\
\hline Reactor (120 hr.) & 73.35 & 7.66 \\
\hline
\end{tabular}




\begin{tabular}{|l|c|l|}
\hline \multicolumn{3}{|c|}{ 10\% fill fraction of support media } \\
\hline \multicolumn{3}{|c|}{ Experiment \#l } \\
\hline Sample name & Turbidity (NTU) & $\mathrm{pH}$ \\
\hline Reactor (initial) & 31.85 & 7.69 \\
\hline Reactor (24 hr.) & 56.58 & 7.71 \\
\hline Reactor (48 hr.) & 71.09 & 7.65 \\
\hline Reactor (72 hr.) & 64.77 & 7.89 \\
\hline Reactor (96 hr.) & 60.92 & 7.92 \\
\hline Reactor (120 hr.) & 60.21 & 7.72 \\
\hline \multicolumn{3}{|c|}{ Experiment \#2 } \\
\hline Reactor (initial) & 29.84 & 7.73 \\
\hline Reactor (24 hr.) & 45.05 & 7.82 \\
\hline Reactor (48 hr.) & 66.84 & 7.88 \\
\hline Reactor (72 hr.) & 74.67 & 7.64 \\
\hline Reactor (96 hr.) & 68.55 & 7.61 \\
\hline Reactor (120 hr.) & 64.31 & 7.70 \\
\hline & Experiment \#3 & 7.65 \\
\hline Reactor (initial) & 33.04 & 7.68 \\
\hline Reactor (24 hr.) & 51.63 & 7.82 \\
\hline Reactor (48 hr.) & 82.34 & 7.74 \\
\hline Reactor (72 hr.) & 77.21 & 7.72 \\
\hline Reactor (96 hr.) & 72.42 & \\
\hline Reactor (120 hr.) & 67.94 & \\
\hline & & \\
\hline
\end{tabular}




\begin{tabular}{|l|c|l|}
\hline \multicolumn{3}{|c|}{ 20\% fill fraction of support media } \\
\hline \multicolumn{3}{|c|}{ Experiment \#1 } \\
\hline Sample name & Turbidity (NTU) & $\mathrm{pH}$ \\
\hline Reactor (initial) & 29.41 & 7.73 \\
\hline Reactor (24 hr.) & 85.46 & 7.89 \\
\hline Reactor (48 hr.) & 70.92 & 7.73 \\
\hline Reactor (72 hr.) & 68.07 & 7.71 \\
\hline Reactor (96 hr.) & 66.31 & 7.75 \\
\hline Reactor (120 hr.) & 61.88 & 7.77 \\
\hline \multicolumn{3}{|c|}{ Experiment \#2 } \\
\hline Reactor (initial) & 35.62 & 7.84 \\
\hline Reactor (24 hr.) & 54.15 & 7.51 \\
\hline Reactor (48 hr.) & 67.43 & 7.62 \\
\hline Reactor (72 hr.) & 78.22 & 7.68 \\
\hline Reactor (96 hr.) & 65.74 & 7.66 \\
\hline Reactor (120 hr.) & 60.55 & 7.71 \\
\hline & Experiment \#3 & 7.65 \\
\hline Reactor (initial) & 28.21 & 7.72 \\
\hline Reactor (24 hr.) & 42.44 & 7.74 \\
\hline Reactor (48 hr.) & 78.53 & 7.91 \\
\hline Reactor (72 hr.) & 71.12 & 7.68 \\
\hline Reactor (96 hr.) & 73.69 & \\
\hline Reactor (120 hr.) & 68.38 & \\
\hline
\end{tabular}




\begin{tabular}{|c|c|c|}
\hline \multicolumn{3}{|c|}{$30 \%$ fill fraction of support media } \\
\hline Sample name & Turbidity (NTU) & $\mathrm{pH}$ \\
\hline \multicolumn{3}{|c|}{ Experiment \#1 } \\
\hline Reactor (initial) & 31.29 & 7.74 \\
\hline Reactor (24 hr.) & 54.50 & 7.94 \\
\hline Reactor (48 hr.) & 60.76 & 7.77 \\
\hline Reactor (72 hr.) & 72.79 & 7.78 \\
\hline Reactor (96 hr.) & 71.88 & 7.72 \\
\hline Reactor $(120 \mathrm{hr})$. & 65.09 & 7.74 \\
\hline \multicolumn{3}{|c|}{ Experiment \#2 } \\
\hline Reactor (initial) & 30.82 & 7.66 \\
\hline Reactor (24 hr.) & 55.77 & 7.74 \\
\hline Reactor $(48 \mathrm{hr})$. & 78.34 & 7.72 \\
\hline Reactor (72 hr.) & 76.81 & 7.81 \\
\hline Reactor (96 hr.) & 63.44 & 7.78 \\
\hline Reactor $(120 \mathrm{hr})$. & 62.52 & 7.70 \\
\hline \multicolumn{3}{|c|}{ Experiment \#3 } \\
\hline Reactor (initial) & 33.45 & 7.88 \\
\hline Reactor (24 hr.) & 57.82 & 7.76 \\
\hline Reactor (48 hr.) & 82.56 & 7.74 \\
\hline Reactor (72 hr.) & 85.22 & 7.78 \\
\hline Reactor $(96 \mathrm{hr})$. & 74.48 & 7.65 \\
\hline Reactor $(120 \mathrm{hr})$. & 68.66 & 7.71 \\
\hline
\end{tabular}




\begin{tabular}{|l|c|l|}
\hline \multicolumn{3}{|c|}{ 0\% fill fraction of support media } \\
\hline \multicolumn{3}{|c|}{ Experiment \#1 } \\
\hline Sample name & Turbidity (NTU) & pH \\
\hline Feed (initial) & 28.46 & 7.77 \\
\hline Feed (24 hr.) & 24.33 & 7.71 \\
\hline Feed (48 hr.) & 25.31 & 7.60 \\
\hline Feed (72 hr.) & 22.12 & 7.72 \\
\hline Feed (96 hr.) & 25.66 & 7.66 \\
\hline Feed (120 hr.) & 24.85 & 7.68 \\
\hline \multicolumn{3}{|c|}{ Experiment \#2 } \\
\hline Feed (initial) & 30.45 & 7.89 \\
\hline Feed (24 hr.) & 28.77 & 7.88 \\
\hline Feed (48 hr.) & 29.05 & 7.87 \\
\hline Feed (72 hr.) & 26.78 & 7.64 \\
\hline Feed (96 hr.) & 23.56 & 7.75 \\
\hline Feed (120 hr.) & 19.88 & 7.76 \\
\hline & Experiment \#3 & 7.72 \\
\hline Feed (initial) & 32.15 & 7.75 \\
\hline Feed (24 hr.) & 28.21 & 7.74 \\
\hline Feed (48 hr.) & 25.78 & 7.76 \\
\hline Feed (72 hr.) & 22.44 & 79.76 \\
\hline Feed (96 hr.) & 18.52 & \\
\hline Feed (120 hr.) & & \\
\hline
\end{tabular}




\begin{tabular}{|l|c|l|}
\hline \multicolumn{3}{|c|}{ 10\% fill fraction of support media } \\
\hline \multicolumn{3}{|c|}{ Experiment \#I } \\
\hline Sample name & Turbidity (NTU) & pH \\
\hline Feed (initial) & 30.86 & 7.88 \\
\hline Feed (24 hr.) & 29.53 & 7.91 \\
\hline Feed (48 hr.) & 24.77 & 7.89 \\
\hline Feed (72 hr.) & 25.05 & 7.82 \\
\hline Feed (96 hr.) & 22.18 & 7.68 \\
\hline Feed (120 hr.) & 19.68 & 7.70 \\
\hline \multicolumn{3}{|c|}{ Experiment \#2 } \\
\hline Feed (initial) & 28.55 & 7.86 \\
\hline Feed (24 hr.) & 28.31 & 7.74 \\
\hline Feed (48 hr.) & 25.56 & 7.89 \\
\hline Feed (72 hr.) & 21.78 & 7.73 \\
\hline Feed (96 hr.) & 19.35 & 7.77 \\
\hline Feed (120 hr.) & 18.48 & 7.78 \\
\hline & 20.45 & 7.69 \\
\hline Feed (initial) & 19.61 & 7.81 \\
\hline Feed (24 hr.) & 26.34 & 7.79 \\
\hline Feed (48 hr.) & 25.21 & 7.77 \\
\hline Feed (72 hr.) & 20.66 & 78 \\
\hline Feed (96 hr.) & Experiment \#3 & \\
\hline Feed (120 hr.) & 27.81 & \\
\hline
\end{tabular}




\begin{tabular}{|c|c|c|}
\hline \multicolumn{3}{|c|}{$20 \%$ fill fraction of support media } \\
\hline Sample name & Turbidity (NTU) & $\overline{\mathrm{pH}}$ \\
\hline \multicolumn{3}{|c|}{ Experiment \#1 } \\
\hline Feed (initial) & 29.25 & 7.64 \\
\hline Feed $(24 \mathrm{hr})$. & 26.77 & 7.82 \\
\hline Feed (48 hr.) & 25.81 & 7.78 \\
\hline Feed (72 hr.) & 23.78 & 7.63 \\
\hline Feed $(96 \mathrm{hr})$. & 20.05 & 7.69 \\
\hline Feed (120 hr.) & 18.67 & 7.74 \\
\hline \multicolumn{3}{|c|}{ Experiment \#2 } \\
\hline Feed (initial) & 31.26 & 7.85 \\
\hline Feed (24 hr.) & 27.64 & 7.88 \\
\hline Feed (48 hr.) & 24.88 & 7.79 \\
\hline Feed (72 hr.) & 22.75 & 7.74 \\
\hline Feed $(96 \mathrm{hr})$. & 20.16 & 7.77 \\
\hline Feed $(120 \mathrm{hr})$. & 19.82 & 7.76 \\
\hline \multicolumn{3}{|c|}{ Experiment \#3 } \\
\hline Feed (initial) & 26.88 & 7.75 \\
\hline Feed (24 hr.) & 28.51 & 7.78 \\
\hline Feed (48 hr.) & 24.78 & 7.63 \\
\hline Feed (72 hr.) & 24.42 & 7.66 \\
\hline Feed (96 hr.) & 21.68 & 7.72 \\
\hline Feed (120 hr.) & 20.71 & 7.70 \\
\hline
\end{tabular}




\begin{tabular}{|c|c|c|}
\hline \multicolumn{3}{|c|}{$30 \%$ fill fraction of support media } \\
\hline Sample name & Turbidity (NTU) & $\overline{\mathrm{pH}}$ \\
\hline \multicolumn{3}{|c|}{ Experiment \#1 } \\
\hline Feed (initial) & 28.88 & 7.65 \\
\hline Feed (24 hr.) & 26.41 & 7.81 \\
\hline Feed (48 hr.) & 25.72 & 7.84 \\
\hline Feed $(72 \mathrm{hr})$. & 22.06 & 7.79 \\
\hline Feed (96 hr.) & 20.28 & 7.76 \\
\hline Feed $(120 \mathrm{hr})$. & 19.44 & 7.68 \\
\hline \multicolumn{3}{|c|}{ Experiment \#2 } \\
\hline $\begin{array}{l}\text { Feed (initial) } \\
\end{array}$ & 30.02 & 7.89 \\
\hline Feed (24 hr.) & 29.77 & 7.85 \\
\hline Feed (48 hr.) & 26.84 & 7.90 \\
\hline Feed (72 hr.) & 24.63 & 7.78 \\
\hline Feed $(96$ hr.) & 22.95 & 7.73 \\
\hline Feed $(120 \mathrm{hr})$. & 21.45 & 7.75 \\
\hline \multicolumn{3}{|c|}{ Experiment \#3 } \\
\hline Feed (initial) & 27.66 & 7.71 \\
\hline Feed (24 hr.) & 26.42 & 7.76 \\
\hline Feed (48 hr.) & 23.82 & 7.68 \\
\hline Feed (72 hr.) & 20.15 & 7.70 \\
\hline Feed $(96 \mathrm{hr})$. & 19.77 & 7.66 \\
\hline Feed $(120 \mathrm{hr})$. & 18.64 & 7.65 \\
\hline
\end{tabular}




\begin{tabular}{|c|c|c|c|}
\hline \multicolumn{4}{|c|}{$0 \%$ fill fraction of support media } \\
\hline Sample name & $\begin{array}{c}\text { Turbidity } \\
\text { (NTU) }\end{array}$ & $\mathrm{pH}$ & Flow $(\mathrm{mL} / \mathrm{min})$ \\
\hline \multicolumn{4}{|c|}{ Experiment \#1 } \\
\hline Permeate (initial) & 0.00 & 7.60 & 30 \\
\hline Permeate (24 hr.) & 0.03 & 7.76 & 29.5 \\
\hline Permeate (48 hr.) & 0.04 & 7.58 & 28 \\
\hline Permeate $(72 \mathrm{hr})$. & 0.01 & 7.80 & 27 \\
\hline Permeate ( $96 \mathrm{hr}$.) & 0.00 & 7.93 & 26.5 \\
\hline $\begin{array}{l}\text { Permeate (120 } \\
\text { hr.) }\end{array}$ & 0.02 & 7.91 & 26.5 \\
\hline \multicolumn{4}{|c|}{ Experiment \#2 } \\
\hline Permeate (initial) & 0.02 & 7.57 & 30 \\
\hline Permeate (24 hr.) & 0.01 & 7.67 & 30 \\
\hline Permeate (48 hr.) & 0.00 & 7.64 & 28 \\
\hline Permeate $(72 \mathrm{hr})$. & 0.01 & 7.65 & 27.5 \\
\hline Permeate ( $96 \mathrm{hr})$. & 0.03 & 7.60 & 27 \\
\hline $\begin{array}{l}\text { Permeate (120 } \\
\text { hr.) }\end{array}$ & 0.00 & 7.66 & 27 \\
\hline \multicolumn{4}{|c|}{ Experiment $\# 3$} \\
\hline Permeate (initial) & 0.00 & 7.61 & 29.5 \\
\hline Permeate $(24 \mathrm{hr})$. & 0.01 & 7.68 & 29 \\
\hline Permeate (48 hr.) & 0.01 & 7.62 & 29 \\
\hline Permeate $(72 \mathrm{hr})$. & 0.04 & 7.57 & 28.5 \\
\hline Permeate ( $96 \mathrm{hr}$.) & 0.02 & 7.64 & 28 \\
\hline $\begin{array}{l}\text { Permeate (120 } \\
\text { hr.) }\end{array}$ & 0.01 & 7.55 & 26.5 \\
\hline
\end{tabular}




\begin{tabular}{|c|c|c|c|}
\hline \multicolumn{4}{|c|}{$10 \%$ fill fraction of support media } \\
\hline Sample name & $\begin{array}{l}\text { Turbidity } \\
\text { (NTU) }\end{array}$ & $\mathrm{pH}$ & Flow $(\mathrm{mL} / \mathrm{min})$ \\
\hline \multicolumn{4}{|c|}{ Experiment \#1 } \\
\hline Permeate (initial) & 0.00 & 7.72 & 30 \\
\hline Permeate (24 hr.) & 0.05 & 7.68 & 29.5 \\
\hline Permeate (48 hr.) & 0.01 & 7.66 & 29.5 \\
\hline Permeate ( $72 \mathrm{hr})$. & 0.02 & 7.65 & 28.5 \\
\hline Permeate $(96 \mathrm{hr})$. & 0.00 & 7.74 & 28 \\
\hline $\begin{array}{l}\text { Permeate (120 } \\
\text { hr.) }\end{array}$ & 0.02 & 7.65 & 28 \\
\hline \multicolumn{4}{|c|}{ Experiment \#2 } \\
\hline Permeate (initial) & 0.02 & 7.64 & 30 \\
\hline Permeate $(24 \mathrm{hr})$. & 0.02 & 7.66 & 29 \\
\hline Permeate (48 hr.) & 0.03 & 7.62 & 28.5 \\
\hline Permeate (72 hr.) & 0.00 & 7.59 & 28.5 \\
\hline Permeate $(96 \mathrm{hr})$. & 0.04 & 7.60 & 28 \\
\hline $\begin{array}{l}\text { Permeate (120 } \\
\text { hr.) }\end{array}$ & 0.01 & 7.67 & 27.5 \\
\hline \multicolumn{4}{|c|}{ Experiment $\# 3$} \\
\hline Permeate (initial) & 0.01 & 7.78 & 30 \\
\hline Permeate $(24 \mathrm{hr}$.) & 0.02 & 7.76 & 30 \\
\hline \begin{tabular}{|l} 
Permeate ( $48 \mathrm{hr})$. \\
\end{tabular} & 0.01 & 7.77 & 30 \\
\hline Permeate $(72 \mathrm{hr})$. & 0.00 & 7.69 & 29.5 \\
\hline Permeate $(96 \mathrm{hr})$. & 0.00 & 7.71 & 29 \\
\hline $\begin{array}{l}\text { Permeate (120 } \\
\text { hr.) }\end{array}$ & 0.02 & 7.65 & 28 \\
\hline
\end{tabular}




\begin{tabular}{|c|c|c|c|}
\hline \multicolumn{4}{|c|}{$20 \%$ fill fraction of support media } \\
\hline Sample name & $\begin{array}{l}\text { Turbidity } \\
\text { (NTU) }\end{array}$ & $\mathrm{pH}$ & Flow (mL/min) \\
\hline \multicolumn{4}{|c|}{ Experiment \#1 } \\
\hline Permeate (initial) & 0.00 & 7.74 & 30 \\
\hline Permeate $(24 \mathrm{hr})$. & 0.00 & 7.61 & 30 \\
\hline Permeate $(48 \mathrm{hr})$. & 0.01 & 7.64 & 30 \\
\hline Permeate $(72 \mathrm{hr})$. & 0.02 & 7.58 & 30 \\
\hline Permeate $(96 \mathrm{hr})$. & 0.01 & 7.63 & 29 \\
\hline $\begin{array}{l}\text { Permeate (120 } \\
\mathrm{hr} \text { ) }\end{array}$ & 0.00 & 7.68 & 29 \\
\hline \multicolumn{4}{|c|}{ Experiment \#2 } \\
\hline \begin{tabular}{|l|} 
Permeate (initial) \\
\end{tabular} & 0.00 & 7.70 & 30 \\
\hline Permeate $(24 \mathrm{hr})$. & 0.00 & 7.67 & 29 \\
\hline Permeate (48 hr.) & 0.03 & 7.78 & 28.5 \\
\hline Permeate $(72 \mathrm{hr})$. & 0.01 & 7.65 & 28.5 \\
\hline Permeate $(96 \mathrm{hr})$. & 0.00 & 7.71 & 27 \\
\hline $\begin{array}{l}\text { Permeate (120 } \\
\text { hr.) }\end{array}$ & 0.01 & 7.62 & 27 \\
\hline \multicolumn{4}{|c|}{ Experiment \#3 } \\
\hline Permeate (initial) & 0.00 & 7.76 & 30 \\
\hline Permeate $(24 \mathrm{hr})$. & 0.04 & 7.80 & 29 \\
\hline \begin{tabular}{|l|} 
Permeate $(48 \mathrm{hr})$. \\
\end{tabular} & 0.01 & 7.64 & 29 \\
\hline Permeate $(72 \mathrm{hr})$. & 0.00 & 7.56 & 28 \\
\hline Permeate $(96 \mathrm{hr})$. & 0.00 & 7.62 & 27.5 \\
\hline $\begin{array}{l}\text { Permeate (120 } \\
\text { hr.) }\end{array}$ & 0.02 & 7.68 & 27.5 \\
\hline
\end{tabular}




\begin{tabular}{|c|c|c|c|}
\hline \multicolumn{4}{|c|}{$30 \%$ fill fraction of support media } \\
\hline Sample name & $\begin{array}{l}\text { Turbidity } \\
\text { (NTU) }\end{array}$ & $\mathrm{pH}$ & Flow $(\mathrm{mL} / \mathrm{min})$ \\
\hline \multicolumn{4}{|c|}{ Experiment \#1 } \\
\hline Permeate (initial) & 0.00 & 7.61 & 30 \\
\hline Permeate $(24 \mathrm{hr})$. & 0.00 & 7.70 & 29.5 \\
\hline Permeate (48 hr.) & 0.01 & 7.68 & 29.5 \\
\hline Permeate $(72 \mathrm{hr})$. & 0.00 & 7.62 & 29 \\
\hline Permeate ( $96 \mathrm{hr}$.) & 0.03 & 7.60 & 29 \\
\hline $\begin{array}{l}\text { Permeate (120 } \\
\text { hr.) }\end{array}$ & 0.01 & 7.65 & 28 \\
\hline \multicolumn{4}{|c|}{ Experiment \#2 } \\
\hline Permeate (initial) & 0.01 & 7.69 & 30 \\
\hline Permeate (24 hr.) & 0.00 & 7.62 & 29 \\
\hline Permeate (48 hr.) & 0.02 & 7.54 & 28 \\
\hline Permeate $(72 \mathrm{hr}$.) & 0.01 & 7.61 & 28 \\
\hline Permeate ( $96 \mathrm{hr})$. & 0.00 & 7.68 & 27 \\
\hline $\begin{array}{l}\text { Permeate (120 } \\
\text { hr.) }\end{array}$ & 0.02 & 7.66 & 26 \\
\hline \multicolumn{4}{|c|}{ Experiment $\# 3$} \\
\hline Permeate (initial) & 0.01 & 7.75 & 30 \\
\hline Permeate (24 hr.) & 0.03 & 7.69 & 28.5 \\
\hline Permeate (48 hr.) & 0.00 & 7.72 & 28 \\
\hline Permeate $(72 \mathrm{hr})$. & 0.00 & 7.64 & 28 \\
\hline Permeate $(96 \mathrm{hr})$. & 0.01 & 7.68 & 28 \\
\hline $\begin{array}{l}\text { Permeate (120 } \\
\mathrm{hr} .)\end{array}$ & 0.02 & 7.71 & 27.5 \\
\hline
\end{tabular}


APPENDIX (G) - Phase A study: replicates experiments

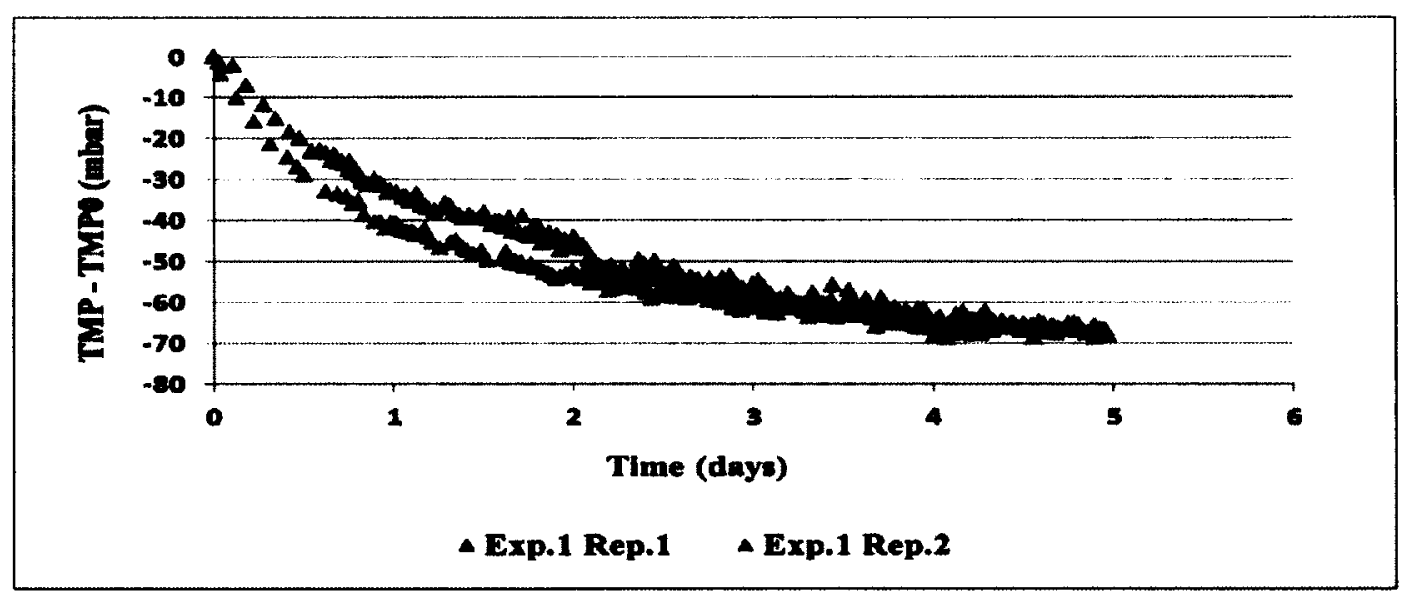

Experiment 1 Replicates

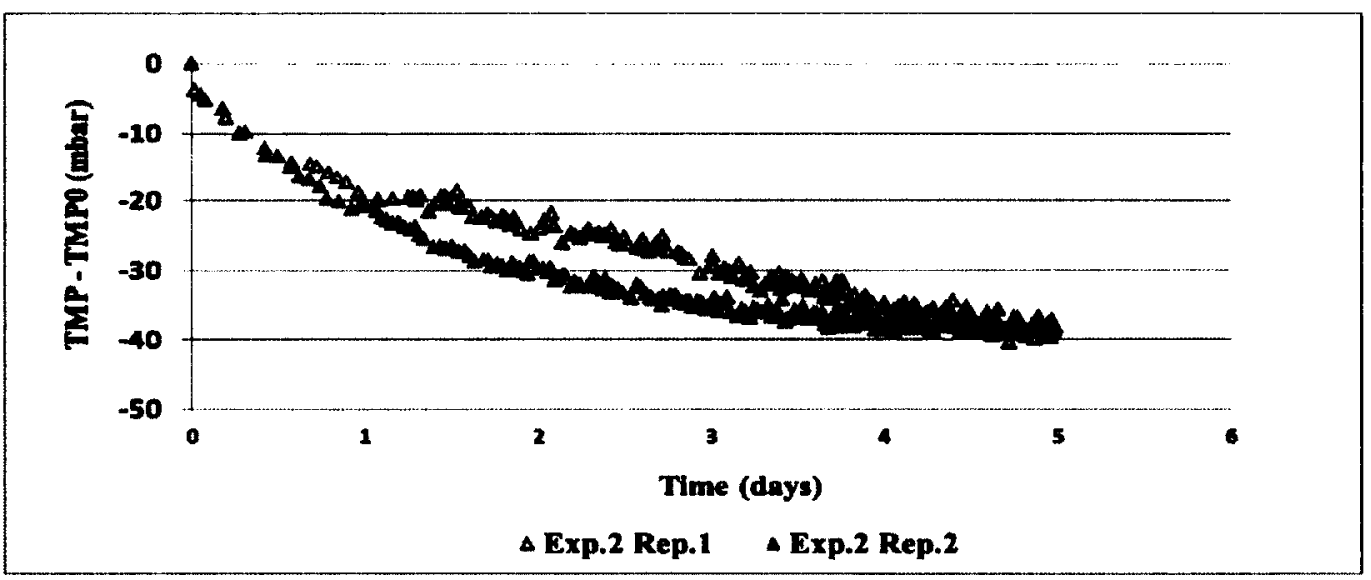

Experiment 2 Replicates

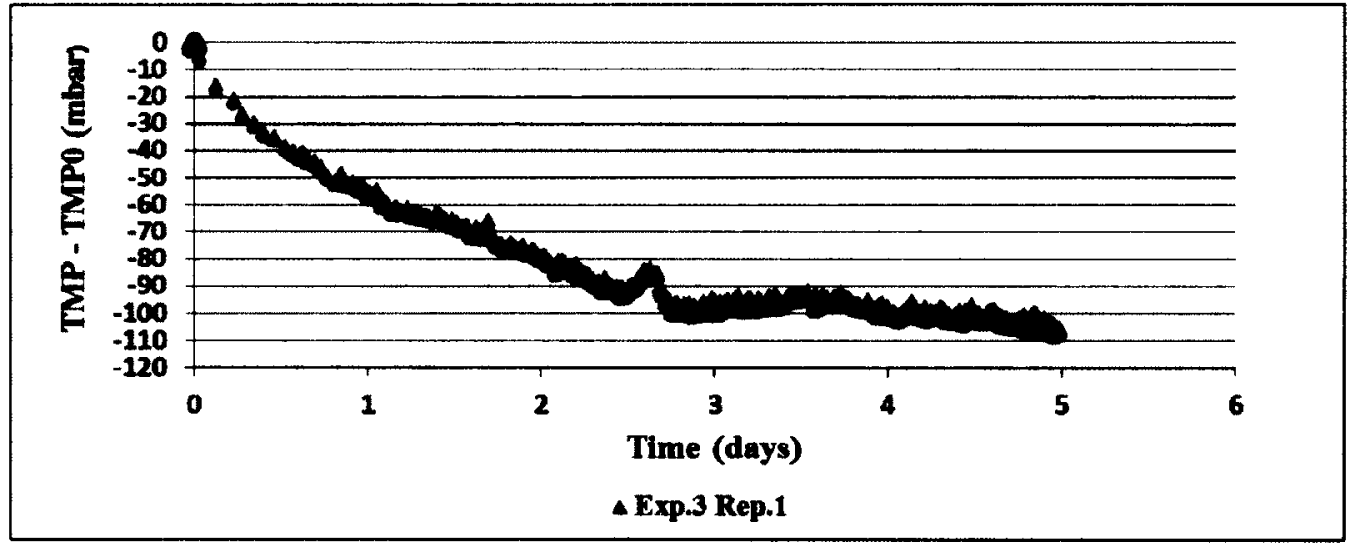

Experiment 3 Replicate 


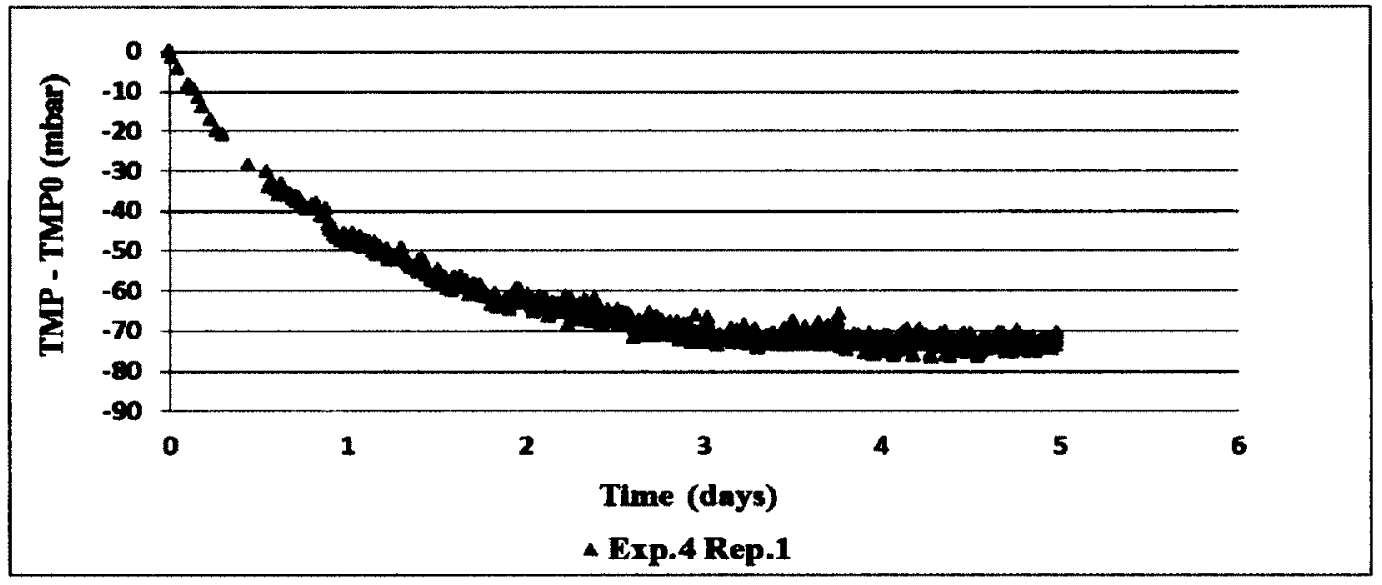

Experiment 4 Replicate

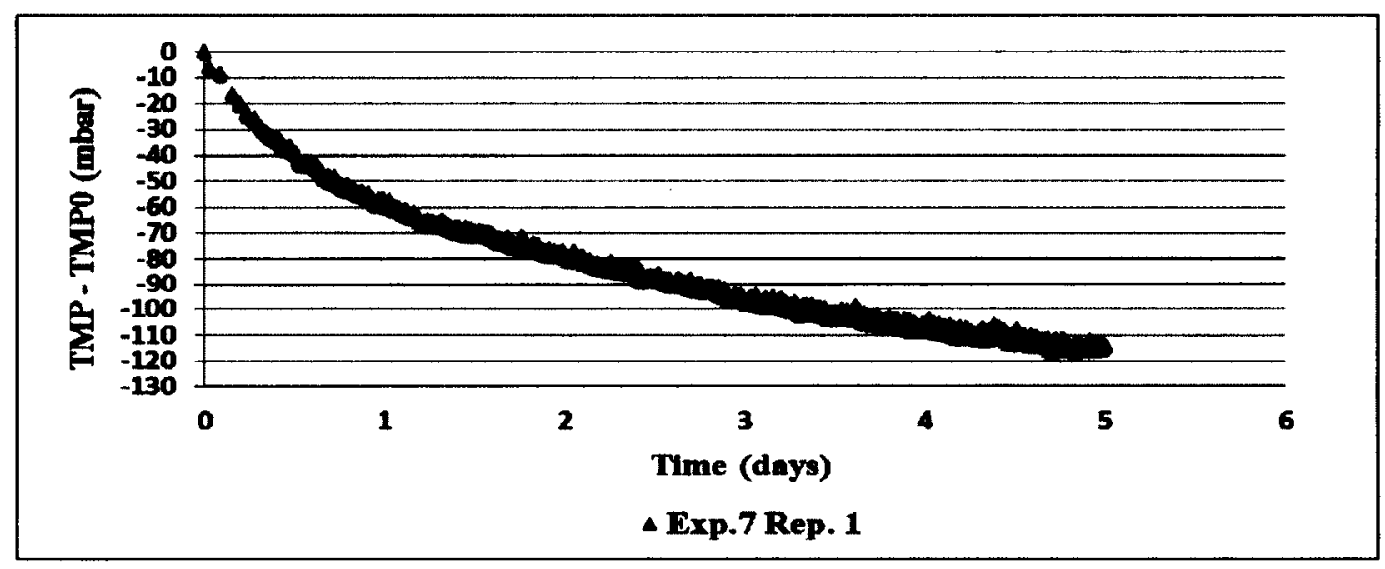

Experiment 7 Replicate

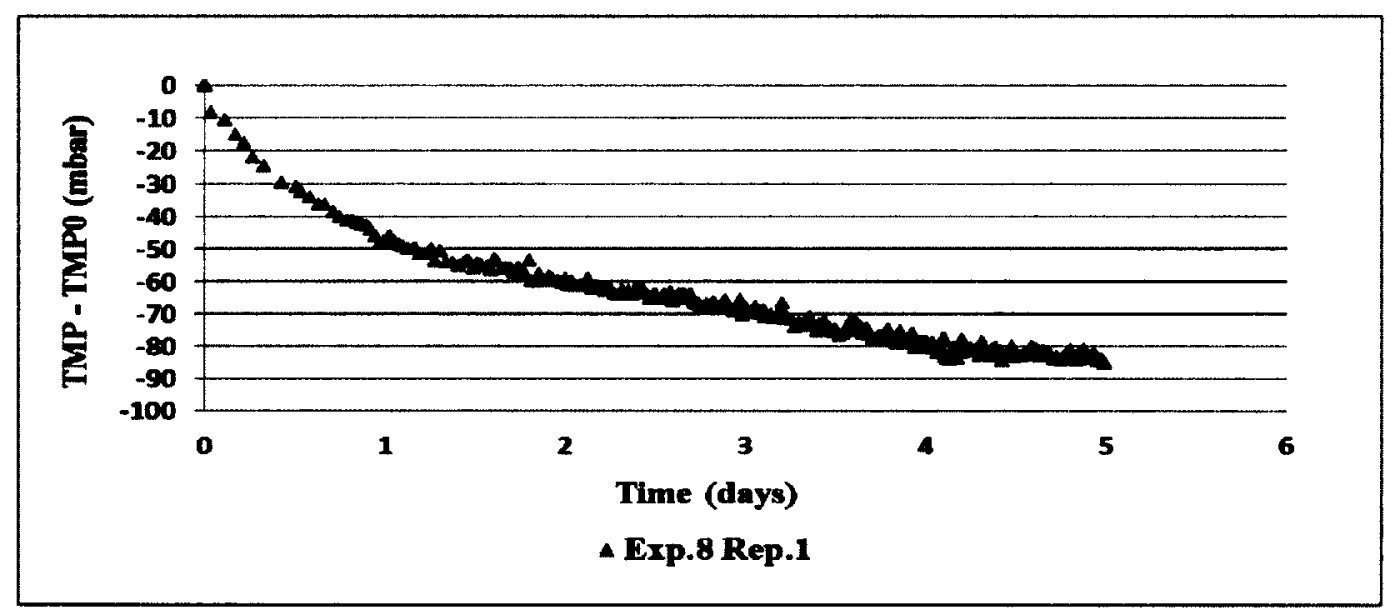

Experiment 8 Replicate 
TMP values for phase A experiments replicates

\begin{tabular}{|c|c|c|c|c|c|c|}
\hline & Exp. 1 & Exp. 2 & Exp. 3 & Exp. 4 & Exp. 7 & Exp. 8 \\
\hline $\begin{array}{c}\text { Replicate 1 } \\
\text { (mbar) }\end{array}$ & -65.75 & -38.93 & -108.45 & -73.19 & -118.35 & -81.06 \\
\hline $\begin{array}{c}\text { Replicate 2 } \\
\text { (mbar) }\end{array}$ & -66.64 & -37.70 & & & & \\
\hline
\end{tabular}


APPENDIX (H) - Stepwise regression output estimated by SPSS 20.0 based on phase A results Regression Coefficients estimated in each stepwise regression sequence

\begin{tabular}{|c|c|c|c|c|c|c|c|c|}
\hline \multirow{2}{*}{\multicolumn{2}{|c|}{ Model }} & \multicolumn{2}{|c|}{ Unstandardized Coefficients } & \multirow{2}{*}{$\begin{array}{c}\begin{array}{c}\text { Standardized } \\
\text { Coefficients }\end{array} \\
\text { Beta } \\
\end{array}$} & \multirow[t]{2}{*}{$\mathbf{t}$} & \multirow[t]{2}{*}{ Sig. } & \multicolumn{2}{|c|}{$\begin{array}{c}95.0 \% \text { Confidence Interval for } \\
\text { B } \\
\end{array}$} \\
\hline & & B & Std. Error & & & & Lower Bound & Upper Bound \\
\hline 1 & $\begin{array}{c}\text { (Constant) } \\
\text { (M) Media (\%) }\end{array}$ & $\begin{array}{c}-76.203 \\
19.128\end{array}$ & $\begin{array}{l}7.778 \\
7.778\end{array}$ & 0.708 & $\begin{array}{r}-9.797 \\
2.459\end{array}$ & $\begin{array}{l}0.000 \\
0.049\end{array}$ & $\begin{array}{c}-95.235 \\
0.095\end{array}$ & $\begin{array}{r}-57.170 \\
38.160\end{array}$ \\
\hline 2 & $\begin{array}{c}\text { (Constant) } \\
\text { (M) Media (\%) } \\
\text { (O) Organic (mg/L TOC) }\end{array}$ & $\begin{array}{l}-76.203 \\
19.128 \\
-18.310\end{array}$ & $\begin{array}{l}2.356 \\
2.356 \\
2.356\end{array}$ & $\begin{array}{r}0.708 \\
-0.678\end{array}$ & $\begin{array}{l}-32.350 \\
8.120 \\
-7.773\end{array}$ & $\begin{array}{l}0.000 \\
0.000 \\
0.001\end{array}$ & $\begin{array}{r}-82.258 \\
13.072 \\
-24.365\end{array}$ & $\begin{array}{l}-70.147 \\
25.183 \\
-12.255\end{array}$ \\
\hline 3 & $\begin{array}{c}\text { (Constant) } \\
\text { (M) Media (\%) } \\
\text { (O) Organic (mg/L TOC) } \\
\text { (IO) Inorganic (NTU) }\end{array}$ & $\begin{array}{l}-76.203 \\
19.128 \\
-18.310 \\
-4.740\end{array}$ & $\begin{array}{l}1.149 \\
1.149 \\
1.149 \\
1.149\end{array}$ & $\begin{array}{l}0.708 \\
-0.678 \\
-0.176\end{array}$ & $\begin{array}{l}-66.347 \\
16.654 \\
-15.942 \\
-4.127\end{array}$ & $\begin{array}{l}0.000 \\
0.000 \\
0.000 \\
0.015\end{array}$ & $\begin{array}{l}-79.391 \\
15.939 \\
-21.499 \\
-7.929\end{array}$ & $\begin{array}{l}-73.014 \\
22.316 \\
-15.121 \\
-1.551\end{array}$ \\
\hline 4 & $\begin{array}{c}\text { (Constant) } \\
\text { (M) Media (\%) }\end{array}$ & $\begin{array}{c}-76.203 \\
19.128\end{array}$ & $\begin{array}{l}0.587 \\
0.587\end{array}$ & 0.708 & $\begin{array}{r}-129.860 \\
32.596\end{array}$ & $\begin{array}{l}0.000 \\
0.000\end{array}$ & $\begin{array}{r}-78.070 \\
17.260\end{array}$ & $\begin{array}{r}-74.335 \\
20.995\end{array}$ \\
\hline
\end{tabular}




\begin{tabular}{|c|c|c|c|c|c|c|c|} 
(O) Organic (mg/L TOC) & -18.310 & 0.587 & -0.678 & -31.203 & 0.000 & -20.177 \\
(IO) Inorganic (NTU) & -4.740 & 0.587 & -0.176 & -8.078 & 0.004 & -6.607 \\
$\mathbf{M}^{\star} \mathbf{O}$ & 2.060 & 0.587 & 0.076 & 3.511 & 0.039 & 0.193 & -2.873 \\
\hline
\end{tabular}


Excluded Variables in each stepwise regression sequence

\begin{tabular}{|c|c|c|c|c|c|c|}
\hline \multirow{2}{*}{\multicolumn{2}{|c|}{ Model }} & $\begin{array}{c}\text { Un- } \\
\text { standardized }\end{array}$ & \multirow{2}{*}{$\begin{array}{l}\text { Beta } \\
\text { In }\end{array}$} & \multirow[t]{2}{*}{$\mathbf{t}$} & \multirow[t]{2}{*}{ Sig. } & \multirow{2}{*}{$\begin{array}{c}\text { Partial } \\
\text { Correlation }\end{array}$} \\
\hline & & B & & & & \\
\hline \multirow{6}{*}{1} & (0) Organic (mg/L TOC) & -18.310 & -0.678 & -7.773 & 0.001 & -0.961 \\
\hline & (IO) Inorganic (NTU) & -4.740 & -0.176 & -0.574 & 0.591 & -0.249 \\
\hline & $\mathbf{M}^{\star} \mathbf{O}$ & 2.060 & 0.076 & 0.243 & 0.818 & 0.108 \\
\hline & $\mathbf{M}^{\star} \mathbf{I O}$ & 0.130 & 0.005 & 0.015 & 0.988 & 0.007 \\
\hline & O*IO & 0.918 & 0.034 & 0.108 & 0.918 & 0.048 \\
\hline & $M^{*} \mathbf{O}^{*} \mathrm{IO}$ & 0.418 & 0.015 & 0.049 & 0.963 & 0.022 \\
\hline \multirow{5}{*}{2} & (IO) Inorganic (NTU) & -4.740 & -0.176 & -4.127 & 0.015 & -0.900 \\
\hline & $\mathbf{M}^{\star} \mathbf{O}$ & 2.060 & 0.076 & 0.850 & 0.443 & 0.391 \\
\hline & M*IO & 0.130 & 0.005 & 0.049 & 0.963 & 0.025 \\
\hline & $0 * 10$ & 0.918 & 0.034 & 0.354 & 0.741 & 0.174 \\
\hline & $M^{*} O^{*} \mathbf{I O}$ & 0.418 & 0.015 & 0.159 & 0.881 & 0.079 \\
\hline \multirow{4}{*}{3} & $\mathbf{M}^{*} \mathbf{O}$ & 2.060 & 0.076 & 3.511 & 0.039 & 0.897 \\
\hline & $\mathbf{M}^{*} \mathbf{I O}$ & 0.130 & 0.005 & 0.098 & 0.928 & 0.057 \\
\hline & $0 * 10$ & 0.918 & 0.034 & 0.755 & 0.505 & 0.399 \\
\hline & $M^{\star} O^{*} I O$ & 0.418 & 0.015 & 0.320 & 0.770 & 0.182 \\
\hline \multirow{3}{*}{4} & M*IO & 0.130 & 0.005 & 0.182 & 0.872 & 0.128 \\
\hline & O*IO & 0.918 & 0.034 & 2.967 & 0.097 & 0.903 \\
\hline & $M^{*} \mathbf{O}^{*} \mathrm{IO}$ & 0.418 & 0.015 & 0.637 & 0.589 & 0.411 \\
\hline
\end{tabular}




\section{Regression summary}

ANOVA

\begin{tabular}{|c|c|c|c|c|c|c|}
\hline \multicolumn{2}{|r|}{ Model } & $\begin{array}{c}\text { Sum of } \\
\text { Squares }\end{array}$ & df & Mean Square & $\mathbf{F}$ & Sig. \\
\hline \multirow{3}{*}{1} & Regression & 2926.890 & 1 & 2926.890 & 6.047 & 0.049 \\
\hline & Residual & 2904.002 & 6 & 484.000 & & \\
\hline & Total & 5830.893 & 7 & & & \\
\hline \multirow{3}{*}{2} & Regression & 5608.939 & 2 & 2804.469 & 63.177 & 0.000 \\
\hline & Residual & 221.954 & 5 & 44.391 & & \\
\hline & Total & 5830.893 & 7 & & & \\
\hline \multirow{3}{*}{3} & Regression & 5788.680 & 3 & 1929.560 & 182.841 & 0.000 \\
\hline & Residual & 42.213 & 4 & 10.553 & & \\
\hline & Total & 5830.893 & 7 & & & \\
\hline \multirow{3}{*}{4} & Regression & 5822.628 & 4 & 1455.657 & 528.427 & 0.000 \\
\hline & Residual & 8.264 & 3 & 2.755 & & \\
\hline & Total & 5830.893 & 7 & & & \\
\hline
\end{tabular}

Model Summary

\begin{tabular}{|c|c|c|c|c|}
\hline Model & $\mathbf{R}$ & R Square & $\begin{array}{c}\text { Adjusted R } \\
\text { Square }\end{array}$ & $\begin{array}{c}\text { Std. Error of } \\
\text { the Estimate }\end{array}$ \\
\hline $\mathbf{1}$ & 0.708 & 0.502 & 0.419 & 22.000 \\
\hline $\mathbf{2}$ & 0.981 & 0.962 & 0.947 & 6.662 \\
\hline $\mathbf{3}$ & 0.996 & 0.993 & 0.987 & 3.248 \\
\hline $\mathbf{4}$ & 0.999 & 0.999 & 0.997 & 1.659 \\
\hline
\end{tabular}

Residuals Statistics

\begin{tabular}{|c|c|c|c|c|c|}
\hline & Minimum & Maximum & Mean & $\begin{array}{c}\text { Std. } \\
\text { Deviation }\end{array}$ & N \\
\hline Predicted Value & -120.4400 & -36.0850 & -76.2025 & 28.84101 & 8 \\
Residual & -1.46500 & 1.46500 & 0.00000 & 1.08655 & 8 \\
Std. Predicted Value & -1.534 & 1.391 & 0.000 & 1.000 & 8 \\
Std. Residual & -0.883 & 0.883 & 0.000 & 0.655 & 8 \\
\hline
\end{tabular}


APPENDIX (I) Water quality assessment for phase A experiments

\begin{tabular}{|c|c|c|c|}
\hline Sample name & Turbidity (NTU) & pH & $\operatorname{COD}(\mathrm{mg} / \mathrm{L})$ \\
\hline \multicolumn{4}{|c|}{ Experiment $\# 1(-M,-O,-I O)$} \\
\hline Reactor (initial) & 8.47 & 7.97 & 11.50 \\
\hline Reactor (24 hr.) & 14.18 & 7.85 & 15.50 \\
\hline Reactor (48 hr.) & 11.52 & 7.85 & 15.00 \\
\hline Reactor (72 hr.) & 7.97 & 7.82 & 9.00 \\
\hline Reactor (96 hr.) & 7.29 & 7.86 & 7.50 \\
\hline Reactor $(120 \mathrm{hr})$. & 7.02 & 7.87 & 8.00 \\
\hline \multicolumn{4}{|c|}{ Experiment $\# 2(+M,-O,-I O)$} \\
\hline Reactor (initial) & 8.24 & 7.96 & 12.50 \\
\hline Reactor (24 hr.) & 13.13 & 7.87 & 10.00 \\
\hline Reactor (48 hr.) & 11.56 & 7.92 & 7.00 \\
\hline Reactor (72 hr.) & 7.90 & 7.84 & 8.50 \\
\hline Reactor $(96 \mathrm{hr})$. & 7.65 & 7.88 & 6.00 \\
\hline Reactor $(120 \mathrm{hr})$. & 7.14 & 7.81 & 6.50 \\
\hline \multicolumn{4}{|c|}{ Experiment $\# 3(-M,+O,-I O)$} \\
\hline Reactor (initial) & 12.24 & 7.91 & 21.00 \\
\hline Reactor (24 hr.) & 20.65 & 7.86 & 17.50 \\
\hline Reactor (48 hr.) & 16.72 & 7.85 & 14.50 \\
\hline Reactor (72 hr.) & 11.73 & 7.88 & 15.00 \\
\hline Reactor (96 hr.) & 10.77 & 7.87 & 12.00 \\
\hline Reactor $(120 \mathrm{hr})$. & 9.41 & 7.87 & 13.50 \\
\hline \multicolumn{4}{|c|}{ Experiment $\# 4(+M,+O,-I O)$} \\
\hline Reactor (initial) & 15.07 & 7.91 & 28.00 \\
\hline
\end{tabular}




\begin{tabular}{|c|c|c|c|}
\hline Reactor (24 hr.) & 24.26 & 7.85 & 24.00 \\
\hline Reactor (48 hr.) & 22.11 & 7.83 & 21.00 \\
\hline Reactor (72 hr.) & 18.74 & 7.86 & 16.50 \\
\hline Reactor (96 hr.) & 15.53 & 7.85 & 15.50 \\
\hline Reactor $(120 \mathrm{hr})$. & 12.39 & 7.84 & 14.50 \\
\hline \multicolumn{4}{|c|}{ Experiment $\# 5(-M,-O,+I O)$} \\
\hline Reactor (initial) & 34.53 & 7.89 & 15.00 \\
\hline Reactor (24 hr.) & 65.51 & 7.82 & 16.50 \\
\hline Reactor (48 hr.) & 50.23 & 7.84 & 14.00 \\
\hline Reactor $(72 \mathrm{hr})$. & 43.58 & 7.87 & 13.50 \\
\hline Reactor (96 hr.) & 41.00 & 7.84 & 10.00 \\
\hline Reactor $(120 \mathrm{hr})$. & 39.66 & 7.82 & 9.50 \\
\hline \multicolumn{4}{|c|}{ Experiment $\# 6(+M,-O,+I O)$} \\
\hline Reactor (initial) & 36.18 & 7.89 & 14.50 \\
\hline Reactor $(24 \mathrm{hr})$. & 58.61 & 7.84 & 14.00 \\
\hline Reactor (48 hr.) & 49.93 & 7.81 & 15.50 \\
\hline Reactor ( $72 \mathrm{hr})$. & 46.44 & 7.86 & 12.50 \\
\hline Reactor (96 hr.) & 45.31 & 7.84 & 11.50 \\
\hline Reactor $(120 \mathrm{hr})$. & 44.12 & 7.80 & 10.00 \\
\hline \multicolumn{4}{|c|}{ Experiment \#7 $(-M,+O,+I O)$} \\
\hline Reactor (initial) & 33.02 & 7.86 & 30.50 \\
\hline Reactor (24 hr.) & 58.62 & 7.84 & 36.50 \\
\hline Reactor (48 hr.) & 49.84 & 7.88 & 29.00 \\
\hline Reactor (72 hr.) & 45.44 & 7.83 & 21.50 \\
\hline
\end{tabular}




\begin{tabular}{|l|c|c|c|}
\hline Reactor $(96 \mathrm{hr})$. & 42.88 & 7.91 & 16.00 \\
\hline Reactor $(120 \mathrm{hr})$. & 41.35 & 7.88 & 11.50 \\
\hline \multicolumn{4}{|c|}{ Experiment $\# \mathbf{8}(+\boldsymbol{M},+\mathbf{O},+\mathbf{I O})$} \\
\hline Reactor (initial) & 34.62 & 7.85 & 27.50 \\
\hline Reactor $(24 \mathrm{hr})$. & 59.60 & 7.85 & 34.50 \\
\hline Reactor $(48 \mathrm{hr})$. & 58.96 & 7.87 & 21.50 \\
\hline Reactor $(72 \mathrm{hr})$. & 47.89 & 7.81 & 15.00 \\
\hline Reactor $(96 \mathrm{hr})$. & 40.08 & 7.91 & 12.50 \\
\hline Reactor $(120 \mathrm{hr})$. & 43.30 & 7.82 & 13.50 \\
\hline
\end{tabular}




\begin{tabular}{|c|c|c|c|}
\hline Sample name & Turbidity (NTU) & pH & $\operatorname{COD}(\mathrm{mg} / \mathrm{L})$ \\
\hline \multicolumn{4}{|c|}{ Experiment $\# I(-M,-O,-I O)$} \\
\hline Feed (initial) & 7.05 & 7.95 & 10.00 \\
\hline Feed (24 hr.) & 6.61 & 7.88 & 12.50 \\
\hline Feed (48 hr.) & 5.83 & 7.84 & 11.00 \\
\hline Feed (72 hr.) & 5.22 & 7.81 & 10.50 \\
\hline Feed (96 hr.) & 4.88 & 7.87 & 8.00 \\
\hline Feed $(120 \mathrm{hr})$. & 4.36 & 7.81 & 6.00 \\
\hline \multicolumn{4}{|c|}{ Experiment $\# 2(+M,-O,-I O)$} \\
\hline Feed (initial) & 8.80 & 7.88 & 11.00 \\
\hline Feed (24 hr.) & 6.33 & 7.84 & 11.50 \\
\hline Feed (48 hr.) & 5.81 & 7.80 & 9.50 \\
\hline Feed (72 hr.) & 5.45 & 7.83 & 8.50 \\
\hline Feed (96 hr.) & 5.32 & 7.79 & 7.00 \\
\hline Feed $(120 \mathrm{hr})$. & 4.88 & 7.76 & 7.00 \\
\hline \multicolumn{4}{|c|}{ Experiment $\# 3(-M,+0,-10)$} \\
\hline Feed (initial) & 8.51 & 7.92 & 18.50 \\
\hline Feed (24 hr.) & 7.19 & 7.81 & 16.00 \\
\hline Feed ( $48 \mathrm{hr})$. & 6.15 & 7.82 & 14.00 \\
\hline Feed (72 hr.) & 5.45 & 7.86 & 12.50 \\
\hline Feed (96 hr.) & 4.59 & 7.87 & 9.50 \\
\hline Feed $(120 \mathrm{hr})$. & 4.14 & 7.82 & 7.00 \\
\hline \multicolumn{4}{|c|}{ Experiment $\# 4(+M,+O,-10)$} \\
\hline Feed (initial) & 9.33 & 8.02 & 17.00 \\
\hline Feed $(24 \mathrm{hr})$. & 7.92 & 7.80 & 15.50 \\
\hline
\end{tabular}




\begin{tabular}{|c|c|c|c|}
\hline Feed (48 hr.) & 7.45 & 7.82 & 12.00 \\
\hline Feed $(72 \mathrm{hr})$. & 6.29 & 7.85 & 13.50 \\
\hline Feed (96 hr.) & 6.08 & 7.85 & 12.00 \\
\hline Feed $(120 \mathrm{hr})$. & 5.10 & 7.88 & 10.00 \\
\hline \multicolumn{4}{|c|}{ Experiment $\# 5(-M,-O,+I O)$} \\
\hline Feed (initial) & 26.24 & 8.01 & 11.50 \\
\hline Feed $(24 \mathrm{hr})$. & 24.22 & 7.81 & 10.00 \\
\hline Feed (48 hr.) & 20.52 & 7.84 & 9.00 \\
\hline Feed (72 hr.) & 18.91 & 7.84 & 9.50 \\
\hline Feed (96 hr.) & 17.51 & 7.82 & 7.00 \\
\hline Feed $(120 \mathrm{hr})$. & 16.72 & 7.81 & 6.50 \\
\hline \multicolumn{4}{|c|}{ Experiment $\# 6(+M,-O,+I O)$} \\
\hline Feed (initial) & 24.66 & 7.96 & 10.50 \\
\hline Feed (24 hr.) & 20.68 & 7.83 & 11.50 \\
\hline Feed ( $48 \mathrm{hr})$. & 19.42 & 7.88 & 12.00 \\
\hline Feed $(72 \mathrm{hr})$. & 18.81 & 7.85 & 11.50 \\
\hline Feed $(96 \mathrm{hr})$. & 16.09 & 7.80 & 8.00 \\
\hline Feed $(120 \mathrm{hr})$. & 15.62 & 7.83 & 9.00 \\
\hline \multicolumn{4}{|c|}{ Experiment \#7 $(-M,+O,+I O)$} \\
\hline Feed (initial) & 25.67 & 7.96 & 18.00 \\
\hline Feed (24 hr.) & 24.43 & 7.84 & 16.00 \\
\hline Feed (48 hr.) & 22.88 & 7.87 & 13.00 \\
\hline Feed (72 hr.) & 20.67 & 7.86 & 10.00 \\
\hline Feed $(96 \mathrm{hr})$. & 21.71 & 7.87 & 8.00 \\
\hline
\end{tabular}




\begin{tabular}{|l|c|c|c|}
\hline Feed $(120 \mathrm{hr})$. & 18.41 & 7.79 & 8.00 \\
\hline \multicolumn{3}{|c|}{ Experiment $\# \mathbf{8}(+\mathbf{M},+\mathbf{O},+\mathbf{I O})$} \\
\hline Feed (initial) & 28.87 & 7.97 & 17.00 \\
\hline Feed (24 hr.) & 22.98 & 7.84 & 13.00 \\
\hline Feed (48 hr.) & 21.72 & 7.81 & 16.50 \\
\hline Feed (72 hr.) & 20.64 & 7.88 & 11.00 \\
\hline Feed $(96 \mathrm{hr})$. & 19.99 & 7.83 & 9.00 \\
\hline Feed $(120 \mathrm{hr})$. & 16.60 & 7.86 & 10.50 \\
\hline
\end{tabular}




\begin{tabular}{|c|c|c|c|c|}
\hline Sample name & Turbidity (NTU) & pH & $\operatorname{COD}(\mathrm{mg} / \mathrm{L})$ & $\begin{array}{c}\text { Flow } \\
(\mathrm{mL} / \mathrm{min})\end{array}$ \\
\hline \multicolumn{5}{|c|}{ Experiment \#1(-M, $-O,-I O)$} \\
\hline Permeate (initial) & 0.00 & 7.74 & 2.50 & 30.00 \\
\hline Permeate (24 hr.) & 0.03 & 7.76 & 2.00 & 29.50 \\
\hline Permeate (48 hr.) & 0.01 & 7.72 & 0.00 & 29.00 \\
\hline Permeate ( $72 \mathrm{hr})$. & 0.00 & 7.77 & 2.00 & 29.00 \\
\hline Permeate ( 96 hr.) & 0.00 & 7.85 & 0.00 & 28.00 \\
\hline $\begin{array}{l}\text { Permeate (120 } \\
\text { hr.) }\end{array}$ & 0.03 & 7.79 & 0.00 & 28.00 \\
\hline \multicolumn{5}{|c|}{ Experiment $\# 2(+M,-O,-I O)$} \\
\hline Permeate (initial) & 0.00 & 7.76 & 1.00 & 30.00 \\
\hline Permeate $(24 \mathrm{hr})$. & 0.02 & 7.82 & 0.00 & 30.00 \\
\hline Permeate (48 hr.) & 0.02 & 7.74 & 0.00 & 30.00 \\
\hline Permeate (72 hr.) & 0.00 & 7.89 & 1.50 & 29.50 \\
\hline Permeate ( $96 \mathrm{hr})$. & 0.00 & 7.81 & 0.00 & 29.50 \\
\hline $\begin{array}{l}\text { Permeate (120 } \\
\text { hr.) }\end{array}$ & 0.01 & 7.77 & 1.00 & 29.50 \\
\hline \multicolumn{5}{|c|}{ Experiment $\# 3(-M,+O,-I O)$} \\
\hline Permeate (initial) & 0.01 & 7.80 & 0.00 & 30.00 \\
\hline Permeate $(24 \mathrm{hr})$. & 0.00 & 7.82 & 1.00 & 29.00 \\
\hline Permeate ( $48 \mathrm{hr})$. & 0.02 & 7.79 & 3.00 & 28.00 \\
\hline Permeate ( $72 \mathrm{hr})$. & 0.01 & 7.78 & 0.00 & 27.50 \\
\hline Permeate ( $96 \mathrm{hr}$.) & 0.01 & 7.77 & 2.00 & 27.50 \\
\hline $\begin{array}{l}\text { Permeate (120 } \\
\text { hr.) }\end{array}$ & 0.02 & 7.82 & 0.00 & 27.00 \\
\hline \multicolumn{5}{|c|}{ Experiment $\# 4(+M,+O,-10)$} \\
\hline Permeate (initial) & 0.00 & 7.98 & 0.00 & 30.00 \\
\hline
\end{tabular}




\begin{tabular}{|l|c|c|c|c|}
\hline Permeate (24 hr.) & 0.02 & 7.91 & 1.00 & 30.00 \\
\hline Permeate (48 hr.) & 0.00 & 7.81 & 1.00 & 30.00 \\
\hline Permeate (72 hr.) & 0.01 & 7.87 & 0.00 & 29.50 \\
\hline Permeate (96 hr.) & 0.00 & 7.81 & 3.50 & 29.00 \\
\hline $\begin{array}{l}\text { Permeate (120 } \\
\text { hr.) }\end{array}$ & 0.01 & 7.82 & 0.00 & 28.50 \\
\hline \multicolumn{5}{|c|}{ Experiment \#5 (-M, -O,+IO) } \\
\hline Permeate (initial) & 0.04 & 7.82 & 2.00 & 30.00 \\
\hline Permeate (24 hr.) & 0.00 & 7.91 & 0.00 & 30.00 \\
\hline Permeate (48 hr.) & 0.00 & 7.82 & 0.00 & 29.50 \\
\hline Permeate (72 hr.) & 0.01 & 7.88 & 0.00 & 29.00 \\
\hline Permeate (96 hr.) & 0.00 & 7.85 & 2.00 & 28.00 \\
\hline $\begin{array}{l}\text { Permeate (120 } \\
\text { hr.) }\end{array}$ & 0.01 & 7.84 & 3.00 & 28.00 \\
\hline \multicolumn{5}{|c|}{ Experiment \#6(+M, -O, +IO) } \\
\hline Permeate (initial) & 0.05 & 7.88 & 0.00 & 30.00 \\
\hline Permeate (24 hr.) & 0.02 & 7.88 & 3.00 & 30.00 \\
\hline Permeate (48 hr.) & 0.00 & 7.81 & 2.00 & 29.50 \\
\hline Permeate (72 hr.) & 0.00 & 7.85 & 0.00 & 29.50 \\
\hline Permeate (96 hr.) & 0.01 & 7.83 & 0.00 & 29.00 \\
\hline $\begin{array}{l}\text { Permeate (120 } \\
\text { hr.) }\end{array}$ & 0.00 & 7.84 & 1.00 & 29.00 \\
\hline Permeate (initial) & 0.02 & 7.95 & 2.00 & 30.00 \\
\hline Permeate (24 hr.) & 0.00 & 7.86 & 0.00 & 29.50 \\
\hline Permeate (48 hr.) & 0.00 & 7.88 & 0.00 & 28.50 \\
\hline Permeate (72 hr.) & 0.04 & 7.85 & 1.00 & 27.50 \\
\hline
\end{tabular}




\begin{tabular}{|l|c|c|c|c|}
\hline Permeate (96 hr.) & 0.02 & 7.81 & 1.00 & 27.00 \\
\hline $\begin{array}{l}\text { Permeate (120 } \\
\text { hr.) }\end{array}$ & 0.01 & 7.85 & 0.00 & 26.50 \\
\hline \multicolumn{5}{|c|}{ Experiment $\# \mathbf{8}(+\boldsymbol{M},+\boldsymbol{O},+\mathbf{I O})$} \\
\hline Permeate (initial) & 0.00 & 7.89 & 0.00 & 30.00 \\
\hline Permeate (24 hr.) & 0.00 & 7.84 & 0.00 & 30.00 \\
\hline Permeate (48 hr.) & 0.00 & 7.82 & 0.00 & 29.00 \\
\hline Permeate (72 hr.) & 0.01 & 7.78 & 1.00 & 29.00 \\
\hline Permeate (96 hr.) & 0.02 & 7.88 & 0.00 & 28.50 \\
\hline $\begin{array}{l}\text { Permeate (120 } \\
\text { hr.) }\end{array}$ & 0.00 & 7.94 & 2.50 & 28.00 \\
\hline
\end{tabular}


APPENDIX (J) Cellulose vs. Humic acid fouling during first hour of filtration
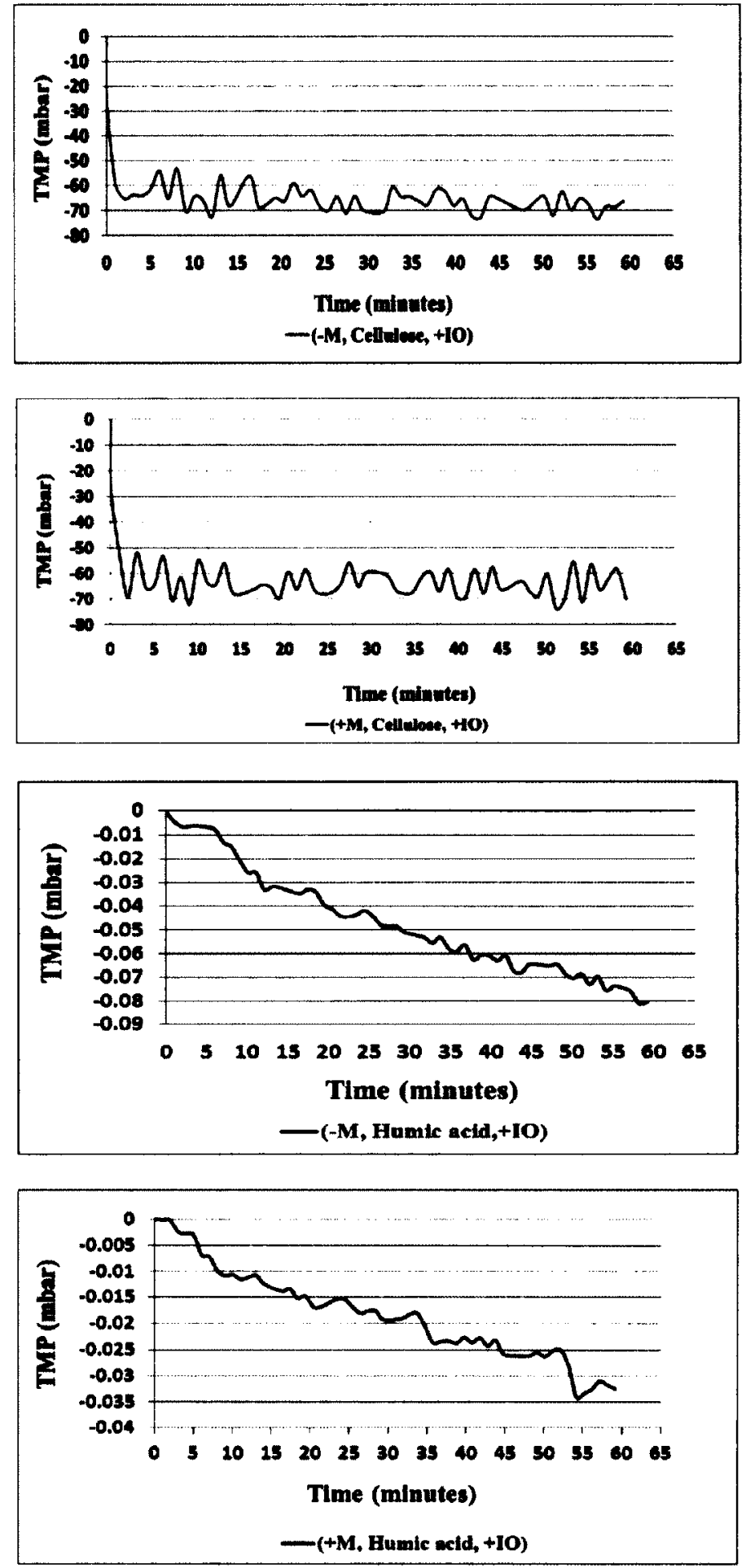
APPENDIX (K) - Stepwise regression output estimated by SPSS 20.0 based on phase B results

\section{Regression Coefficients estimated in each stepwise regression sequence}

\begin{tabular}{|c|c|c|c|c|c|c|c|c|}
\hline & \multirow[t]{2}{*}{ Model } & \multicolumn{2}{|c|}{ Unstandardized Coefficients } & \multirow{2}{*}{$\begin{array}{c}\begin{array}{c}\text { Standardized } \\
\text { Coefricients }\end{array} \\
\text { Beta }\end{array}$} & \multirow[t]{2}{*}{$\mathbf{t}$} & \multirow[t]{2}{*}{ Sig. } & \multicolumn{2}{|c|}{$\begin{array}{c}95.0 \% \text { Confidence Interval for } \\
\text { B }\end{array}$} \\
\hline & & B & Std. Error & & & & Lower Bound & Upper Bound \\
\hline \multirow{2}{*}{1} & (Constant) & -80.058 & 5.395 & & -14.839 & 0.000 & -93.259 & -66.856 \\
\hline & (O) Organic type & -15.205 & 5.395 & -0.755 & -2.818 & 0.030 & -28.406 & -2.004 \\
\hline 2 & (M) Media & 9.325 & 4.188 & 0.563 & 2.527 & 0.046 & -1.440 & 20.090 \\
\hline \multirow{3}{*}{3} & (Constant) & -80.058 & 1.583 & & -50.571 & 0.000 & -84.453 & -75.662 \\
\hline & (O) Organic type & -15.205 & 1.583 & -0.755 & -9.605 & 0.001 & -19.600 & -10.810 \\
\hline & (M) Media & 9.325 & 1.583 & 0.563 & 5.890 & 0.004 & 4.930 & 13.720 \\
\hline
\end{tabular}


Excluded Variables in each stepwise regression sequence

\begin{tabular}{|c|c|c|c|c|c|}
\hline \multicolumn{2}{|r|}{ Model } & Beta In & $\mathbf{t}$ & Sig. & $\begin{array}{c}\text { Partial } \\
\text { Correlation }\end{array}$ \\
\hline \multirow{6}{*}{1} & (M) Media & 0.563 & 2.527 & 0.046 & 0.706 \\
\hline & (IO) Inorganic & -0.116 & -0.400 & 0.706 & -0.176 \\
\hline & MXO & 0.437 & 2.001 & 0.102 & 0.667 \\
\hline & MXIO & 0.015 & 0.052 & 0.961 & 0.023 \\
\hline & OXIO & -0.105 & -.363 & 0.732 & -0.160 \\
\hline & MXOXIO & 0.010 & 0.034 & 0.974 & 0.015 \\
\hline \multirow{5}{*}{2} & (IO) Inorganic & -0.116 & -0.513 & 0.635 & -0.249 \\
\hline & MXO & 0.437 & 5.567 & 0.005 & 0.941 \\
\hline & MXIO & 0.015 & 0.065 & 0.951 & 0.033 \\
\hline & OXIO & -0.105 & -0.464 & 0.667 & -0.226 \\
\hline & MXOXIO & 0.010 & 0.043 & 0.968 & 0.022 \\
\hline \multirow{4}{*}{3} & (IO) Inorganic & -0.116 & -1.878 & 0.157 & -0.735 \\
\hline & MXIO & 0.015 & 0.168 & 0.878 & 0.096 \\
\hline & OXIO & -0.105 & -1.555 & 0.218 & -0.668 \\
\hline & MXOXIO & 0.010 & 0.111 & 0.919 & 0.064 \\
\hline
\end{tabular}




\section{Regression summary}

\begin{tabular}{|cc|c|c|c|c|c|}
\hline \multicolumn{2}{|c|}{ Model } & $\begin{array}{c}\text { Sum of } \\
\text { Squares }\end{array}$ & df & $\begin{array}{c}\text { Mean } \\
\text { Square }\end{array}$ & F & Sig. \\
\hline \multirow{3}{*}{$\mathbf{1}$} & Regression & 1849.536 & 1 & 1849.536 & 7.943 & 0.030 \\
& Residual & 1397.122 & 6 & 232.854 & & \\
& Total & 3246.659 & 7 & & & \\
\hline & Regression & 2545.181 & 2 & 1272.591 & 9.071 & 0.022 \\
& Residual & 701.477 & 5 & 140.295 & & \\
& Total & 3246.659 & 7 & & & \\
\hline & Regression & 3166.462 & 3 & 1055.487 & 52.645 & 0.001 \\
& Residual & 80.196 & 4 & 20.049 & & \\
& Total & 3246.659 & 7 & & & \\
\hline
\end{tabular}

Model Summary

\begin{tabular}{|c|c|c|c|c|}
\hline Model & $\mathbf{R}$ & R Square & Adjusted R Square & $\begin{array}{c}\text { Std. Error of the } \\
\text { Estimate }\end{array}$ \\
\hline $\mathbf{1}$ & 0.755 & 0.570 & 0.498 & 15.25955 \\
\hline $\mathbf{2}$ & 0.885 & 0.784 & 0.698 & 11.84464 \\
\hline $\mathbf{3}$ & 0.988 & 0.975 & 0.957 & 4.47761 \\
\hline
\end{tabular}

Residuals Statistics

\begin{tabular}{|c|c|c|c|c|c|}
\hline & Minimum & Maximum & Mean & Std. Deviation & N \\
\hline Predicted Value & -113.4000 & -64.3400 & -80.0575 & 21.26856 & 8 \\
Residual & -4.95000 & 4.95000 & .00000 & 3.38476 & 8 \\
Std. Predicted Value & -1.568 & .739 & .000 & 1.000 & 8 \\
Std. Residual & -1.105 & 1.105 & .000 & .756 & 8 \\
\hline
\end{tabular}


APPENDIX (L) Water quality assessment for phase B experiments

\begin{tabular}{|l|c|c|}
\hline Sample name & Turbidity (NTU) & pH \\
\hline \multicolumn{2}{|c|}{ Experiment \#1 (-M, Cellulose, -IO) } \\
\hline Reactor (initial) & 9.06 & 7.98 \\
\hline Reactor (24 hr.) & 10.55 & 7.65 \\
\hline Reactor (48 hr.) & 12.66 & 7.71 \\
\hline Reactor (72 hr.) & 9.65 & 7.64 \\
\hline Reactor (96 hr.) & 8.22 & 7.62 \\
\hline Reactor (120 hr.) & 8.04 & 7.65 \\
\hline Experiment \#2 (+M, Cellulose, -IO) \\
\hline Reactor (initial) & 7.01 & 7.91 \\
\hline Reactor (24 hr.) & 11.81 & 7.85 \\
\hline Reactor (48 hr.) & 12.68 & 7.83 \\
\hline Reactor (72 hr.) & 8.09 & 7.86 \\
\hline Reactor (96 hr.) & 6.65 & 7.85 \\
\hline Reactor (120 hr.) & 6.22 & 7.84 \\
\hline \multicolumn{2}{|c|}{ Experiment \#3 (-M, Humic Acid, -IO) } \\
\hline Reactor (initial) & 12.14 & 7.66 \\
\hline Reactor (24 hr.) & 18.38 & 7.84 \\
\hline Reactor (48 hr.) & 11.82 & 7.69 \\
\hline Reactor (72 hr.) & 8.30 & \\
\hline Reactor (96 hr.) & 8.21 & \\
\hline Reactor (120 hr.) & 7.75 & \\
\hline & & \\
\hline
\end{tabular}




\begin{tabular}{|c|c|c|}
\hline Reactor (initial) & 8.66 & 7.87 \\
\hline Reactor (24 hr.) & 15.67 & 7.80 \\
\hline Reactor (48 hr.) & 9.13 & 7.82 \\
\hline Reactor (72 hr.) & 9.02 & 7.85 \\
\hline Reactor (96 hr.) & 8.48 & 7.85 \\
\hline Reactor $(120 \mathrm{hr})$. & 8.09 & 7.88 \\
\hline \multicolumn{3}{|c|}{ Experiment $\# 5(-M$, Cellulose, $+I O)$} \\
\hline Reactor (initial) & 33.93 & 7.88 \\
\hline Reactor (24 hr.) & 36.54 & 7.86 \\
\hline Reactor ( $48 \mathrm{hr})$. & 28.88 & 7.76 \\
\hline Reactor $(72 \mathrm{hr})$. & 25.65 & 7.72 \\
\hline Reactor (96 hr.) & 22.01 & 7.83 \\
\hline Reactor $(120 \mathrm{hr})$. & 21.66 & 7.85 \\
\hline \multicolumn{3}{|c|}{ Experiment $\# 6(+M$, Cellulose,$+I O)$} \\
\hline Reactor (initial) & 20.33 & 7.64 \\
\hline Reactor (24 hr.) & 45.40 & 7.81 \\
\hline Reactor (48 hr.) & 47.47 & 7.77 \\
\hline Reactor ( $72 \mathrm{hr})$. & 41.23 & 7.62 \\
\hline Reactor (96 hr.) & 35.46 & 7.84 \\
\hline Reactor $(120 \mathrm{hr})$. & 33.21 & 7.73 \\
\hline \multicolumn{3}{|c|}{ Experiment \#7 (-M, Humic Acid, + IO) } \\
\hline Reactor (initial) & 34.62 & 7.71 \\
\hline Reactor (24 hr.) & 38.55 & 7.74 \\
\hline Reactor (48 hr.) & 33.51 & 7.86 \\
\hline
\end{tabular}




\begin{tabular}{|l|l|l|}
\hline Reactor (72 hr.) & 27.70 & 7.76 \\
\hline Reactor $(96 \mathrm{hr})$. & 25.39 & 7.65 \\
\hline Reactor $(120 \mathrm{hr})$. & 23.66 & 7.70 \\
\hline \multicolumn{2}{|c|}{ Experiment $\# \mathbf{8}(\mathbf{M}$, Humic Acid, + IO $)$} \\
\hline Reactor (initial) & 23.14 & 7.63 \\
\hline Reactor $(24 \mathrm{hr})$. & 34.55 & 7.65 \\
\hline Reactor $(48 \mathrm{hr})$. & 40.23 & 7.66 \\
\hline Reactor $(72 \mathrm{hr})$. & 31.36 & 7.85 \\
\hline Reactor $(96 \mathrm{hr})$. & 28.65 & 7.75 \\
\hline Reactor $(120 \mathrm{hr})$. & 24.33 & 7.73 \\
\hline
\end{tabular}




\begin{tabular}{|c|c|c|c|c|}
\hline Sample name & Turbidity (NTU) & pH & TOC (mg C /L) & $\begin{array}{c}\mathrm{UV}_{254 \mathrm{~nm}} \\
\text { absorbance } \\
\left(\mathrm{cm}^{-1}\right)\end{array}$ \\
\hline \multicolumn{5}{|c|}{ Experiment \#1 (-M, Cellulose, -10$)$} \\
\hline Feed (initial) & 8.85 & 7.88 & 1.71 & 0.120 \\
\hline Feed $(24 \mathrm{hr})$. & 8.81 & 7.65 & 1.03 & 0.065 \\
\hline Feed ( $48 \mathrm{hr})$. & 7.55 & 7.85 & 0.68 & 0.051 \\
\hline Feed $(72 \mathrm{hr})$. & 6.68 & 7.83 & 0.58 & 0.040 \\
\hline Feed $(96 \mathrm{hr})$. & 6.22 & 7.78 & 0.44 & 0.038 \\
\hline Feed $(120 \mathrm{hr})$. & 4.88 & 7.75 & 0.41 & 0.027 \\
\hline \multicolumn{5}{|c|}{ Experiment $\# 2(+M$, Cellulose,$-I O)$} \\
\hline Feed (initial) & 6.88 & 7.97 & 1.38 & 0.180 \\
\hline Feed (24 hr.) & 5.28 & 7.84 & 1.21 & 0.156 \\
\hline Feed $(48 \mathrm{hr})$. & 4.71 & 7.81 & 1.05 & 0.123 \\
\hline Feed $(72 \mathrm{hr})$. & 4.52 & 7.88 & 0.90 & 0.094 \\
\hline Feed $(96 \mathrm{hr})$. & 4.23 & 7.83 & 0.85 & 0.066 \\
\hline Feed $(120 \mathrm{hr})$. & 4.06 & 7.86 & 0.66 & 0.048 \\
\hline \multicolumn{5}{|c|}{ Experiment \#3 (-M, Humic Acid, $-I O)$} \\
\hline Feed (initial) & 10.66 & 7.77 & 3.07 & 0.320 \\
\hline Feed $(24 \mathrm{hr})$. & 6.92 & 7.64 & 2.82 & 0.210 \\
\hline Feed $(48 \mathrm{hr})$. & 6.55 & 7.68 & 2.21 & 0.190 \\
\hline Feed $(72 \mathrm{hr})$. & 4.48 & 7.71 & 1.56 & 0.160 \\
\hline Feed $(96 \mathrm{hr})$. & 3.80 & 7.89 & 1.31 & 0.120 \\
\hline Feed $(120 \mathrm{hr})$. & 3.55 & 7.70 & 1.22 & 0.110 \\
\hline \multicolumn{5}{|c|}{ Experiment $\# 4(+M$, Humic Acid,$-I O)$} \\
\hline Feed (initial) & 7.54 & 7.89 & 2.98 & 0.380 \\
\hline
\end{tabular}




\begin{tabular}{|c|c|c|c|c|}
\hline Feed $(24 \mathrm{hr})$. & 6.62 & 7.84 & 2.52 & 0.170 \\
\hline Feed $(48 \mathrm{hr})$. & 5.48 & 7.81 & 2.31 & 0.160 \\
\hline Feed (72 hr.) & 5.33 & 7.86 & 2.07 & 0.130 \\
\hline Feed $(96 \mathrm{hr})$. & 4.87 & 7.84 & 1.71 & 0.120 \\
\hline Feed $(120 \mathrm{hr})$. & 3.83 & 7.80 & 1.36 & 0.120 \\
\hline \multicolumn{5}{|c|}{ Experiment \#5 (-M, Cellulose , $+I O)$} \\
\hline Feed (initial) & 28.77 & 7.95 & 1.48 & 0.151 \\
\hline Feed (24 hr.) & 18.55 & 7.85 & 1.15 & 0.120 \\
\hline Feed $(48 \mathrm{hr})$. & 16.48 & 7.77 & 0.95 & 0.100 \\
\hline Feed $(72 \mathrm{hr})$. & 11.22 & 7.82 & 0.84 & 0.060 \\
\hline Feed $(96 \mathrm{hr})$. & 10.45 & 7.84 & 0.67 & 0.040 \\
\hline Feed $(120 \mathrm{hr})$. & 10.05 & 7.86 & 0.51 & 0.030 \\
\hline \multicolumn{5}{|c|}{ Experiment $\# 6(+M$, Cellulose,$+I O)$} \\
\hline Feed (initial) & 23.02 & 7.89 & 1.33 & 0.125 \\
\hline Feed (24 hr.) & 18.65 & 7.61 & 1.22 & 0.084 \\
\hline Feed (48 hr.) & 16.55 & 7.64 & 0.71 & 0.065 \\
\hline Feed $(72 \mathrm{hr})$. & 11.45 & 7.69 & 0.56 & 0.042 \\
\hline Feed $(96 \mathrm{hr})$. & 10.66 & 7.75 & 0.48 & 0.038 \\
\hline Feed $(120 \mathrm{hr})$. & 10.21 & 7.84 & 0.42 & 0.026 \\
\hline \multicolumn{5}{|c|}{ Experiment $\# 7(-M$, Humic Acid, $+I O)$} \\
\hline Feed (initial) & 26.51 & 7.89 & 2.95 & 0.357 \\
\hline Feed (24 hr.) & 22.35 & 7.75 & 2.64 & 0.246 \\
\hline Feed $(48 \mathrm{hr})$. & 18.38 & 7.65 & 2.51 & 0.214 \\
\hline Feed $(72 \mathrm{hr})$. & 15.64 & 7.71 & 2.26 & 0.189 \\
\hline
\end{tabular}




\begin{tabular}{|c|c|c|c|c|}
\hline Feed (96 hr.) & 14.98 & 7.77 & 2.03 & 0.140 \\
\hline Feed (120 hr.) & 12.13 & 7.78 & 1.79 & 0.116 \\
\hline \multicolumn{5}{|c|}{ Experiment \#8 (+M, Humic Acid, +IO) } \\
\hline Feed (initial) & 20.04 & 7.64 & 3.05 & 0.290 \\
\hline Feed (24 hr.) & 19.55 & 7.89 & 2.57 & 0.170 \\
\hline Feed (48 hr.) & 15.10 & 7.62 & 2.02 & 0.120 \\
\hline Feed (72 hr.) & 14.56 & 7.81 & 1.85 & 0.080 \\
\hline Feed $(96 \mathrm{hr})$. & 13.22 & 7.75 & 1.43 & 0.065 \\
\hline Feed $(120 \mathrm{hr})$. & 11.85 & 7.69 & 1.10 & 0.060 \\
\hline
\end{tabular}




\begin{tabular}{|c|c|c|c|c|c|}
\hline Sample name & $\begin{array}{c}\text { Turbidity } \\
\text { (NTU) }\end{array}$ & pH & $\begin{array}{c}\text { TOC } \\
(\mathrm{mg} \mathrm{C} / \mathrm{L})\end{array}$ & $\begin{array}{c}\mathrm{UV}_{254 \mathrm{~nm}} \\
\text { absorbance } \\
\left(\mathrm{cm}^{-1}\right)\end{array}$ & $\begin{array}{c}\text { Flow } \\
\text { (mL/min) }\end{array}$ \\
\hline \multicolumn{6}{|c|}{ Experiment $\# 1(-M$, Cellulose, $-1 O)$} \\
\hline $\begin{array}{c}\text { Permeate } \\
\text { (initial) }\end{array}$ & 0.01 & 7.84 & 0.88 & 0.025 & 30.00 \\
\hline $\begin{array}{c}\text { Permeate } \\
(24 \mathrm{hr} .)\end{array}$ & 0.00 & 7.65 & 0.37 & 0.018 & 30.00 \\
\hline $\begin{array}{c}\text { Permeate } \\
(48 \mathrm{hr} .)\end{array}$ & 0.00 & 7.89 & 0.37 & 0.015 & 30.00 \\
\hline $\begin{array}{c}\text { Permeate } \\
(72 \mathrm{hr} \text { ) }\end{array}$ & 0.01 & 7.81 & 0.35 & 0.011 & 30.00 \\
\hline $\begin{array}{c}\text { Permeate } \\
(96 \mathrm{hr} .)\end{array}$ & 0.00 & 7.84 & 0.34 & 0.008 & 29.50 \\
\hline $\begin{array}{l}\text { Permeate } \\
(120 \mathrm{hr} .)\end{array}$ & 0.00 & 7.77 & 0.31 & 0.004 & 29.50 \\
\hline \multicolumn{6}{|c|}{ Experiment $\# 2(+M$, Cellulose,$-1 O)$} \\
\hline $\begin{array}{c}\text { Permeate } \\
\text { (initial) }\end{array}$ & 0.02 & 7.98 & 0.68 & 0.022 & 30.00 \\
\hline $\begin{array}{c}\text { Permeate } \\
\text { (24 hr.) }\end{array}$ & 0.00 & 7.91 & 0.63 & 0.020 & 30.00 \\
\hline $\begin{array}{c}\text { Permeate } \\
\text { (48 hr.) }\end{array}$ & 0.00 & 7.81 & 0.60 & 0.017 & 30.00 \\
\hline $\begin{array}{c}\text { Permeate } \\
(72 \mathrm{hr} .)\end{array}$ & 0.01 & 7.87 & 0.58 & 0.013 & 30.00 \\
\hline $\begin{array}{c}\text { Permeate } \\
(96 \mathrm{hr} .)\end{array}$ & 0.02 & 7.81 & 0.52 & 0.007 & 29.50 \\
\hline $\begin{array}{l}\text { Permeate } \\
(120 \mathrm{hr} .)\end{array}$ & 0.01 & 7.82 & 0.42 & 0.005 & 29.50 \\
\hline \multicolumn{6}{|c|}{ Experiment $\# 3(-M$, Humic Acid , -IO) } \\
\hline $\begin{array}{l}\text { Permeate } \\
\text { (initial) }\end{array}$ & 0.01 & 7.78 & 0.85 & 0.060 & 30.00 \\
\hline $\begin{array}{c}\text { Permeate } \\
(24 \mathrm{hr} .)\end{array}$ & 0.00 & 7.88 & 0.72 & 0.050 & 30.00 \\
\hline $\begin{array}{c}\text { Permeate } \\
(48 \mathrm{hr} .)\end{array}$ & 0.02 & 7.81 & 0.68 & 0.060 & 29.50 \\
\hline $\begin{array}{c}\text { Permeate } \\
(72 \mathrm{hr} .)\end{array}$ & 0.01 & 7.85 & 0.66 & 0.050 & 29.50 \\
\hline $\begin{array}{c}\text { Permeate } \\
(96 \mathrm{hr} .)\end{array}$ & 0.01 & 7.79 & 0.61 & 0.020 & 28.50 \\
\hline $\begin{array}{l}\text { Permeate } \\
(120 \mathrm{hr} .)\end{array}$ & 0.02 & 7.74 & 0.58 & 0.015 & 27.50 \\
\hline \multicolumn{6}{|c|}{ Experiment $\# 4(+M$, Humic Acid,$-I O)$} \\
\hline $\begin{array}{c}\text { Permeate } \\
\text { (initial) }\end{array}$ & 0.00 & 7.95 & 0.65 & 0.041 & 30.00 \\
\hline
\end{tabular}




\begin{tabular}{|c|c|c|c|c|c|}
\hline $\begin{array}{c}\text { Permeate } \\
(24 \mathrm{hr} .)\end{array}$ & 0.02 & 7.86 & 0.62 & 0.036 & 30.00 \\
\hline $\begin{array}{c}\text { Permeate } \\
(48 \mathrm{hr} \text { ) }\end{array}$ & 0.02 & 7.88 & 0.60 & 0.038 & 29.50 \\
\hline $\begin{array}{c}\text { Permeate } \\
(72 \mathrm{hr} .)\end{array}$ & 0.03 & 7.85 & 0.59 & 0.033 & 29.50 \\
\hline $\begin{array}{c}\text { Permeate } \\
(96 \mathrm{hr} .)\end{array}$ & 0.00 & 7.81 & 0.52 & 0.028 & 29.00 \\
\hline $\begin{array}{l}\text { Permeate } \\
\text { (120 hr.) }\end{array}$ & 0.01 & 7.85 & 0.44 & 0.021 & 28.50 \\
\hline \multicolumn{6}{|c|}{ Experiment $\# 5(-M$, Cellulose,$+I O)$} \\
\hline $\begin{array}{c}\text { Permeate } \\
\text { (initial) }\end{array}$ & 0.00 & 7.81 & 0.68 & 0.045 & 30.00 \\
\hline $\begin{array}{l}\text { Permeate } \\
(24 \mathrm{hr} .)\end{array}$ & 0.00 & 7.80 & 0.54 & 0.041 & 30.00 \\
\hline $\begin{array}{c}\text { Permeate } \\
(48 \mathrm{hr} .)\end{array}$ & 0.02 & 7.74 & 0.49 & 0.036 & 30.00 \\
\hline $\begin{array}{c}\text { Permeate } \\
(72 \mathrm{hr} .)\end{array}$ & 0.02 & 7.81 & 0.41 & 0.022 & 29.00 \\
\hline $\begin{array}{c}\text { Permeate } \\
(96 \mathrm{hr} .)\end{array}$ & 0.00 & 7.76 & 0.40 & 0.019 & 29.00 \\
\hline $\begin{array}{l}\text { Permeate } \\
(120 \mathrm{hr} .)\end{array}$ & 0.01 & 7.88 & 0.38 & 0.018 & 29.00 \\
\hline \multicolumn{6}{|c|}{ Experiment $\# 6(+M$, Cellulose, $+I O)$} \\
\hline $\begin{array}{c}\text { Permeate } \\
\text { (initial) }\end{array}$ & 0.01 & 7.82 & 0.55 & 0.020 & 30.00 \\
\hline $\begin{array}{l}\text { Permeate } \\
(24 \mathrm{hr} .)\end{array}$ & 0.00 & 7.85 & 0.43 & 0.017 & 30.00 \\
\hline $\begin{array}{c}\text { Permeate } \\
\text { (48 hr.) }\end{array}$ & 0.00 & 7.84 & 0.32 & 0.019 & 30.00 \\
\hline $\begin{array}{c}\text { Permeate } \\
(72 \mathrm{hr} .)\end{array}$ & 0.02 & 7.78 & 0.28 & 0.012 & 30.00 \\
\hline $\begin{array}{c}\text { Permeate } \\
\text { (96 hr.) }\end{array}$ & 0.01 & 7.86 & 0.22 & 0.009 & 29.50 \\
\hline $\begin{array}{l}\text { Permeate } \\
(120 \mathrm{hr} \text { ) }\end{array}$ & 0.00 & 7.88 & 0.21 & 0.006 & 29.00 \\
\hline \multicolumn{6}{|c|}{ Experiment \#7 (-M, Humic Acid, $+I O)$} \\
\hline $\begin{array}{c}\text { Permeate } \\
\text { (initial) }\end{array}$ & 0.00 & 7.81 & 0.89 & 0.038 & 30.00 \\
\hline $\begin{array}{c}\text { Permeate } \\
(24 \mathrm{hr} .)\end{array}$ & 0.01 & 7.84 & 0.77 & 0.036 & 30.00 \\
\hline $\begin{array}{c}\text { Permeate } \\
(48 \mathrm{hr} .)\end{array}$ & 0.01 & 7.76 & 0.62 & 0.038 & 29.00 \\
\hline $\begin{array}{c}\text { Permeate } \\
(72 \mathrm{hr} .)\end{array}$ & 0.02 & 7.84 & 0.51 & 0.033 & 28.50 \\
\hline
\end{tabular}




\begin{tabular}{|c|c|c|c|c|c|}
\hline $\begin{array}{c}\text { Permeate } \\
(96 \mathrm{hr} .)\end{array}$ & 0.03 & 7.73 & 0.39 & 0.026 & 27.50 \\
\hline $\begin{array}{c}\text { Permeate } \\
(120 \mathrm{hr} .)\end{array}$ & 0.02 & 7.75 & 0.35 & 0.013 & 27.00 \\
\hline \multicolumn{5}{|c|}{ Experiment \#8 (+M, Humic Acid, +IO) } \\
\hline $\begin{array}{c}\text { Permeate } \\
\text { (initial) }\end{array}$ & 0.00 & 7.66 & 0.75 & 0.030 & 30.000 \\
\hline $\begin{array}{c}\text { Permeate } \\
(24 \mathrm{hr} .)\end{array}$ & 0.02 & 7.83 & 0.59 & 0.025 & 30.00 \\
\hline $\begin{array}{c}\text { Permeate } \\
(48 \mathrm{hr} .)\end{array}$ & 0.03 & 7.84 & 0.55 & 0.014 & 29.50 \\
\hline $\begin{array}{c}\text { Permeate } \\
(72 \mathrm{hr} .)\end{array}$ & 0.01 & 7.69 & 0.32 & 0.010 & 29.50 \\
\hline $\begin{array}{c}\text { Permeate } \\
(96 \mathrm{hr} .)\end{array}$ & 0.01 & 7.88 & 0.28 & 0.006 & 29.00 \\
\hline $\begin{array}{c}\text { Permeate } \\
(120 \mathrm{hr} .)\end{array}$ & 0.02 & 7.72 & 0.27 & 0.008 & 28.00 \\
\hline
\end{tabular}


APPENDIX (M) SEM images of membrane units

No media

With media

Salmatoy

Dat:esetse

Howneratop

EaTH:DWW

10.7.891 m

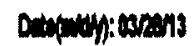

rearistery

smp 